\title{
Essays on Disaster Risk Management and Policy in New Zealand
}

By

\section{THOA THI THU HOANG}

\author{
A thesis \\ Submitted to the Victoria University of Wellington \\ In fulfilment of the requirements for the degree of \\ Doctor of Philosophy
}

Victoria University of Wellington 


\section{ACKNOWLEDGEMENTS}

This dissertation would not have been possible without support from many people.

My greatest thanks go to my primary supervisor Prof. Ilan Noy for his patient guidance, profound knowledge, invaluable experiences, and constant encouragement during the process of this work. I also would like to express my sincerest gratitude to my co-supervisor Dr. Olga Filippova (University of Auckland) for her invaluable comments and support.

I am grateful to my examiners for providing thoughtful feedback. Many thanks to the Chair in the Economics of Disaster and Climate Change for the fully funded Ph.D. scholarship. Thanks also to Victoria University of Wellington, Statistics New Zealand for providing data access to the Integrated Data Infrastructure.

Thanks to my family, my friends, my colleagues, who always encourage and support me throughout the process of this study. 


\section{IDI DISCLAIMER}

The results in the fourth chapter of this thesis are not official statistics. They have been created for research purposes from the Integrated Data Infrastructure (IDI) managed by Statistics New Zealand.

Access to the anonymised data used in this study was provided by Statistics New Zealand in accordance with security and confidentiality provisions of the Statistics Act 1975 . The findings are not Official Statistics. The results are based on tax data supplied by Inland Revenue to Statistics NZ under the Tax Administration Act 1994. This tax data must be used only for statistical purposes, and no individual information may be published or disclosed in any other form or provided to Inland Revenue for administrative or regulatory purposes. Any person who has had access to the unit record data has certified that they have been shown, have read, and have understood section 81 of the Tax Administration Act 1994, which relates to secrecy. Any discussion of data limitations or weaknesses is in the context of using the IDI for statistical purposes and is not related to the data's ability to support Inland Revenue's core operational requirements.

The opinions, findings, recommendations, and conclusions expressed in this chapter are those of the author(s), not Statistics NZ or Victoria University of Wellington. 


\begin{abstract}
New Zealand has experienced several strong earthquakes in its history. While an earthquake cannot be prevented from occurring, planning can reduce its consequences when it does occur. This dissertation research examines various aspects of disaster risk management policy in Aotearoa New Zealand.

Chapter 2 develops a method to rank and prioritise high-rise buildings for seismic retrofitting in Wellington, the earthquake-prone capital city of New Zealand. These buildings pose risks to Wellington's long-term seismic resilience that are of clear concern to current and future policymakers. The prioritization strategy we propose, based on multi-criteria decision analysis (MCDA) methods, considers a variety of data on each building, including not only its structural characteristics, but also its location, its economic value to the city, and its social importance to the community around it. The study demonstrates how different measures, within four general criteria - life safety, geo-spatial location of the building, its economic role, and its sociocultural role - can be operationalized into a viable framework for determining retrofitting/demolition policy priorities.
\end{abstract}

Chapter 3 and chapter 4 analyse the Residential Red Zone (RRR) program that was implemented in Christchurch after the 2011 earthquake. In the program, approximately 8,000 homeowners were told that their homes were no longer permittable, and they were bought by the government (through the Canterbury Earthquake Recovery Authority).

Chapter 3 examines the subjective wellbeing of the RRR residents (around 16000 people) after they were forced to move. We consider three indicators of subjective wellbeing: quality of life, stress, and emotional wellbeing. We found that demographic factors, health conditions, and the type of government compensation the residents accepted, were all significant determinants of the wellbeing of the Red Zone residents. More social relations, better financial circumstances, and the perception of better government communication were also all associated positively with a higher quality of life, less stress, and higher emotional wellbeing.

Chapter 4 concentrates on the impact of this managed retreat program on RRR residents' income. We use individual-level comprehensive, administrative, panel data from Canterbury, and difference in difference evaluation method to explore the effects of displacement on Red Zone residential residents. We found that compared to non-relocated neighbours, the displaced people experience a significant initial decrease in their wages and salaries, and their total 
income. The impacts vary with time spent in the Red Zone and when they moved away. Wages and salaries of those who were red-zoned and moved in 2011 were reduced by $8 \%$, and $5.4 \%$ for those who moved in 2012. Females faced greater decreases in wages and salaries, and total income, than males. There were no discernible impacts of the relocation on people's selfemployment income. 


\section{LIST OF FIGURES}

Figure 2.1. Share of building functions, ground and above use

Figure 2.2. GIS map of 384 buildings ranked by the TOPSIS method

Figure 2.3. GIS map of 384 buildings ranked by the VIKOR method

Figure 2.4. Percentage of total building area by priority group

Figure 3.1. Residential Red Zone Properties

Figure 4.1: Redzone areas and time of being RRZ residents

Figure 4.2: Average wages and salaries from 2004 to 2018

Figure 4.3: Average total income from 2004 to 2018

Figure 4.4. Effects of relocation on wages and salaries by age over time

Figure 4.5: Event study estimates for effect of managed retreat on wages \& salaries for those who were in RRZ areas in 2011

Figure 4.6: Event study estimates for effect of managed retreat on wages \& salaries for those who were in RRZ areas in 2012 


\section{LIST OF TABLES}

Table 2.1. Resilience criteria and their corresponding prioritisation criteria

Table 2.2. Pairwise comparisons and weights of the main criteria

Table 2.3. Pairwise comparisons of the life safety criterion

Table 2.4. Pairwise comparisons of the flooring systems criterion

Table 2.5. Pairwise comparisons of the lateral systems criterion

Table 2.6. Pairwise comparisons of the spatial location criterion

Table 2.7. Pairwise comparisons of the socio-cultural role

Table 2.8. Pairwise comparisons of the economic role

Table 2.9. Pairwise comparisons of building functions in terms of the economic role

Table 2.10. Weights of the criteria

Table 2.11. Comparison of all buildings ranked by VIKOR in relation to TOPSIS

Table 3.1. Characteristics of the sample $(\mathrm{N}=1890)$

Table 3.2. WHO-5 emotional well-being index

Table 3.3. The total score and frequency of the WHO-5 index

Table 3.4. Indicators for factor analysis

Table 3.5. Model estimation results (LHS: quality of life)

Table 3.6. Model estimation results (LHS: the stress level)

Table 3.7. Model estimation results (LHS: emotional wellbeing)- OLS

Table 3.8. Model estimation results (LHS: the WHO-5 wellbeing)- OLS

Table 4.1. Number and percentages of boundary and non-boundary RedZone meshblocks

Table 4.2. Number and percentages of people in RedZone areas

Table 4.3. Destinations of relocated households

Table 4.4. Destination and time movement of people who were in RRZ areas in 2011

Table 4.5. Descriptive statistics

Table 4.6. Wages and salaries effects by the timing of being RRZ residents

Table 4.7. Wages and salaries effects by the timing of being RRZ residents and moving

Table 4.8. Total income effects by the timing of being RRZ residents

Table 4.9. Total income effects by the timing of being RRZ residents and moving

Table 4.10. The regression coefficients differences by gender following the relocation 


\section{TABLE OF CONTENTS}

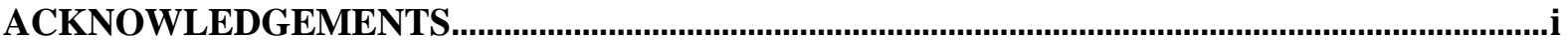

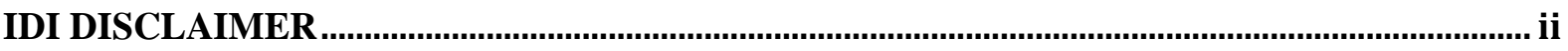

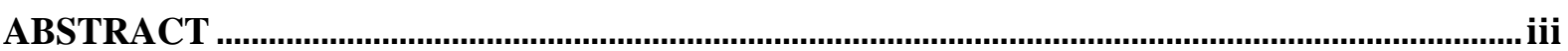

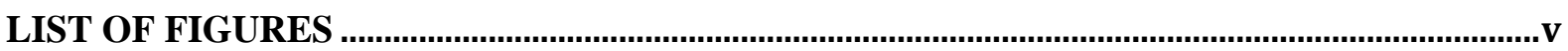





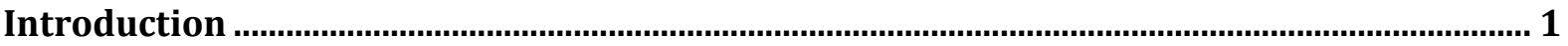

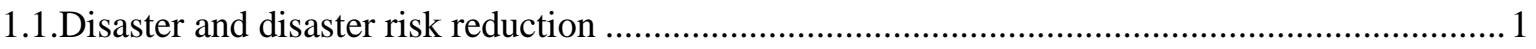

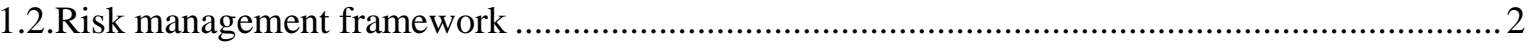

1.3.New Zealand and earthquake risk management policy........................................................... 3

1.3.1.A strategy to reduce damages of earthquakes in Wellington, New Zealand ........................... 3

1.3.2.A review of monetary-based methods used for priority-setting ............................................ 4

1.3.3. Multi-criteria decision analysis (MCDA) for the retrofitting buildings in Wellington CBD 5

1.3.4.Managed retreat in New Zealand and its impacts on relocated households ........................ 7

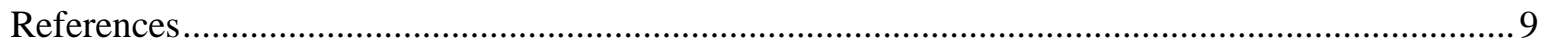



Prioritising earthquake retrofitting in Wellington, New Zealand ........................................11

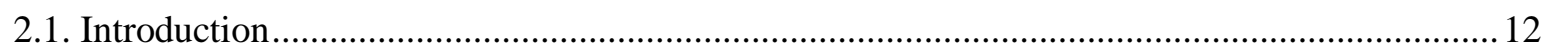

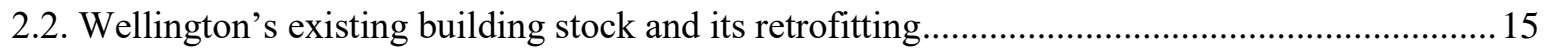

2.3. Retrofitting priorities and the measurement of multiple criteria .............................................. 16

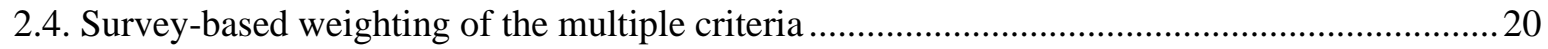

2.5. Multi-criteria decision analysis (MCDA) methodology: TOPSIS and VIKOR .......................21

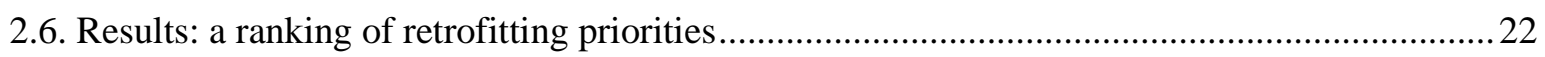

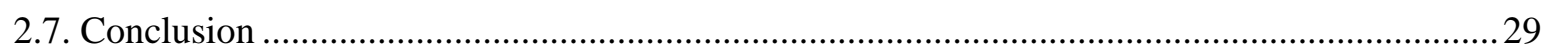

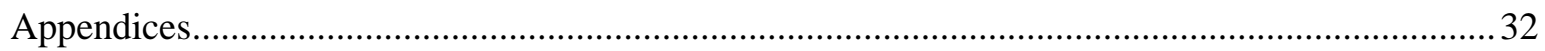



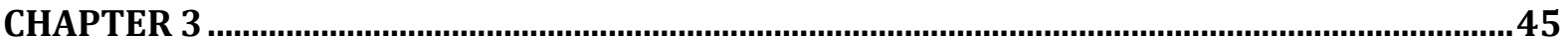

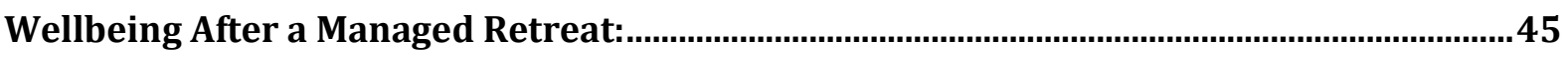



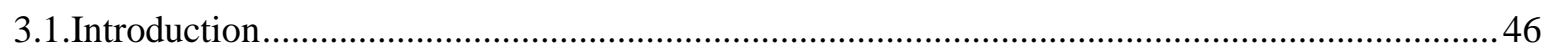

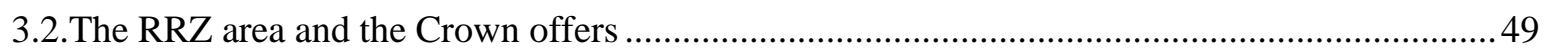

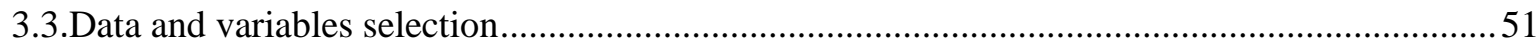

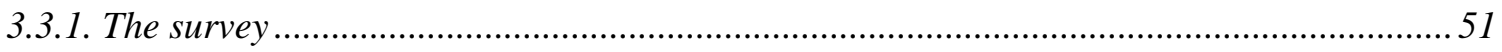

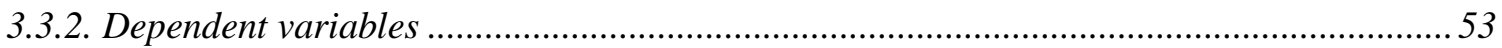

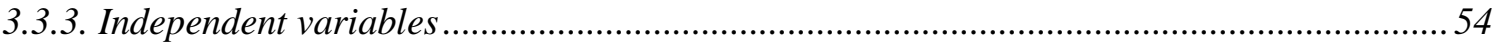




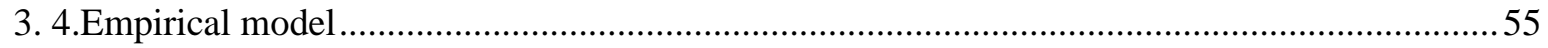

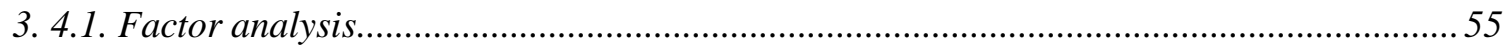

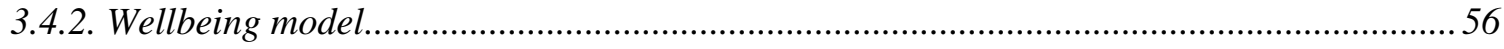

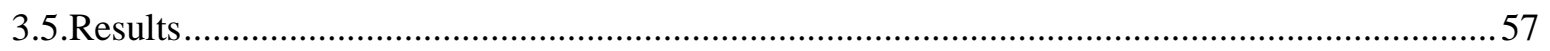

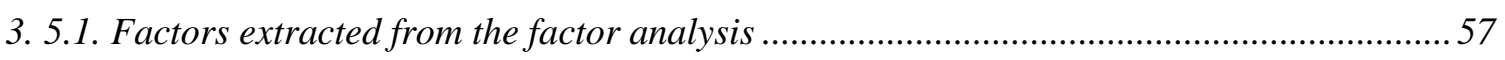

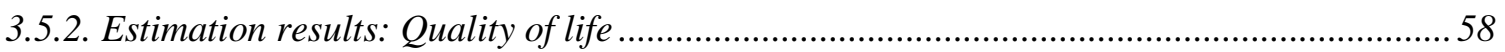



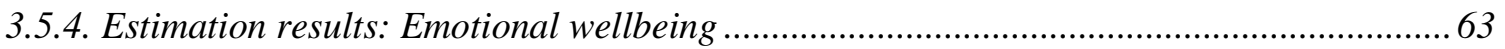

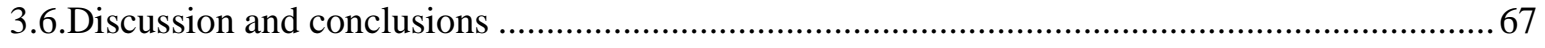

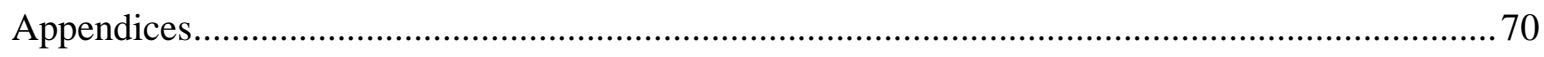



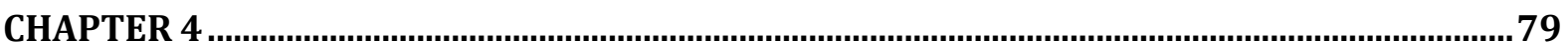

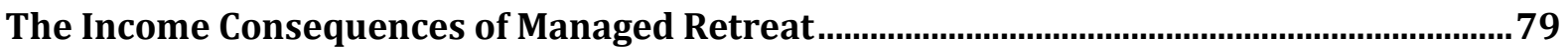

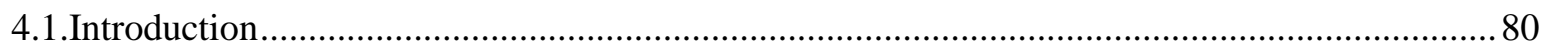

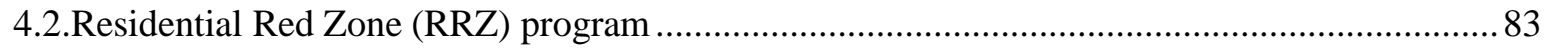

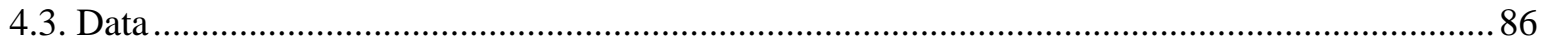

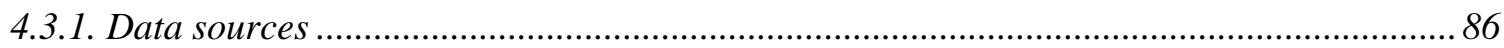

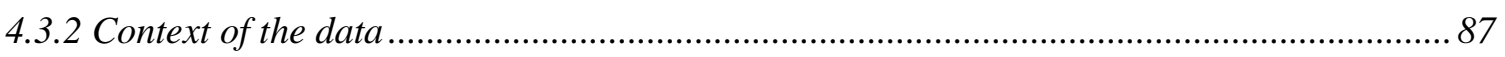

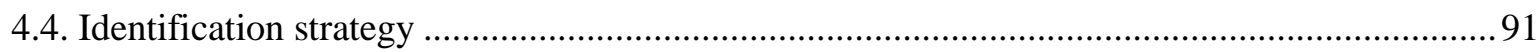

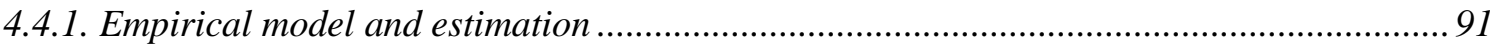

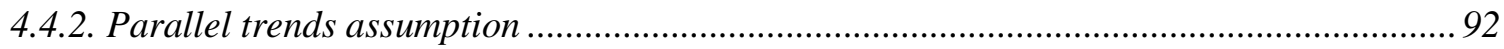

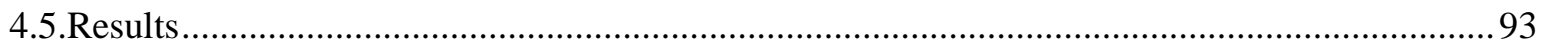

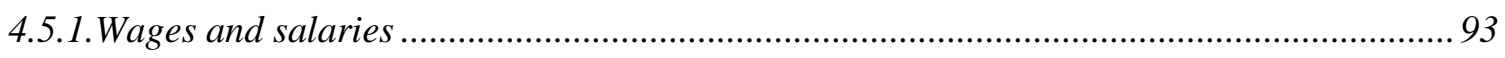

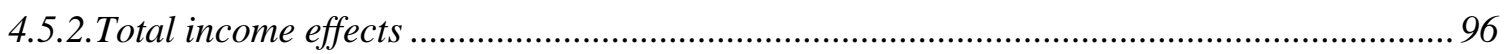

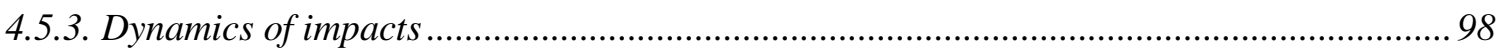

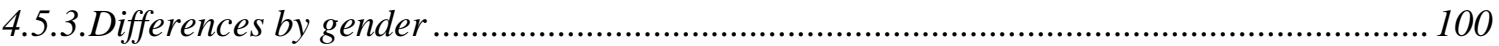



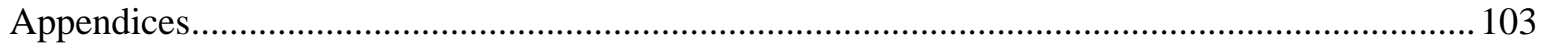

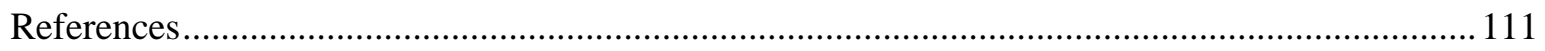



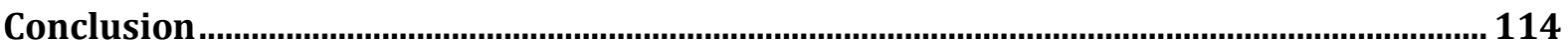




\section{Chapter 1}

\section{Introduction}

The extreme consequences of natural hazards and disasters that we experience all over the world highlight the need to improve risk prevention and management to reduce human, social, and economic damages and losses. The three policy-related research projects included in this thesis hopefully provide a valuable evidence base that can improve disaster risk management in New Zealand in the years to come, within the context of both seismic and climate change risks. The dissertation consists of five chapters. The current chapter briefly explains the risk management framework, the motivation, and research questions that are the centre of each of the main chapters (chapters 2-4).

\subsection{Disaster and disaster risk reduction}

A disaster is defined as a serious disruption to the functioning of a community or a society causing widespread human, material, economic or environmental losses that exceed the ability of the affected community or society to cope with using its resources (UNISDR, 2009). A disaster's consequences cause direct tangible costs (e.g., to buildings), indirect tangible costs (e.g., infrastructure or business disruption); direct intangible costs (e.g., injuries); and indirect intangible costs (e.g., psychological trauma, loss of trust in authorities). Lives can be lost, properties damaged, economic activity disrupted, communities disconnected, cultural heritage wrecked, and physical and mental health adversely affected.

Infrequent but high consequence hazards are difficult to assess and prioritize for mitigation precisely because they are infrequent and therefore may not have occurred within a human lifetime. We mostly cannot control the scale and intensity of hazards. Beyond the current risk, climate change is widely acknowledged to be increasing these risks from extreme weather events (IPCC Working Group I, 2021). However, we can reduce disasters' impact, now and in the future, by preparing for them, reducing our exposure and vulnerability to them, and building our capacity to recover from them (e.g., increasing our resilience to them).

Disaster risk reduction (DRR) is defined as the concept and practice of reducing disaster risk through systematic efforts to manage the causal factors of disasters (UNISDR, 2009). This is achieved by identifying and planning how to adapt to them or mitigate their impact. After 
the disaster, DRR in the post-disaster recovery phase is about 'building back better,' in line with the fourth priority of The Sendai Framework for DRR 2015-2030: Enhancing disaster preparedness for effective response and to "Build Back Better" in recovery, rehabilitation, and reconstruction.

\subsection{Risk management framework}

The Australian New Zealand Risk Management Standard (AS/NZ 4360:2004) suggests five steps in a process of general risk management:

1. Establishing the context: defining the context is fundamental to any risk management process. We need to determine who is going to make decisions about the risks, and what metrics of risk they will use.

2. Risk Assessment: this next step requires adequate knowledge of the hazard. This step includes three sub-steps: risk identification, analysis, and evaluation. The preferred approach to identifying risks is consulting with a wider group of experts, to draw on their collective knowledge, and thus reduce the danger that insufficient attention will be given to new and emerging issues. The risk analysis stage assigns each risk a significance rating, considering any existing factors which will operate to control the risk. Risk evaluation reviews the initial analysis and adjusts any assessment as needed.

3. Risk treatment: This step consists of determining what should be done in response to the risks previously identified.

4. Monitoring and review: the outputs of the risk assessment step must be kept consistently under review as time moves on and the risks are treated. Changes in the environment or simply the discovery of better information might make the original assessment no longer relevant or accurate. It is also necessary to monitor the previous steps to ensure that the risk management process is conducted cost-effectively.

5. Communication and consultation: These are key components of the risk management process and a major co-benefit from it. Successful risk management relies on achieving a high level of creative input and involving all the relevant stakeholders. It is important to ensure that all those who need to be involved are given adequate opportunity to do so and are kept informed of developments in understanding risks and the measures taken to deal with them.

Lessons from the management of recent earthquake events are potentially important for the design of future risk management policies and plans. The next section briefly describes the 
context of two New Zealand earthquake management policies that focus on this dissertation: (1) strengthening high-rise buildings in earthquake-prone Wellington; and (2) a managed retreat program in Christchurch after the 2011 earthquake.

\subsection{New Zealand and earthquake risk management policy}

Aotearoa New Zealand is located on the boundary between the Australian and Pacific tectonic plates. It is thus very exposed to earthquakes, tsunamis, and volcanic eruptions. Several very damaging earthquakes have occurred in New Zealand since 2010. The Canterbury earthquakes of 2010 and 2011 cost New Zealand approximately 30 billion US\$ or 20 percent of the country's GDP in rebuilding costs (Wood et al., 2016). Another very costly earthquake occurred along the Kaikoura coast in 2016. Recently, New Zealanders have also experienced more floods and droughts due to climate change (Frame et al., 2020). Coastal areas will also become more vulnerable to storm surges because of sea levels rise, and we can expect more severe windstorms in the West. The scale of the potential damages requires planned and farreaching actions from the government. It is also important for policymakers to assess previous policies to consider what could have been done better, and thus improve future attempts to do the same.

\subsubsection{A strategy to reduce damages of earthquakes in Wellington, New Zealand.}

Damages from earthquakes result from ground shaking, landslides, liquefaction, tsunamis, and ground rupture across active faults. Much of the damage and injuries occur when built structures respond poorly to shaking. While an earthquake cannot be prevented from occurring, planning can reduce its consequences when it does occur. The most effective mitigation measures include the seismic design of new buildings, seismic retrofitting of existing buildings, and avoidance of hazardous sites (e.g., liquefaction-prone land).

Within New Zealand, several earthquake-related regulatory frameworks, such as the Building Act (2004), the National Building Standards, and several other regulations have been enacted to mitigate earthquake risks and disaster losses. New buildings must be built to the National Building Standard (NBS), which requires a specified degree of seismic integrity, as laid out in the standard NZS 1170.5:2004. For existing buildings not built to the current NBS, the law gives powers to local authorities to require owners of earthquake-prone buildings (EPBs) to demolish or strengthen those buildings within specific time frames. A building is considered to be earthquake-prone if its capacity is assessed to be less than or equal to one- 
third of that required for a new building (that is, less than 34\% NBS). The Act necessitates that the owners of buildings strengthen them up to at least $34 \%$ NBS, or demolish the building. The Act does not allow authorities to require strengthening to more than 34 percent, although they can incentivize strengthening to a higher standard.

The calamitous Christchurch earthquake on 22 February 2011 and the Kaikoura earthquake on 14 November 2016 led to an increasing desire to reduce the risk profile of the building stock in Wellington - widely perceived to be the highest-risk large city in the country. This desire is accompanied by an awareness that dozens if not hundreds of existing buildings require seismic strengthening. Strengthening or demolishing many buildings quickly, and at the same time, is not feasible (or advisable) because of financial and other constraints, and the short-term consequences for the functioning of the city's economy. Strengthening has to be done sequentially; with the sequence being determined by some criteria. However, a building is evaluated differently by different stakeholders. Therefore, identifying a strategy for sequentially retrofitting buildings must be based on multiple criteria. Despite the importance of such priority-setting being generally well accepted, the development of prioritization lists remains challenging in practice. This motivates the need to develop a prioritization strategy for the retrofitting or demolition of buildings to mitigate the negative consequences of an earthquake in Wellington. Such a prioritization algorithm is developed in the second chapter.

\subsubsection{A review of monetary-based methods used for priority-setting}

Methods based on monetary-based techniques are sometimes used for priority-setting for seismic retrofitting. Valcárcel et al. (2013) proposed a cost-benefit analysis technique for the seismic rehabilitation of buildings. This study estimates benefit-cost ratios at a country level by comparing the expected reduction in the average annual loss with the retrofitting costs. Li et al. (2009) provided an example of an evaluation of seismic retrofitting alternatives by an approach of maximizing the ratio of risk marginal reduction to the expenditure associated with this reduction. Li et al. argue that the prioritizing process should be based on marginal benefits and costs, and not on the net present values. ${ }^{1}$

\footnotetext{
${ }^{1}$ Marginal benefit is the increase of total benefit because of the extra (additional) investment in risk reduction. It is often assumed in economics that as the amount of any one input is increased, holding all other inputs constant, the amount that output increases is diminishing for each additional unit of the expanding input. There therefore typically exists an optimal amount of input such that the efficiency of the investment is maximized (when the marginal benefit is equal to the marginal cost).
} 
Cost-benefit analysis (CBA) techniques have some advantages. They value impacts based on only one measurement scale. Therefore, it easily demonstrates that implementing an option is worthwhile relative to choosing other options and whether the option is preferable to the status quo. Moreover, in theory at least, CBA can consider the gains and losses to all members of the society on whose behalf the CBA is being undertaken. However, CBA's main limitation is that impacts that cannot be quantified on the same monetary scale are typically ignored. It also does not generally take into account the interactions between different impacts. For example, people might feel more negatively about a project that imposes both environmental and social costs than would be estimated by adding separate valuations of the two negative effects. In such circumstances, Multi-Criteria Decision Analysis (MCDA) techniques can be preferable.

\subsubsection{Multi-criteria decision analysis (MCDA) for the retrofitting buildings in Wellington CBD}

MCDA is a method of looking at complex problems that are characterized by any mix of monetary and non-monetary objectives. It can handle large amounts of complex information consistently by breaking the problem into more manageable pieces to allow data and judgments to be brought to bear, and then reassembling the pieces to present a coherent overall picture for decision-makers.

MCDA uses both quantitative and qualitative approaches to handle multiple conflicting goals and different stakeholders within the decision-making process. A key feature of MCDA is its emphasis on the judgment of the decision-making team, in establishing objectives and criteria, rather than letting them be based on a subjective opinion of a limited set of individuals (possibly the researchers themselves).

MCDA has attracted increasing attention from policymakers and researchers by explicitly forming and solving the multi-dimensional aspects of a problem. Furthermore, the choice of objectives and criteria that any decision-making group may make is open to analysis and to change if they are felt to be inappropriate. Because scores and weights are also explicit and are developed according to established techniques, MCDA can provide an important means of communication, within the decision-making body and between that body and the wider community. 
Numerous MCDA models and methods have been proposed for dealing with complex decision-making. The traditional methods can be classified into different main groups based on their characteristics: scoring methods, distance-based methods, pairwise comparison methods, outranking, and utility/value methods (See table 1.1). An important initial consideration in the choice of MCDA technique is that of the number of alternatives to be appraised. Other criteria are whether it is transparent and easy to use, requires a reasonable number of resources for the analysis, and can be provided with an audit trail.

Scoring methods are the simplest MCDA methods using basic arithmetical operations. They obtain the sum of the weighted normalized values of all the criteria. The pairwise comparison and outranking methods are very useful for obtaining the weight of the different criteria and comparing alternatives concerning a subjective criterion. However, the drawback of these methods is that they take longer to implement when there are a large number of alternatives. Utility methods are based on an expected utility theory. It is premised on assigning a utility to every possible consequence and calculating the best possible utility for the different scenarios being considered. However, these approaches require a large number of inputs at every step of the procedure to accurately record the decision maker's preferences (utility), making these methods extremely data intensive. The preferences of the decision-makers also need to be precise, giving specific weights to each of the consequences, which requires stronger assumptions at each level.

In chapter 2, I applied distance-based methods - Technique for Order of Preference by Similarity to Ideal Solution (TOPSIS) and VIKOR (the multi-criteria ranking index based on a particular measure of "closeness" to the "ideal" solution - to suggest a prioritization strategy for the retrofitting/demolition of buildings in Wellington CBD. These methods' basic principle is obtaining the distance among each alternative and a special point. Their algorithms are both simple and efficient, which allows periodic recalculation with new data or applications elsewhere. Moreover, the algorithms allow us to rank a large number of observations. Together with these techniques, four main criteria were examined: life safety, spatial location, sociocultural role, and economic role. These criteria are not just focused on life safety (often the explicit and exclusive priority of governments) and commercial value (the main concern of many building owners and market forces), but also other societal prioritization preferences, such as a building's economic and socio-cultural role in the community. The analytic hierarchy process (AHP) was applied to determine the weight of the criteria. 


\subsubsection{Managed retreat in New Zealand and its impacts on relocated households}

Managed retreat programs aim to relocate households or remove homes and other infrastructure out of the reach of hazards. It involves the physical process of removing people (and their assets) to new lower-risk areas, rather than attempting to reduce the exposure to the hazard in the existing location (Hino et al. 2017, Neal et al., 2017). Managed retreat is among the most effective risk reduction techniques to reduce future losses when compared to other approaches like the elevation or retrofitting of structures or the construction of defensive infrastructure (e.g., sea walls). In many cases, when engineering solutions are no longer able to ensure the demand for safety (Thaler et al., 2016) or repairing properties would take considerable time and resources, a managed retreat is an option to reduce exposure to future losses caused by disasters. However, the managed retreat is typically constrained by the strong emphasis in some legal systems on private property rights (Hartmann, 2011).

Given the challenges that at-risk communities and their governing authorities face, understanding how a managed retreat program worked in practice can assist in developing successfully managed retreat programs in the future. This knowledge can help planners design programs that are more effective and avoid some of the well-intentioned failures that often beset such efforts.

In New Zealand, the large managed-retreat program was implemented in Christchurch after the 2010/11 earthquake the city experienced. In June 2011 the government decided to rezone some of the affected areas in the Great Christchurch as "red zones" and offered homeowners two options: (1) The Crown Option: the government buys both the building and land at their 2007 assessed values - in return the government owns any outstanding residual insurance claim for damage from the earthquakes. (2) The Insurance Option: The Crown only purchases the land at its 2007 assessed value, and the homeowner retains any remaining claim against their insurer for any damage the building on that land incurred.

In this Residential Red Zone (RRZ) program, more than 16000 people have been relocated from their communities, but little is known about the impact this move has had on them. Chapter 3-4 in this dissertation provide an answer to this important policy question: What were the economic impacts of this managed retreat program on the relocated households? Besides this dissertation, there has been little long-term follow-up on populations that have been forced to relocate in managed retreat programs, globally. This is despite the obvious and increasing importance of these programs as a central adaptation tool for climatic change. 
In Chapter 3, I examine the subjective well-being of the RRR residents after they were forced to move. I consider three indicators of subjective wellbeing: quality of life, stress, and emotional wellbeing. The main objectives are (1) to describe the (subjective) wellbeing of the RRZ residents after they were forced to move and identify which factors affect their well-being having already moved to new places. (2) to describe the subjective experience of the residents in their communication with the government and their relationship with the community, (3) to identify the effect of economic factors (household annual income, homeownership, and financial impacts) on wellbeing.

In Chapter 4, I concentrate on the impact of this managed retreat program on RRR residents' income. I aim (1) to estimate the impact of mandatory relocation (managed retreat) on the income of displaced individuals over time; (2) to evaluate whether the impact of relocation varies by the timing of the move and demographic factors (gender, age, and ethnicity). I hope that the findings from chapters 3-4 can provide possible lessons for policymakers when designing managed retreat programs.

Since the consequences of climate change are becoming more severe, managed retreats programs will progressively become a more common policy tool in years to come in many jurisdictions. Some places where communities are located, especially along the coasts, will become increasingly less suitable as the climate continues to change and the oceans continue to rise. People's need to move will only increase. These studies thus provide a valuable quantitative evidence-based for policymakers to design managed retreats programs in ways that increase wellbeing, rather than detract from it.

Lindell (2013) highlights that disaster literature has not maintained a balance between theory and practice. Indeed, disaster risk management becomes less effective if theory and practice are set apart from one another (Palliyaguru et al.,2014). In this thesis, we try to develop a quantitative evidence-based for policymakers to answer two practical questions: how to mitigate potential earthquake risks through prioritization of seismic retrofitting, and how to implement an effective managed retreat policy. 


\section{References}

David, F.; Suzanne, R.; Ilan, N.; Luke, H.; Trevor, C.S.; Sarah, S.; Dáithí, S.; Sam, D.(2020)

Climate change attribution and the economic costs of extreme weather events: a study on damages from extreme rainfall and drought. Climatic Change (2020), 162, 781-797

Hartmann T (2011) Contesting land policies for space for rivers - rational, viable, and clumsy floodplain management. Journal Flood Risk Management 4(3):165-175

Hino, M.; Field, C.B.; Mach, K.J (2017) Managed retreat as a response to natural hazard risk. Natural Climate Change 7, 364-370

Neal, W.J.; Bush, D.M.; Pilkey, O.H. Managed Retreat (2017) In Encyclopaedia of Engineering Geology; Finki, C., Makowski, C., Eds.; Encyclopaedia of Earth Sciences Series; Springer International Publishing: Cham, Switzerland; pp. 1-7. ISBN 978-3-319$12127-7$

Li, Jiawei; Pollard, Simon; Kendall, Graham; Soane, Emma and Davies, Gareth (2009). Optimizing risk reduction: an expected utility approach for marginal risk reduction during regulatory decision making. Reliability Engineering and System Safety, 94(11) pp. 1729-1734

Lindell, M.K., 2013. Disaster studies. Current Sociology Review, 61(5-6), pp.797-825

Palliyaguru, R., Amaratunga, D. \& Baldry, D., 2014. Constructing a holistic approach to disaster risk reduction: The significance of focusing on vulnerability reduction. Disasters, 38, pp.45-61

United Nations Office for Disaster Reduction (2009). UNISDR Terminology on Disaster Risk Reduction. Retrieved from: Geneva, May 2009. http://www.unisdr.org/we/inform/terminology

Thaler, T. Just retreat-how different countries deal with it: examples from Austria and England. Journal of Environmental Studies and Science 11, 412-419 (2021) 
Valcárcel, J. et al. (2013) 'Methodology and applications for the benefit cost analysis of the seismic risk reduction in building portfolios at broad scale'. Natural Hazards. 69(1). pp. $845-868$.

Wood Amy, Ilan Noy, and Miles Parker 2016. The Canterbury Rebuild Five Years on from the Christchurch Earthquake. Reserve Bank of NZ Bulletin 79(3), 1-16.

Table 1.1. MCDA groups and methods

\begin{tabular}{|l|l|}
\hline \multicolumn{1}{|c|}{ MCDA group } & \multicolumn{1}{c|}{ MCDA method } \\
\hline Scoring methods & $\begin{array}{l}\text { Simple additive weighting (SAW) } \\
\text { Complex proportional assessment (COPRAS) }\end{array}$ \\
\hline Distance-based methods & $\begin{array}{l}\text { Goal programming (GP) } \\
\text { Compromise programming (CP) } \\
\text { Technique for order of preference by similarity to ideal } \\
\text { solution (TOPSIS) Multicriteria optimization and } \\
\text { compromise solution (VIKOR) Data envelopment analysis } \\
\text { (DEA) }\end{array}$ \\
\hline $\begin{array}{l}\text { Pairwise comparison } \\
\text { methods }\end{array}$ & $\begin{array}{l}\text { Analytic hierarchy process (AHP) } \\
\text { Analytic network process (ANP) } \\
\text { Measuring Attractiveness by a Categorical Based } \\
\text { Evaluation Technique (MACBETH) }\end{array}$ \\
\hline Outranking methods & $\begin{array}{l}\text { Preference ranking organization method for enrichment of } \\
\text { evaluations (PROMETHEE) } \\
\text { Elimination and choice expressing reality (ELECTRE) }\end{array}$ \\
\hline Other & $\begin{array}{l}\text { Multi-attribute utility theory (MAUT) } \\
\text { Multi-attribute value theory (MAVT) }\end{array}$ \\
\hline
\end{tabular}




\title{
Chapter 2
}

\section{Prioritising earthquake retrofitting in}

\section{Wellington, New Zealand}

\begin{abstract}
:
This chapter describes the application of multi-criteria decision analysis (MCDA) to prioritise the seismic risk mitigation of existing buildings in earthquake-prone Wellington, New Zealand. Through retrofitting or demolition, this is an important requirement in many cities around the Pacific Rim and in other high-level seismic hazard locations. The prioritisation strategy proposed here, based on MCDA methods, can provide decision-makers with a fast and reliable support tool for identifying the optimal sequencing of their retrofitting programmes. The premise of the MCDA analysis presented in this chapter is that there are multiple criteria that determine societal prioritisation preferences; these are limited not just to life safety (often the explicit/exclusive priority of governments) and commercial value (the main concern of many building owners). We demonstrate how different measures, within four general criteria-life safety and geo-spatial, economic, and socio-cultural roles - can be operationalised as a viable framework for establishing intervention policy priorities.
\end{abstract}




\subsection{Introduction}

Wellington, the capital of New Zealand, has experienced several strong earthquakes in its history, which have resulted in significant loss of life and considerable damage to a number of buildings. The most recent one, the Kaikoura earthquake on 14 November 2016, caused major devastation and claimed the lives of two people, leading to the identification of specific vulnerabilities in medium- and high-rise buildings in the city and augmenting public pressure on the government to reduce the risk. This event followed the calamitous Christchurch earthquake on 22 February 2011, during which the collapse of one reinforced-concrete structure, the CTV Building, was responsible for 115 of the 185 fatalities (Wood, Noy, and Parker, 2016). This tragedy prompted amendments to the Building Act (2004) aimed at improving structural aspects of the existing building stock in New Zealand.

These two disasters ultimately led to reconsideration of earthquake policy in New Zealand and, eventually, to changes in the government's policy framework for dealing with existing earthquake-prone buildings. It is the increasing desire to reduce the risk profile of the building stock in Wellington, accompanied by awareness that probably dozens, if not hundreds, of buildings require strengthening, that motivate the risk-reduction multiple-criteria prioritisation algorithm described in this chapter.

As in most other countries, much of the policy attention directed at tackling earthquake risk in New Zealand centres on regulating the construction of new buildings; this started quite early in New Zealand, soon after the destructive Hawke's Bay earthquake on 3 February 1931. Knowledge of seismic risk amassed over the ensuing 90 years has been incorporated in subsequent building standards, yet attempts to reduce the seismic risk facing the existing building stock started in earnest only more recently.

The Building Act (2004) included specific measures to address vulnerable structures, but these were perceived to be inadequate, especially after the collapse of the CTV Building in 2011. As a result, the New Zealand Parliament passed the Building (Earthquake-prone Buildings) Amendment Act 2016 (henceforth, the Act); this legislation, which received royal assent on 13 May 2016, introduced a significant tightening of the law on requirements for earthquake strengthening, notably shortening the time frame for implementation.

The Act provides a definition of earthquake-prone (EQP), which is applied to buildings beyond a certain size, and which also is dependent on use and location. An EQP building is defined as one that will exceed its designed capacity during a moderate earthquake, the 
definition of which is region-dependent. While the Act applies to the whole country, the territorial authorities (local councils) carry out implementation. Specifically, these bodies are tasked with identifying EQP buildings and communicating with the owners about their legal obligations to strengthen them. The required time frames vary according to the seismic hazard associated with each region. Wellington is located in the highest hazard zone, and thus faces the tightest deadlines for pinpointing and eliminating risk through retrofitting or demolition.

The required strengthening is based on a relative comparison with that required for a new building, referred to as a percentage of New Building Standard (\%NBS). A building is considered to be earthquake-prone if its capacity is assessed to be less than or equal to onethird of that required for a new building (that is, less than $34 \%$ NBS). The Act necessitates that the owners of buildings strengthen them up to at least $34 \% \mathrm{NBS}$; or eradicate the risk by demolishing the building. The Act does not allow authorities to demand strengthening in the case of more than 34 per cent, although they can incentivise strengthening to a higher standard.

Prior to the Kaikoura earthquake of 2016, the research engineering community and policymakers focused on buildings built before 1976 (a year in which new building standards took effect) because of their acknowledged seismic vulnerability; many were classified as earthquake-prone. In Wellington, and indeed throughout New Zealand, many EQP buildings are two to four storey unreinforced masonry buildings constructed before the 1950s- these fell out of favour after the Hawke's Bay earthquake of 1931, and were finally banned in 1965. Indeed, after 2016, Wellington City Council undertook a remediation programme to secure unreinforced masonry facades and parapets to mitigate the risk to public safety under the Hurunui/Kaikōura Earthquakes Recovery (Unreinforced Masonry Buildings) Order 2017; this investment project ended in 2018. Similar vulnerability-related initiatives and policies exclusively targeting unreinforced masonry buildings were also pursued in other cities around the world, such as in Los Angeles, California, in the United States (Comerio, 1992).

Most of the damage caused by the Kaikoura earthquake in 2016, however, was too taller (five storeys or more) modern buildings made of reinforced concrete (Henry et al., 2017). Previously, such structures were not widely perceived to be EQP, nor were they classified as so (that is, they were not considered to be less than $34 \% \mathrm{NBS}$ ). Statistics House, for instance, experienced the collapse of two precast floor units during the Kaikoura earthquake. Fortunately, the event occurred just after midnight when the building was unoccupied. 
The Kaikoura earthquake exposed vulnerabilities in many existing buildings in the central business district (CBD) of Wellington that were not fully appreciated beforehand. It is the new awareness of the need to mitigate the risk posed by the existing stock of reinforced concrete buildings that is the topic of this chapter.

Overall, there are approximately 400 high-rise (five storeys or more) buildings in the database of CBD buildings (Puranam et al., 2019). In most cases, their structural vulnerabilities are not significant enough for them to be classified as EQP (and therefore requiring retrofitting). While the buildings may not present a risk to life safety in a 'moderate earthquake' - the focus of earthquake-prone legislation and the EQP designation - they do pose a significant risk in stronger earthquakes.

There is currently no legal obligation to strengthen buildings with seismic vulnerabilities that were not classified as earthquake-prone by the local council, although reinvestigations of existing buildings may lead some to be re-classified as such (which has happened in the case of a number of council-owned properties). EQP buildings will have a mandated retrofit deadline of 15 years from the time they are identified as earthquake-prone- 7.5 years if they are situated along strategic emergency routes.

All of these buildings (EQP or 'just earthquake-vulnerable') represent risks to Wellington's long-term seismic resilience that are clearly of concern to current and future policymakers. This risk is not only to life safety, but also to the ability of the city to continue functioning after an earthquake. A long-term closure of Wellington's CBD, similar to what occurred in Christchurch after the earthquake of 2011, will have a far-reaching detrimental impact on the local and national economy (Shrestha et al., 2019). In light of these concerns, it is in the interest of the city's government to facilitate a deliberate programme of retrofits and demolitions that will increase Wellington's resilience to seismic events in the future.

The question asked in this chapter is: how should one prioritise the mitigation of the risk posed by these buildings? Retrofitting (or demolishing) a large number of buildings quickly, and at the same time, is not feasible (or advisable) because of financial and other constraints and the short-term consequences for the functioning of the city's economy. Hence, optimally sequencing the task of retrofitting buildings is of paramount importance, and is the aim of the work described herein.

Buildings are valued differently by different stakeholders. They yield rents for property owners, business revenue for commercial building occupiers (such as retail outlets), cultural 
value for the community where they are located, and social value for the various communities with connections to and a need for them. Identifying the priorities for retrofitting buildings must, therefore, inherently be based on multiple criteria.

Several engineering papers have used multi-criteria decision analysis (MCDA) when evaluating the vulnerability of other facilities, such as bridges, highways, and water treatment facilities (see, for example, Bana e Costa, Oliveira, and Vieira, 2008; Joerin et al., 2010; Ali et al., 2014). As far as we are aware, none has used an MCDA method when analysing residential and commercial buildings in the context of seismic retrofitting, and incorporating information from several disciplinary domains.

\subsection{Wellington's existing building stock and its retrofitting}

A recently assembled inventory database of all high-rise buildings in Wellington was utilised for this study (Puranam et al., 2019). It was created by combining different datasets supplied by Colliers International, the Earthquake Commission, the Ministry of Business, Innovation and Employment, and Wellington City Council, and validated by a street survey, and includes complete multidisciplinary information on the majority of taller buildings in Wellington's CBD: 384 buildings with five or more storeys. For each building, the database contains structural information (such as lateral and floor systems), non-structural details (such as age and size, façade, and type of exterior cladding), and occupancy information (such as industry classification and primary use).

The building stock is composed of a mixture of construction types, including unreinforced masonry, reinforced concrete, precast concrete, and structural steel. Reinforced concrete was used in New Zealand from the early 1900s (Reed, Schoonees, and Salmond, 2008), but became more prevalent following the decline of unreinforced masonry in the 1930s, after many such buildings collapsed in the Hawke's Bay earthquake of 1931. Buildings with precast floors also comprise a large proportion of commercial building stock in Wellington, although some of them have been converted more recently from commercial to residential use (Elwood et al., 2020).

Other vulnerabilities exist as well, including non-structural elements such as cladding or internal fittings and furniture. Unfortunately, we do not have information on the non-structural elements, and view this lacuna as an opportunity for data collection in the future. 
As is described in Figure 2.1 for occupancy, 61 per cent of buildings use the ground floor for retail, whereas only 9 per cent are residential at ground level (apartments), and 15 per cent are offices. Above ground floor, 29 per cent of buildings are used for residential use, 6 per cent for retail (above ground floor), and 44 per cent as offices.

Figure 2.1. Share of building functions, ground and above use



\subsection{Retrofitting priorities and the measurement of multiple criteria}

Valcárcel et al. (2013) conducted an analysis of retrofitting priorities at the macro scale, using benefit-cost analysis, but they did not address the challenge of simultaneously applying multiple criteria. Methodologically similar evaluations are to be found in Schulze et al. (1987) and a US government report by the National Institute of Science and Technology (NIST, 2013). In contrast, Santa-Cruz et al. (2016) accounted for the presence of multiple criteria, but they did not attempt to value them together, and compare and weigh them accordingly.

In relation to critical infrastructure (bridges and tunnels), Bana e Costa, Oliveira, and Vieira (2008) tested a prioritisation model by categorising each structure based on four criteria: public safety; emergency response; local economic impacts; and interface with other lifelines. They developed this list following expert focus groups and interviews with civil engineers and city employees during their research on prioritisation for road infrastructure retrofitting investment in Lisbon, Portugal. In addition, Ali et al. (2014) examined highway bridges in a similar context 
of seismic retrofitting, whereas Joerin et al. (2010) concentrated on general vulnerability of water utility facilities.

Flynn et al. (1999) surveyed the general population in the US city of Portland, Oregon, after an apparent increase in knowledge of high seismic risk in the region. They asked people to prioritise three classes of building: those with the greatest number of people at risk; those where vulnerable people are at risk (such as children); and those most likely to fail in an earthquake. Interestingly, their respondents appear to have understood well that the choice given is quite problematic, as the first two criteria focus on the nature of the occupants, and the last one spotlighted the building itself. As their first choice, respondents ranked all three about equally. In separate questions, maybe not surprisingly, respondents showed a strong preference to use public funding to retrofit publicly-owned buildings (rather than privately-owned structures).

A two-day workshop dedicated to seismic research for this study also yielded four main criteria: public safety; spatial location (important in determining city-wide interference with emergency transportation and in minimising the need for cordoning); the economic role of the building; and its socio-cultural role. The attendees constituted a group of 15 academics, from various disciplines (for instance, law, planning, seismology, and structural engineering), who are engaged in assessing the seismic risk posed by the existing building stock in New Zealand.

Table 2.1 shows the relationship between the four criteria identified and their corresponding proxies or measures. Five of the considered measures - educational/medical facilities, flooring system, lateral systems, heritage/community buildings, and building use - are qualitative, whereas the remainder are quantitative. For each qualitative criterion and criteria weights, the binary comparisons technique was applied to develop a matrix of preferences. For each comparison, a corresponding judgement on the relative importance of two alternatives measures (for the qualitative criteria) or two criteria (for the criteria weight) was determined numerically using the analytic hierarchy process (AHP), as described in Vona et al. (2017) and in Appendix 2.1. 
Table 2.1. Resilience criteria and their corresponding prioritisation criteria

\begin{tabular}{|c|c|c|c|c|}
\hline \multirow[t]{6}{*}{ Life safety } & & Criteria & Type & $\begin{array}{l}\text { Associated } \\
\text { with }\end{array}$ \\
\hline & $\mathrm{C} 1$ & Building area & Quantitative & Benefit criteria \\
\hline & $\mathrm{C} 2$ & Educational/medical buildings & Qualitative & Benefit criteria \\
\hline & $\mathrm{C} 3$ & Flooring systems & Qualitative & Benefit criteria \\
\hline & $\mathrm{C} 4$ & Lateral systems & Qualitative & Benefit criteria \\
\hline & $\mathrm{C} 5$ & Building age & Quantitative & Benefit criteria \\
\hline \multirow[t]{3}{*}{$\begin{array}{l}\text { Spatial } \\
\text { location }\end{array}$} & C6 & $\begin{array}{l}\text { Distance from the nearest } \\
\text { emergency transport routes }\end{array}$ & Quantitative & Cost criteria \\
\hline & $\mathrm{C} 7$ & $\begin{array}{l}\text { Quantity of crossroads in a } \\
\text { radius of } 50 \text { metres from the } \\
\text { buildings }\end{array}$ & Quantitative & Benefit criteria \\
\hline & $\mathrm{C} 8$ & $\begin{array}{l}\text { Building heights (failure will } \\
\text { expand the required cordon) }\end{array}$ & Quantitative & Benefit criteria \\
\hline $\begin{array}{l}\text { Socio- } \\
\text { cultural role }\end{array}$ & C9 & $\begin{array}{l}\text { Heritage buildings or } \\
\text { community buildings }\end{array}$ & Qualitative & Benefit criteria \\
\hline \multirow{2}{*}{$\begin{array}{l}\text { Economic } \\
\text { role }\end{array}$} & $\mathrm{C} 10$ & Improvement value & Quantitative & Benefit criteria \\
\hline & $\mathrm{C} 11$ & Building functions & Qualitative & Benefit criteria \\
\hline
\end{tabular}

Several sub-criteria play a fundamental role in the appraisal of the life safety criterion. Although the exact number of occupants in each building was unknown, each building's floor area was known. It is assumed that the larger the building, the higher the number of occupants. Since almost all buildings in the CBD have a similar enough density (residential, retail, or office), this is a plausible assumption; no buildings are used for industrial purposes or for storage (given the high rental costs in the CBD). The ideal would be to have direct occupancy data for each building; or preferably, data on occupancy during working hours, afterhours, and weekends, and at night-time. A fuller prioritisation would take these into account, and provide details of average occupancy of the building during the week. Only such information would permit full accounting of exposure of people to a building collapse.

The building function also has to be contemplated in this context. Educational use (preschool, primary school, and secondary school) and health and other public medical buildings 
are accorded higher priority in the life safety criterion, given their role in protecting vulnerable populations (children) and the uninterrupted operation of medical services. Lastly, certain types of building construction (lateral and flooring system) and building age are used to assess which buildings pose a higher risk to life safety in the event of an earthquake.

For the spatial location criterion, the study measured the building's distance from emergency transport routes (as defined by Wellington City Council), the number of crossroads within a 50-metre radius of the building, and the height of a building as a proxy for how its failure will expand the required cordon — see Shrestha et al. (2019) for information on the detrimental impact of a long-term cordon after a seismic occurrence. Data on other lifeline networks (such as electricity and water) were not used, as these are all below ground, and nothing was known about their vulnerability to a building failure.

In terms of socio-cultural role, function was considered by identifying heritage and communal use buildings. The Heritage List is maintained by Heritage New Zealand, a governmental agency, and it aims to include places of cultural or historical significance or value, as specified in the Heritage New Zealand Pouhere Taonga Act 2014. Community buildings are noted if they are used for religious purposes, including places of worship, or provide services that entail interfacing with members of the general public as direct clients, such as the New Zealand Post Office and Justice Centre, as well as police stations and Wellington City Council offices.

The economic importance of a building is evaluated according to two criteria: monetary value (the capital worth of the building itself, excluding the land on which it is located); and function. According to Wellington City Council, capital value, as it is measured in the Council's rates roll, is the probable price that would be paid for the property at the valuation date. The value of the land on which the building is located and the value of the building itself (the 'improvement value') are separate. Only the latter is used here, as the land value is not representative of the importance of the capital asset to the local economy. For building function, five types of use are noted: tourist accommodation; retail; office; residential; and other. Table 2.1 summarises the criteria employed. 


\subsection{Survey-based weighting of the multiple criteria}

To establish the prioritisation ranking of the buildings of interest, the weights of the four criteria had to be determined. This was done using the AHP proposed by Saaty (1980), a subjective method to ascertain weighting schemes for differential criteria. The AHP generates a weight for each evaluation criterion according to the decision-makers' pairwise comparisons of different criteria. The societal relevance of the weights of these criteria can be enhanced if the pairwise comparisons are based on surveyed and averaged group preferences.

To arrive at a weighting scheme for the various criteria, a voluntary and anonymous questionnaire was provided to all participants at the 'Wellington Earthquake Resilience Collaboratory' workshop organised by QuakeCoRE (a Centre of Research Excellence funded by the New Zealand Tertiary Education Commission). The event was held on 3 September 2019 in the city of Nelson on the South Island of New Zealand and attended by approximately 80 researchers and policymakers working on seismic risk. Of these, 54 chose to respond to the survey (responses were confidential; the study's weighting scheme is based on their responses.

The survey was composed of a total of 16 questions, including two demographic questions (the profession or occupation of the respondent and the duration of their work experience). The other 14 questions were designed, based on the AHP, to determine the weights of the four pre-determined criteria (see Appendix 2.3). The completed questionnaire contained the participants' views on the relative importance of the pairwise comparisons between the different criteria and sub-criteria.

Of the respondents, 72 per cent were active (seismic) researchers, 9 per cent were practising seismic engineers, 8 per cent were government officials, and 11 per cent worked in other fields, and of the researchers, 50 per cent focused on engineering, 30 per cent were social scientists, and 20 per cent worked in other fields. Almost 40 per cent of the respondents have worked in their field for more than 15 years. The percentage of those who have worked between ' 0 ' and ' 5 ' years and between ' 5 ' and ' 15 ' years were approximately equal (30 per cent). Altogether, therefore, the respondents constitute an exceptionally experienced group of people with relevant expertise.

When asked which building they would prefer to be prioritised for retrofit, they were requested to judge which criteria should be more important. A scale from ' 1 ' to ' 9 ' was employed, where ' 1 ' is criteria A, much more important than criteria $B$, and ' 9 ' is criteria $B$, much more important than criteria A; '5' signified indifference towards them. All variables 
were rescaled to reconcile with the original scale, as suggested by Saaty (1980) (see Table 2.A1 in Appendix 2.1).

The AHP was initially created to assist a single decision-maker in finding a solution to a problem with multiple and, possibly, conflicting criteria. Thus, when the AHP is implemented with multiple participants, the geometric mean is used to aggregate the participants' responses into single values (Dong et al., 2010), as per the following formula:

$$
P_{A B}=\sqrt[54]{\prod_{i=1}^{54} x_{i A B}}
$$

$P_{A B}$ is a pairwise comparison index of criteria $A$ and $B$ and $x_{i A B}$ is the pairwise comparisons of criteria $A$ and $B$ of participant $i^{\text {th }}(i=1,2, \ldots, 54)$. The full algorithm of the AHP to determine the criteria's weights, and a numerical example, are provided in the Appendices. The final resulting weights from this algorithm are shown in Table 2.10.

\subsection{Multi-criteria decision analysis (MCDA) methodology: TOPSIS and VIKOR}

As noted, MCDA was employed to rank buildings for risk mitigation. MCDA aids decisionmaking, assisting stakeholders in minimising the possibility of post-decision miscategorisation. It is suitable for addressing complex problems involving high uncertainty, conflicting objectives, different forms of data and information, and multi interests and perspectives to generate an integrated evaluation (Wang, 2009).

This chapter uses two MCDA methods: TOPSIS (Technique for Order Performance by Similarity to Ideal Solution) (Hwang and Yoon, 1981); and VIKOR (VlseKriterijumska Optimizacija I Kompromisno; Multi-criteria Optimisation and Compromise Solution) (Opricovic, 1979). They were selected because of their simplicity, which will allow periodic recalculation with new data or application elsewhere, and their suitability to rank a large number of observations. The detailed steps of TOPSIS and VIKOR are listed in Appendix 2.2. One should note that these are not superior to several other algorithms that are also available (Morton, Keisler, and Salo, 2016) — for a survey of the many MCDA methods proposed in the literature, see Greco, Ehrgott, and Rui Figueira (2016).

To apply the MCDA methods, four fundamental steps were defined during this work:

- $\quad$ step 1-identify the criteria;

- $\quad$ step 2 -identify the weights of the criteria; 
- $\quad$ step 3 - choose the multi-criteria algorithms that will be used in combination with the calculations obtained from the previous steps; and

- step 4-priority rank each building, and compare the results using TOPSIS and VIKOR.

TOPSIS is an objective measure developed by Hwang and Yoon (1981), based on the idea of the positive ideal solution (PIS) and the negative ideal solution (NIS). The PIS maximises the benefit criteria and minimises the cost criteria, whereas the NIS maximises the cost criteria and minimises the benefit criteria. The principle of TOPSIS is that the solution alternative must simultaneously be the shortest distance from the PIS and the farthest distance from the NIS. The technique combines both distances to the PIS and NIS to measure the relative closeness of each alternative location to the PIS. Next, the options are ranked based on this combined measure.

VIKOR, meanwhile, was developed by Opricovic (1979) to provide compromise solutions to discrete multiple criteria problems that include non-commensurable and conflicting criteria. Its theoretical background is closely related to TOPSIS because they are both based on an aggregating function representing the 'closeness to the ideal'. VIKOR determines the compromise solution according to the best and worst performance of the alternatives for each criterion analysed.

Decision-makers could accept the obtained compromise solution because it offers a maximum utility of the majority (represented by $\max \mathrm{S}_{\mathrm{i}}$ ), and a minimum individual regret of the opponent (represented by min $R_{i}$ ). The measures $S_{i}$ and $R_{i}$ are integrated into $Q_{i}$ for a compromise solution. The alternatives are ranked based on the $\mathrm{Q}_{\mathrm{i}}$ values. The better solution is defined by the smallest $Q_{i}$ value if two acceptance conditions (acceptable advantage and acceptable stability of decision-making) are satisfied.

One should note that we have no reason to prefer one of these methods, nor distinguish between them and several other optional methodologies. Consequently, this study compares the two to examine whether the results of the study are sensitive to the choice of algorithmultimately, it finds that they are not.

\subsection{Results: a ranking of retrofitting priorities}

Table 2.2 shows the pairwise comparison and weights of the four main criteria, as derived from the questionnaire described earlier. The detailed preference matrices for all of the variables are 
presented in Tables 2.3-2.9. These were derived from a survey (described in the fourth section), except for those pertaining to the structural engineering life safety criterion, which were set after consultation with structural engineering experts. The life safety, socio-cultural, and economic roles were weighted at $0.67,0.15$, and 0.13 , respectively, whereas spatial criteria are weighted at 0.06 . The weights of all 11 sub-criteria are detailed in Table 2.10.

Table 2.2. Pairwise comparisons and weights of the main criteria

\begin{tabular}{|l|l|l|l|l|}
\hline & Life safety & Spatial location & Socio-cultural & Economic \\
\hline Life safety & 1 & 7 & 7 & 7 \\
\hline Spatial location & $1 / 7$ & 1 & $1 / 4$ & $1 / 3$ \\
\hline Socio-cultural & $1 / 7$ & 4 & 1 & 1 \\
\hline Economic & $1 / 7$ & 3 & 1 & 1 \\
\hline Weights & $\mathbf{0 . 6 7}$ & $\mathbf{0 . 0 6}$ & $\mathbf{0 . 1 5}$ & $\mathbf{0 . 1 3}$ \\
\hline
\end{tabular}

Table 2.3. Pairwise comparisons of the life safety criterion

\begin{tabular}{|l|l|l|l|l|l|}
\hline & $\begin{array}{l}\text { Building } \\
\text { area }\end{array}$ & $\begin{array}{l}\text { Building } \\
\text { function }\end{array}$ & $\begin{array}{l}\text { Flooring } \\
\text { system }\end{array}$ & $\begin{array}{l}\text { Lateral } \\
\text { system }\end{array}$ & $\begin{array}{l}\text { Building } \\
\text { age }\end{array}$ \\
\hline Building area & 1 & 5 & 7 & 7 & 7 \\
\hline $\begin{array}{l}\text { Building } \\
\text { function }\end{array}$ & $1 / 5$ & 1 & 5 & 5 & 5 \\
\hline $\begin{array}{l}\text { Flooring } \\
\text { system }\end{array}$ & $1 / 7$ & $1 / 5$ & 1 & 1 & 1 \\
\hline $\begin{array}{l}\text { Lateral } \\
\text { system }\end{array}$ & $1 / 7$ & $1 / 5$ & 1 & 1 & 1 \\
\hline Building age & $1 / 7$ & $1 / 5$ & 1 & 1 & 1 \\
\hline
\end{tabular}

Table 2.4. Pairwise comparisons of the flooring systems criterion

\begin{tabular}{|l|l|l|l|}
\hline & Cast-in-place & Precast & Others \\
\hline Cast-in-place & 1 & $1 / 3$ & 5 \\
\hline Precast & 3 & 1 & 5 \\
\hline Other & $1 / 5$ & $1 / 5$ & 1 \\
\hline
\end{tabular}


Table 2.5. Pairwise comparisons of the lateral systems criterion

\begin{tabular}{|l|l|l|l|}
\hline & Reinforced concrete & Unreinforced masonry & Mix \\
\hline Reinforced concrete & 1 & $1 / 7$ & $1 / 3$ \\
\hline Unreinforced masonry & 7 & 1 & 5 \\
\hline Mix & 3 & $1 / 5$ & 1 \\
\hline
\end{tabular}

Table 2.6. Pairwise comparisons of the spatial location criterion

\begin{tabular}{|l|l|l|l|}
\hline & $\begin{array}{l}\text { Distance from emergency } \\
\text { transport routes }\end{array}$ & $\begin{array}{l}\text { Number of } \\
\text { crossroads }\end{array}$ & $\begin{array}{l}\text { Failure will } \\
\text { expand } \\
\text { cordon }\end{array}$ \\
\hline $\begin{array}{l}\text { Distance from emergency } \\
\text { transport routes }\end{array}$ & 1 & 2 & $1 / 3$ \\
\hline Number of crossroads & $1 / 2$ & 1 & $1 / 3$ \\
\hline Failure will expand cordon & 3 & 3 & 1 \\
\hline
\end{tabular}

Table 2.7. Pairwise comparisons of the socio-cultural role

\begin{tabular}{|l|l|l|}
\hline & Heritage buildings & Community buildings \\
\hline Heritage buildings & 1 & $1 / 2$ \\
\hline Community buildings & 2 & 1 \\
\hline
\end{tabular}

Table 2. 8. Pairwise comparisons of the economic role

\begin{tabular}{|l|l|l|}
\hline & Improvement values & Building function \\
\hline Improvement values & 1 & 6 \\
\hline Building function & $1 / 6$ & 1 \\
\hline
\end{tabular}

Table 2.9. Pairwise comparisons of building functions in terms of economic role

\begin{tabular}{|l|l|l|l|l|l|}
\hline & Tourism & Retail & Office & Residential & Other \\
\hline Tourism & 1 & $1 / 2$ & $1 / 2$ & 5 & 5 \\
\hline Retail & 2 & 1 & 1 & 7 & 7 \\
\hline
\end{tabular}




\begin{tabular}{|l|l|l|l|l|l|}
\hline Office & 2 & 1 & 1 & 7 & 7 \\
\hline Residential & $1 / 5$ & $1 / 7$ & $1 / 7$ & 1 & 1 \\
\hline Other & $1 / 5$ & $1 / 7$ & $1 / 7$ & 1 & 1 \\
\hline
\end{tabular}

Table 2.10. Weights of the criteria

\begin{tabular}{|l|l|l|l|l|l|l|l|l|l|l|}
\hline C1 & C2 & C3 & C4 & C5 & C6 & C7 & C8 & C9 & C10 & C11 \\
\hline 0.370 & 0.170 & 0.042 & 0.042 & 0.042 & 0.014 & 0.009 & 0.034 & 0.06 & 0.107 & 0.02 \\
\hline
\end{tabular}

Figures 2.2 and 2.3 map the distribution of the 384 prioritised buildings in Wellington's CBD using TOPSIS and VIKOR, respectively—see Figures 2.A1 and 2.A2 in Appendix 2.4 for three-dimensional versions of the maps. They are separated into five equal-size groups with respect to priority level, with ' 1 ' being the top rating. It is important to point out that it will probably take decades to retrofit or demolish these buildings, during which time many considerations regarding individual structures will change. One should view this specific ranking, therefore, not as a long-term plan for retrofitting, but rather as a current evaluation of where retrofitting resources (public or private), and especially retrofitting evaluations and assessments of viability, should be targeted first.

Figure 2.2. GIS map of 384 buildings ranked by the TOPSIS method




Figure 2.3. GIS map of 384 buildings ranked by the VIKOR method

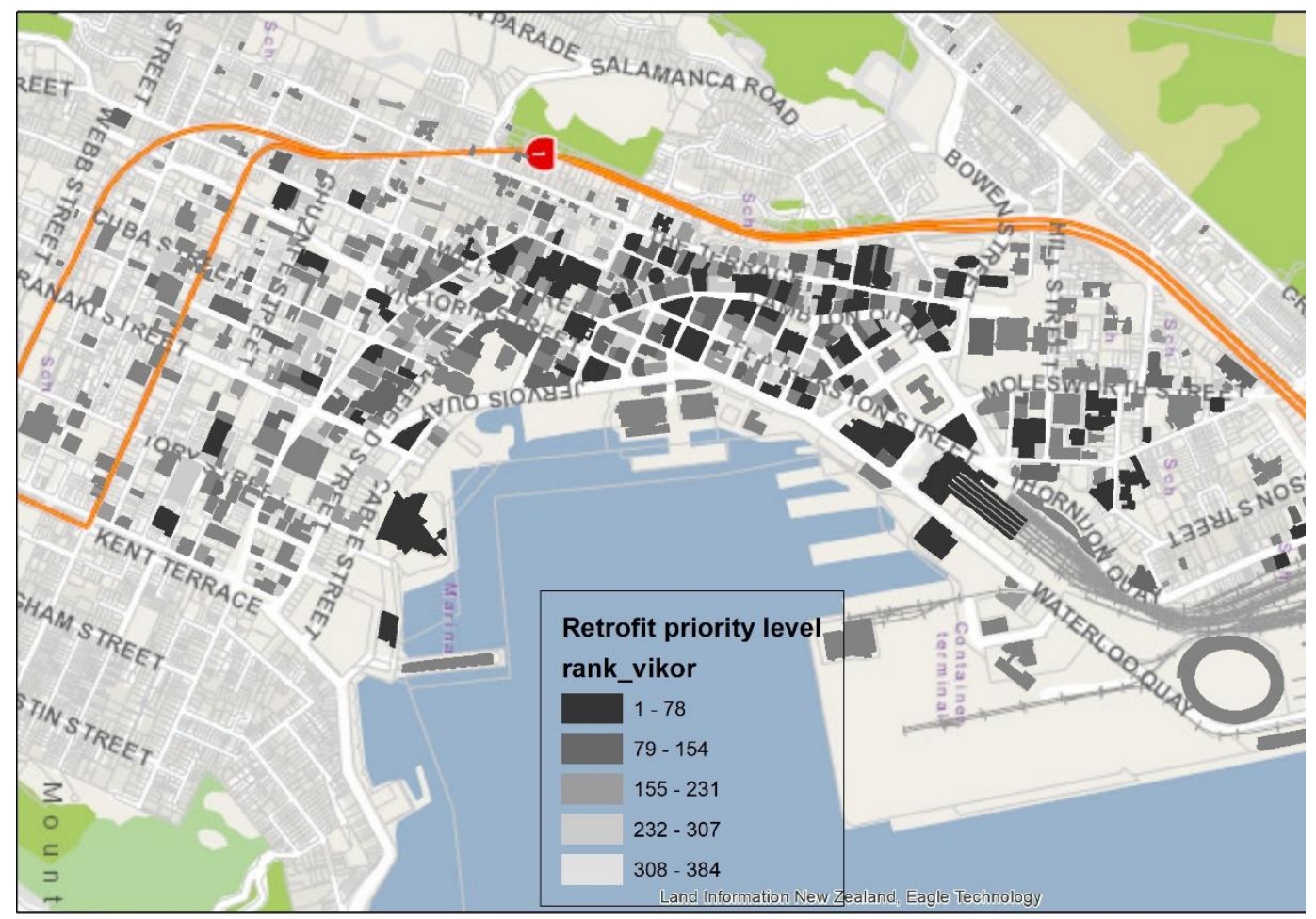

Table 2.11 contains a comparison of the 384 prioritised buildings ranked by TOPSIS and VIKOR. Overall, the order of ranking for each building is not exactly the same across both methods, owing to the different normalisation techniques and the weighting parameter that the decision-maker must choose in VIKOR (this study used v=0.5). The vast majority of buildings, more than 90 per cent, are ranked in the same group by TOPSIS and VIKOR. For those that are 'misclassified' (that is, not ranked in the same quintile by the two techniques), this appears to be equally weighted, so that a similar number of buildings is ranked 'too high' as compared to those that are ranked 'too low' (16 buildings in each group); and only one building is classified differently by the two steps (in group 2 by TOPSIS, and in group 4 by VIKOR).

Table 2.11. Comparison of all buildings ranked by VIKOR in relation to TOPSIS

\begin{tabular}{|l|l|l|l|l|l|l|}
\hline Group & $\mathbf{1}$ & $\mathbf{2}$ & $\mathbf{3}$ & $\mathbf{4}$ & $\mathbf{5}$ & Total \\
\hline $\begin{array}{l}\text { Number of buildings classified in the same } \\
\text { group }\end{array}$ & 74 & 67 & 70 & 69 & 72 & $\mathbf{3 5 2}$ \\
\hline Number of buildings classified as higher priority & 4 & 5 & 3 & 4 & - & $\mathbf{1 6}$ \\
\hline Number of buildings classified as lower priority & - & 4 & 4 & 3 & 5 & $\mathbf{1 6}$ \\
\hline
\end{tabular}


In any case, given the lack of crucial information on the costs of retrofitting, one should use this list as a benchmark to assign broad priority groups, rather than as a detailed roadmap for the exact sequence of risk mitigation in the city. From this perspective, the two lists are not very different. The priority rankings obtained from the two methods are similar enough.

Figure 2.4 shows the percentage of total building area in the different priority groups. All of the buildings in the lowest priority group are smaller than 5,000 square metres, whereas the majority of buildings in the middle priority group are 5,000-10,000 square metres, and most of the buildings in the highest priority group are larger than 10,000 square metres. In the highest priority group, most of the buildings are used for retail and office use (76 per cent). Moreover, five community buildings located very near emergency transport routes are listed in this group.

Buildings in this group represent 45 per cent of the floor area of total buildings, with 78 per cent larger than 10,000 square metres; only three per cent are smaller than 5,000 square metres. These buildings generally have a high improvement value, ranging from NZD 2.7 to 214 million; the majority of them (85 per cent) have an improvement value in excess of NZD 10 million.

The buildings in the lowest priority group are very small, representing only five per cent of the floor area of total buildings under investigation. Of these, 80 per cent are apartments (above the ground floor), while 61 per cent use the ground floor for retail. There are three heritage buildings in this group, and no community buildings or educational/medical buildings are on this list. Their improvement value ranges from NZD 101,000 to 157 million. Only six per cent of the buildings have an improvement value of less than NZD 1 million, 54 per cent are evaluated at between NZD 1-3 million, 15 per cent at between NZD 3-5 million, and nearly 25 per cent at more than NZD 5 million. Altogether, most of the buildings in the highest priority group are large and used for a commercial purpose and have high improvement value; meanwhile, the buildings in the lowest priority group are small with a low improvement value. 
Figure 2.4. Percentage of total building area by priority group

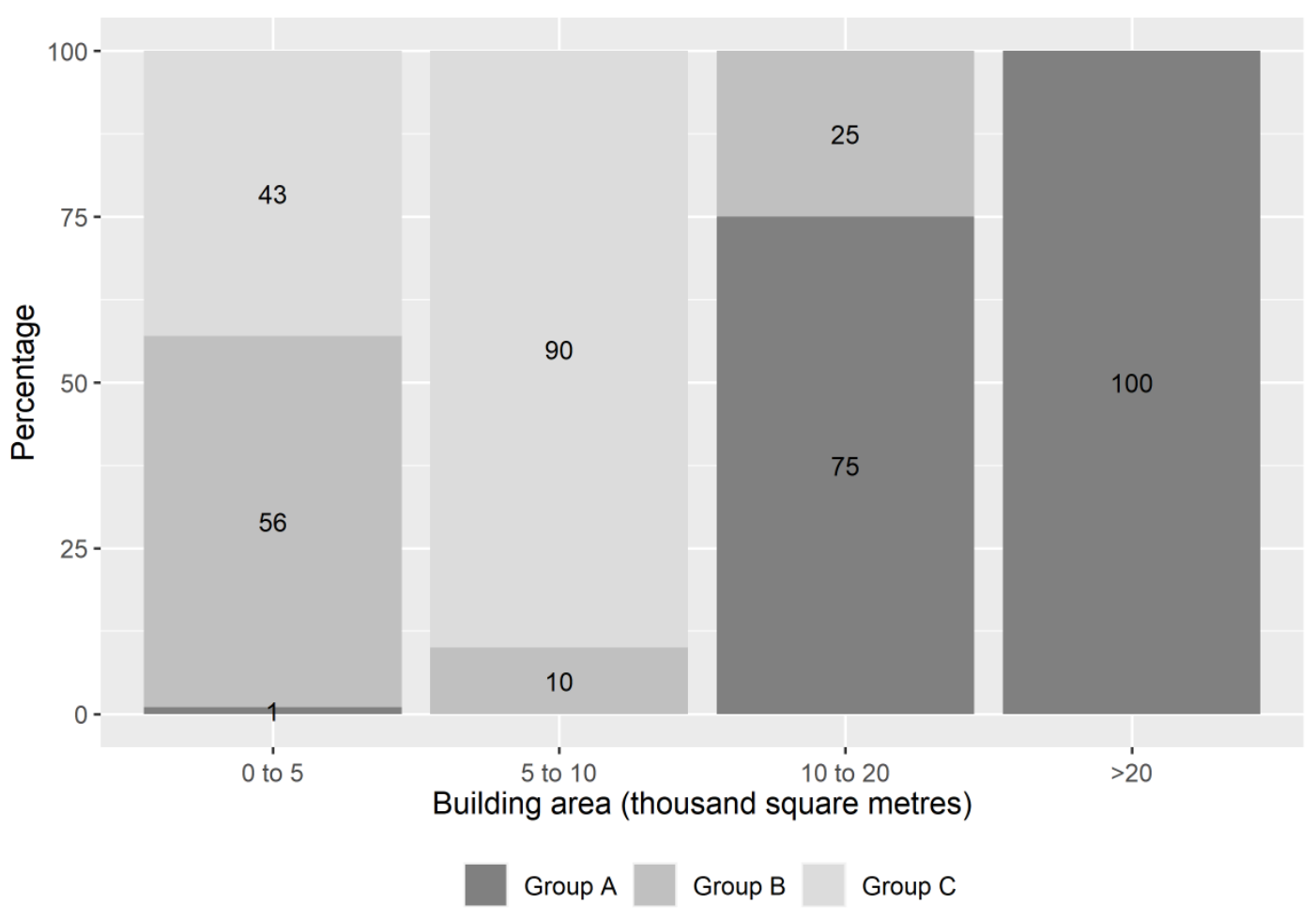

The first prioritised building (ranked by TOPSIS and VIKOR) is the Museum of New Zealand Te Papa Tongarewa. Among the 384 buildings, this is the second largest structure, has the highest improvement value (45,000 square metres of building area and a value of NZD 214 million), and is located next to an emergency transport route. However, it is widely known that the museum already has specialised base-isolated foundations, so it is able to withstand quite strong earthquakes (much above the minimum code requirement) and does not need any seismic retrofitting at this time. This kind of specific information is not available for most of the other buildings in the study's dataset.

Thus, one should think of the priority list proposed here, based on the available data, as a guideline to which buildings should be investigated first, rather than mitigated first. Such an inquiry will entail obtaining more data on their seismic capacity and the cost of doing such retrofitting. It may well be that some of the buildings that are determined to be of high priority (such as Te Papa) do not require any risk mitigation at all. Equally, for some, further evaluation might suggest that the building risk profile is such that the only economical way of reducing the danger is demolition. In that case, the decision whether, and when, to demolish will need to take account of many other parameters, including what are alternative use of the land (its most profitable or its most socially preferable application). 
Besides the Museum of New Zealand Te Papa Tongarewa, two high-occupancy commercial buildings and one public building are among the high priorities for further investigation. One of the commercial buildings spans 20 storeys and has office space over 12 levels for about 2,500 staff. It was evacuated following the Kaikoura earthquake in 2016, and tenants were allowed to move back in after around a week. Engineers identified a number of faults, indicating some earthquake risk, and it was consequently retrofitted in 2017. The top priority public building is ranked third by TOPSIS and fourth by VIKOR on this study's priority list. This multi-storey structure is situated in close proximity to emergency transport routes and has significant economic value (in excess of NZD 135 million).

The three lowest priority buildings ranked by both methods are smaller apartment blocks. Their floor areas range from 460-600 square metres, they are less than 20 metres in height, and they have a low improvement value. There are no major road intersections within a 50-metre radius, and the buildings are relatively far from emergency routes. Their structural characteristics also support the study's finding that they should be in the lowest priority group for assessment.

\subsection{Conclusion}

This chapter describes the application of multi-criteria decision analysis (MCDA) for the prioritisation of risk mitigation (retrofitting or demolitions) of buildings in an earthquakeprone city. This is a new approach to a critical problem that not only confronts New Zealand, but also many other cities and countries around the world, including Los Angeles, Portland, Vancouver, and Washington on the West coast of the US, and Indonesia, Japan, and Taiwan, in the western Pacific. In principle, one can also envisage a similar tool, adapted to local conditions, also being used in the historical city centres of Greece, Italy, or Turkey, among others.

This need for retrofitting is increasing globally, owing to dramatic improvements in knowledge of seismic risk (from its geology to its engineering) over the past few decades; the building stock in many earthquake-prone cities was largely constructed before such information was widely available or utilised. Hence, a prioritisation algorithm like the one developed here could be applied by non-governmental organisations, for instance, when deciding on investment priorities in lower income communities in earthquake-prone cities such as Kathmandu, Nepal, and Lima, Peru. 
The prioritisation strategy presented, based on MCDA, is a fast and reliable tool to support decision-makers in identifying the optimal sequencing of their retrofit programmes. The standard approach of governments to prioritising retrofits, including in New Zealand, is to examine only the criterion of life safety, ignoring all other dimensions. Typically, regulations specify lengthy time frames for any risk mitigation requirements, and/or provide fairly small financial incentives, which are insufficient to deal with costly retrofits (or demolitions) (Segal et al., 2017). In contrast, market forces place importance on the economic role of buildings, and therefore on the return on investment in retrofitting them (most often in terms of increased rent). Market forces frequently ignore issues such as life safety (as long as these do not present any liability-related risks) or the socio-cultural significance of a building. External assistance, in the context of earthquake retrofitting in poor communities, has focused almost exclusively on public buildings, with a strong preference to prioritise the life safety of children by investing in the retrofitting of schools.

The premise of the MCDA method proposed in this chapter is that all of these criteria are relevant, and one's prioritisation decisions should not be based on a single aspect, as is done in the examples above. There are multiple factors that determine societal prioritisation preferences, and these can be measured and operationalised using a viable framework for gauging intervention policy priorities.

The two MCDA algorithms examined here, TOPSIS and VIKOR, yielded broadly similar results. Hence, both appear to be useful approaches when there are numerous alternative sequencing strategies. An investigation into the exact circumstances when one should be preferred over the other is a task for the future.

It is important to emphasise that in the case of Wellington, the information available did not allow us to evaluate fully the structural/seismic integrity of each building — in general, this information is not available globally in other cities as well. As such, many of the buildings most probably do not require retrofitting at all—as demonstrated with respect to several of the highest priority buildings in this study. The priority list of buildings to consider, generated by the MCDA process, constitutes only a suggestion vis-à-vis the evaluation-assessmentretrofit/demolition sequence for each building. There may be other factors for which this research has not accounted, which may change any prioritisation of a building (once assessed). 
The Government of New Zealand should use this list principally to start evaluations from the top and work down at a speed determined by other considerations. An example of a factor that might accelerate a retrofit is availability of public funding.

It is important to note, though, that much of the information used in this analysis is time-dependent (such as the use of a building). A priority list generated in 2020 might no longer be relevant in, say, 2035. Consequently, it follows that the data and the priority list created should be reviewed periodically. The intention of this study is not to construct a final prioritisation list, but rather to apply a methodology, MCDA, in a context in which it has not really been applied before, drawing on as much detailed building-specific multidisciplinary data as are currently available. More engineering data, or more economic or social data, will make the analysis more 'robust.' This contribution should be viewed, therefore, as the first draft of a prioritisation list. Each new version can easily be calculated and presented once new data become available, such as information on all buildings that were already seismically retrofitted, or more detailed facts about day- and night-time occupancy.

Furthermore, this priority list is based on preferences obtained from surveys of 'seismic' professionals (mostly researchers; many of them engineers) and on detailed quantitative data collected. A qualitative investigation of people's preferences might lead to a different ordering of priorities. It is left to future research to gauge if these preferences may differ in significant ways from the preferences expressed, for example, by the general public or government officials. If they do, of course, one should endeavour to understand the sources of the variations, to determine completely what should ideally be the socially optimal set of preferences. 


\section{Appendices}

Appendix 2.1. Analytical Hierarchy Process (AHP) steps and a numerical example

The AHP proposed by Thomas Saaty (1980) is a well-known subjective method to ascertain weight. When applying it, the preferences of the decision criteria are compared in a pairwise manner with the criterion preceding them in the hierarchy. If two criterions are of equal importance, a value of ' 1 ' is accorded in the comparison.

Table 2.A1. The Saaty scale for making judgements

\begin{tabular}{|l|l|}
\hline Importance level (scale) & Verbal judgement \\
\hline 1 & Equal importance \\
\hline 3 & Moderate importance \\
\hline 5 & Strong importance \\
\hline 7 & Very strong importance \\
\hline 9 & Extreme importance \\
\hline $2,4,6,8$ & Can be used to express intermediate values \\
\hline
\end{tabular}

The AHP is composed of the following four steps:

- Step 1-form the pairwise comparison matrix A of the criteria. The comparisons are collected in an $n \times n$ pairwise comparison matrix (matrix A). Saaty (1980) proposed a ' 1 ' to '9' scale, which is used in most AHP applications (see Table A1). Each entry $a_{j k}$ in matrix A represents the importance of the jth criterion relative to the kth criterion.

- Step 2-normalise pairwise comparison matrix $A_{\text {norm }}$. Make the sum of the entries in each column equal to ' 1 ', that is, each entry $\overline{a_{J k}}$ of the matrix $A_{n o r m}$ is computed as: $\overline{a_{J k}}=\frac{a_{j k}}{\sum_{l=1}^{n} a_{l k}}$.

- Step 3-create the criteria weight vector $w$. This is an n-dimensional column vector, which is built by averaging the entries in each row of $A_{n o r m}$, that is, $w_{j}=\frac{\sum_{l=1}^{n} \bar{a}_{j l}}{n}$.

- Step 4 - consistency check the pairwise comparison matrix of the criteria. Given the pairwise comparison matrix of the criteria, its maximum eigenvalue, $\lambda \max$, is equal to $n$ if and only if the matrix is consistent: $I(X)=\frac{\lambda_{\max }-n}{n-1}$, where $C I$ is the consistency index. Given a pairwise comparison matrix of size $\mathrm{n}$, the consistency ratio $(C R)$, the rescaled version of $C I$, can be calculated as follows: $C R(X)=\frac{C I(X)}{R I_{n}}$, where $R I_{n}$ is a real number that estimates the average 
CI obtained from a large data set of randomly generated matrices of size n. Saaty (1977) suggests the value of RI corresponding to $\mathrm{n}$ (see table A2). He also suggests that matrices where $C R \leq 0.1$ are acceptable, whereas matrices where $C R>0.1$ are inconsistent.

Table 2.A2. Random index

\begin{tabular}{|l|l|l|l|l|l|l|l|l|l|l|}
\hline $\mathbf{N}$ & $\mathbf{1}$ & $\mathbf{2}$ & $\mathbf{3}$ & $\mathbf{4}$ & $\mathbf{5}$ & $\mathbf{6}$ & $\mathbf{7}$ & $\mathbf{8}$ & $\mathbf{9}$ & $\mathbf{1 0}$ \\
\hline RI & 0 & 0 & 0.58 & 0.90 & 1.12 & 1.24 & 1.32 & 1.41 & 1.45 & 1.49 \\
\hline
\end{tabular}

\section{A numerical example}

The calculation of the weights of four main criteria serves as a numerical example of the AHP:

Step 1 - form the pairwise comparison matrix of the criteria.

\begin{tabular}{|l|l|l|l|l|}
\hline & Life safety & $\begin{array}{l}\text { Spatial } \\
\text { location }\end{array}$ & Socio-cultural & Economic \\
\hline Life safety & 1 & 7 & 7 & 7 \\
\hline Spatial location & $1 / 7$ & 1 & $1 / 4$ & $1 / 3$ \\
\hline Socio-cultural & $1 / 7$ & 4 & 1 & 1 \\
\hline Economic & $1 / 7$ & 3 & 1 & 1 \\
\hline
\end{tabular}

$$
\mathrm{A}=\left[\begin{array}{cccc}
1 & 7 & 7 & 7 \\
1 / 7 & 1 & 1 / 4 & 1 / 3 \\
1 / 7 & 4 & 1 & 1 \\
1 / 7 & 3 & 1 & 1
\end{array}\right]
$$

Step 2 -normalise pairwise comparison matrix $A_{\text {norm }}$.

$$
A_{\text {norm }}=\left[\begin{array}{cccc}
0.7 & 0.47 & 0.76 & 0.75 \\
0.1 & 0.07 & 0.03 & 0.04 \\
0.1 & 0.27 & 0.11 & 0.11 \\
0.1 & 0.2 & 0.11 & 0.11
\end{array}\right]
$$

Step 3 - create the criteria weight vector $w_{j}$.

$$
w_{j}=\left[\begin{array}{llll}
0.67 & 0.06 & 0.15 & 0.13
\end{array}\right]
$$


Step 4 consistency check the pairwise comparison matrix of the criteria.

The consistency index: $C I(X)=\frac{4.2-4}{4-1}=0.07$

The consistency ratio: $C R(X)=\frac{C I(X)}{R I_{n}}=\frac{0.07}{0.9}=0.078$

Since the consistency ratio is $0.078<0.1$, the consistency of the calculation criteria weights is confirmed.

Appendix 2.2. TOPSIS and VIKOR steps

\section{TOPSIS}

TOPSIS steps can be generated as follows:

Step 1-establish a matrix of decisions (numerical values or linguistic values) in the following format:

$$
\begin{aligned}
& \begin{array}{lll}
C_{1} & \ldots & C_{j}
\end{array} \\
& D=\underset{A l t 1}{A}\left[\begin{array}{ccc}
a_{11} & \cdots & a_{1 j} \\
\vdots & \ddots & \vdots \\
a_{i 1} & \cdots & a_{i j}
\end{array}\right]
\end{aligned}
$$

Where $A l t_{1}, \ldots A l t_{i}$ are i feasible alternatives (buildings) and $C_{1}, \ldots C_{j}$ are j feasible criteria.

Step 2 -normalise a matrix of decisions. The normalised value $v_{i j}$ is calculated as:

$$
v_{i j}=\frac{a_{i j}}{\sqrt{\sum_{i=1}^{i} a_{i j}^{2}}}, \mathrm{j}=1, \ldots \mathrm{j} ; \mathrm{i}=1, \ldots \mathrm{i}
$$

Step 3 -normalise the weighted matrix of decisions.

Step 4: Determine the positive ideal solutions and negative ideal solutions, V+(PIS) and V(NIS), as follows: 


$$
\begin{aligned}
& V^{+}=\left\{v_{1}^{+}, v_{2}^{+}, \ldots v_{n}^{+}\right\}=\left\{\left(\max _{i} v_{i j} \mid j \in J\right),\left(\min _{i} v_{i j} \mid j \in J^{\prime}\right), i=1,2 . . i\right\} \\
& V^{-}=\left\{v_{1}^{-}, v_{2}^{-}, \ldots v_{n}^{-}\right\}=\left\{\left(\min _{i} v_{i j} \mid j \in J\right),\left(\max _{i} v_{i j} \mid j \in J^{\prime}\right), i=1,2 . . i\right\}
\end{aligned}
$$

Where $\mathrm{J}$ is associated with benefit, maximisation criteria, and $\mathrm{J}$ ' is associated with cost, minimisation criteria.

Step 5 - compute the separation measure (geometrical distance) between the positive ideal solution and each alternative, $S_{i}^{+}$, and the separation measure between the negative ideal solution and each alternative, $S_{i}^{-}$(this study's distance metric is Euclidean distance), as follows:

$$
\begin{aligned}
& S_{i}^{+}=\sqrt{\sum_{j=1}^{n} w_{j}^{2}} \cdot\left(\left|v_{i j}-v_{i j}^{+}\right|\right)^{2} \\
& S_{i}^{-}=\sqrt{\sum_{j=1}^{n} w_{j}^{2}} \cdot\left(\left|v_{i j}-v_{i j}^{-}\right|\right)^{2}
\end{aligned}
$$

Where $w_{j}$ are weights.

Step 6 - calculate the relative closeness to the positive ideal solution, $C_{i}^{+}$, for each alternative, using the following equation: $C_{i}^{+}=\frac{s_{i}^{-}}{S_{i}^{+}+S_{i}^{-}}$, where $0<C_{i}^{+}<1$. In this case, an alternative is closer to a positive ideal solution when relative closeness, $C_{i}^{+}$, approaches ' 1 '.

Step 7-rank the final alternative order. The alternative with the highest $C_{i}^{+}$is the optimal alternative.

\section{VIKOR}

VIKOR steps can be generated as follows:

Step 1 -determine the best and the worst values of all criteria functions.

$f_{j}^{*}=\max _{i} f_{i j} ; f_{j}^{-}=\min _{i} f_{i j}, \mathrm{i}=1,2, \ldots \mathrm{m}, \mathrm{j}=1,2 \ldots, \mathrm{n}$; if the $j$ th function is to be maximised (benefit).

$f_{j}^{*}=\min _{i} f_{i j} ; f_{j}^{-}=\max _{i} f_{i j}, \mathrm{i}=1,2, \ldots \mathrm{m}, \mathrm{j}=1,2 \ldots, \mathrm{n}$; if the $j$ th function is to be minimised (cost). 
Step 2 - compute the values $S_{i}$ and $R_{i}$.

$\mathrm{Si}=\sum_{j=1}^{n} w_{j}\left(f_{j}^{*}-f_{i j}\right) /\left(f_{j}^{*}-f_{j}^{-}\right) ; \mathrm{i}=1,2, \ldots \mathrm{m}, \mathrm{j}=1,2 \ldots, \mathrm{n}$

$R_{i}=\max _{j}\left[w_{j}\left(f_{j}^{*}-f_{i j}\right) /\left(f_{j}^{*}-f_{j}^{-}\right)\right] ; \mathrm{i}=1,2, \ldots \mathrm{m}, \mathrm{j}=1,2 \ldots, \mathrm{n}$

Where $w_{j}$ is the weight of the $j$ th criterion.

Step 3 - compute the value $\mathrm{Q}_{\mathrm{i}}$.

$Q_{i}=v\left(S_{i}-S^{*}\right) /\left(S^{-}-S^{*}\right)+(1-v)\left(R_{i}-R^{*}\right) /\left(R^{-}-R^{*}\right) ; \mathrm{i}=1,2, \ldots, \mathrm{m}$

Where $S^{*}=\min _{\mathrm{i}} S_{\mathrm{i}} ; S^{-}=\max _{\mathrm{i}} \mathrm{S}_{\mathrm{i}} ; R^{*}=\min _{\mathrm{i}} \mathrm{R}_{\mathrm{i}} ; R^{-}=\max _{\mathrm{i}} \mathrm{R}_{\mathrm{i}} ;$ and $\nu=0.5$.

Step 4 rank the alternatives, sorting by the values $S, R$, and $Q$ in ascending order. The result is three ranking lists.

Step 5-propose a compromise solution. Propose the alternative $\left[\mathrm{A}^{(1)}\right]$, which is the best ranked by the measure Q (minimum) if the following two conditions are satisfied:

$\mathrm{C} 1$ - acceptable advantage. $\mathrm{Q}(\mathrm{A}(2))-\mathrm{Q}(\mathrm{A}(1))>=\mathrm{DQ}$; where $\mathrm{A}(2)$ is the second ranked alternative by the measure $\mathrm{Q}$ and $\mathrm{DQ}=1 /(\mathrm{m}-1)$

$\mathrm{C} 2$ - acceptable stability in decision-making. The alternative $\mathrm{A}^{(1)}$ must also be the best as ranked by $\mathrm{S}$ and/or $\mathrm{R}$. This compromise solution is stable within a decision-making process.

Appendix 2.3. Questionnaire to identify the weights of criteria

Questionnaire survey. Prioritising earthquake retrofitting in Wellington's CBD

Participants' information:

Q1. What is your profession or occupation?

1. Researcher (engineer)

2. Researcher (other physical science)

3. Researcher (social science)

4. Practising engineer

5. Government/policy

6. Other 
Q2. How many years have you worked in your field?

1. $0-5$

2. $5-15$

3. Greater than 15

Q3-Q8

When deciding which building to prefer to retrofit, which criteria is more important?

Using the scale from ' 1 ' to ' 9 ' (where 1 is $\mathbf{A}$ is much more important than $\mathbf{B}$, and 9 is $B$ is much more important than $A$ )

\begin{tabular}{|c|c|c|c|c|c|c|c|c|c|c|}
\hline A option & 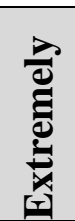 & $e_{d}^{d}$ & $\begin{array}{l}\frac{\lambda}{00} \\
\frac{0}{0} \\
\frac{0}{2}\end{array}$ & 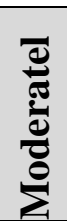 & 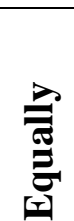 & 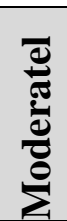 &  & $\sum_{0}^{2}$ & 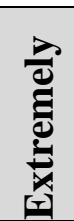 & B option \\
\hline $\begin{array}{l}\text { Life } \\
\text { safety }\end{array}$ & 1 & 2 & 3 & 4 & 5 & 6 & 7 & 8 & 9 & $\begin{array}{l}\text { Spatial } \\
\text { location }\end{array}$ \\
\hline $\begin{array}{l}\text { Life } \\
\text { safety }\end{array}$ & 1 & 2 & 3 & 4 & 5 & 6 & 7 & 8 & 9 & $\begin{array}{l}\text { Socio- } \\
\text { cultural } \\
\text { role }\end{array}$ \\
\hline $\begin{array}{l}\text { Life } \\
\text { safety }\end{array}$ & 1 & 2 & 3 & 4 & 5 & 6 & 7 & 8 & 9 & $\begin{array}{l}\text { Economic } \\
\text { role }\end{array}$ \\
\hline $\begin{array}{l}\text { Spatial } \\
\text { location }\end{array}$ & 1 & 2 & 3 & 4 & 5 & 6 & 7 & 8 & 9 & $\begin{array}{l}\text { Socio- } \\
\text { cultural } \\
\text { role }\end{array}$ \\
\hline $\begin{array}{l}\text { Spatial } \\
\text { location }\end{array}$ & 1 & 2 & 3 & 4 & 5 & 6 & 7 & 8 & 9 & $\begin{array}{l}\text { Economic } \\
\text { role }\end{array}$ \\
\hline $\begin{array}{l}\text { Socio- } \\
\text { cultural } \\
\text { role }\end{array}$ & 1 & 2 & 3 & 4 & 5 & 6 & 7 & 8 & 9 & $\begin{array}{l}\text { Economic } \\
\text { role }\end{array}$ \\
\hline
\end{tabular}

Q9-Q11

To retrofit a building, with respect to its spatial location, please indicate the relative importance of option A (left column) to option B (right column) 


\begin{tabular}{|c|c|c|c|c|c|c|c|c|c|c|}
\hline A option & 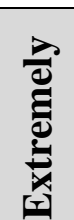 & $\frac{\overrightarrow{0}}{\overrightarrow{0}}$ & $\begin{array}{l}\frac{2}{80} \\
\frac{D}{0} \\
\frac{1}{\infty}\end{array}$ & 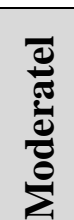 & 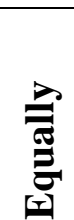 & 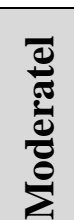 & $\frac{\overrightarrow{2}}{\Delta 0}$ & $\vec{b}_{\overrightarrow{0}}^{\overrightarrow{0}}$ & 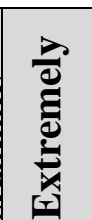 & B option \\
\hline $\begin{array}{l}\text { Distance } \\
\text { from the } \\
\text { emergency } \\
\text { transport } \\
\text { routes }\end{array}$ & 1 & 2 & 3 & 4 & 5 & 6 & 7 & 8 & 9 & $\begin{array}{l}\text { Number of } \\
\text { cross } \\
\text { roads in a } \\
\text { radius of } \\
50 \text { metres } \\
\text { from the } \\
\text { building }\end{array}$ \\
\hline $\begin{array}{l}\text { Distance } \\
\text { from the } \\
\text { emergency } \\
\text { transport } \\
\text { routes }\end{array}$ & 1 & 2 & 3 & 4 & 5 & 6 & 7 & 8 & 9 & $\begin{array}{l}\text { Failure } \\
\text { will } \\
\text { expand the } \\
\text { required } \\
\text { cordon }\end{array}$ \\
\hline $\begin{array}{l}\text { Number of } \\
\text { crossroads } \\
\text { in a radius } \\
\text { of } 50 \\
\text { metres } \\
\text { from the } \\
\text { building }\end{array}$ & 1 & 2 & 3 & 4 & 5 & 6 & 7 & 8 & 9 & $\begin{array}{l}\text { Failure } \\
\text { will } \\
\text { expand the } \\
\text { required } \\
\text { cordon }\end{array}$ \\
\hline
\end{tabular}

Q12

To retrofit a building, with respect to its socio-cultural role, please indicate the relative importance of option A (left column) to option B (right column)

\begin{tabular}{|c|c|c|c|c|c|c|c|c|c|c|}
\hline A option &  & $\stackrel{\overrightarrow{0}}{\overrightarrow{0}}$ &  & 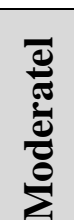 & 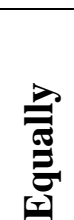 & 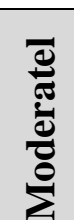 & $\frac{\lambda}{\overrightarrow{b 0}}$ & $\frac{\vec{d}}{\overrightarrow{0}}$ & & B option \\
\hline $\begin{array}{l}\text { Heritage } \\
\text { building }\end{array}$ & 1 & 2 & 3 & 4 & 5 & 6 & 7 & 8 & 9 & $\begin{array}{l}\text { Community } \\
\text { building }\end{array}$ \\
\hline
\end{tabular}


Q13-Q16

To retrofit a building, with respect to its economic role, please indicate $(\mathrm{X})$ the relative importance of option A (left column) to option B (right column)

\begin{tabular}{|c|c|c|c|c|c|c|c|c|c|c|}
\hline A option & 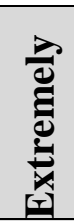 & $\vec{d}_{0}^{2}$ & 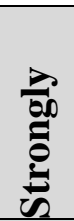 & 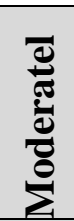 & 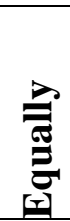 & 胥 & $\frac{D}{800}$ & $\vec{D}_{0}^{0}$ & $\frac{z}{d}$ & B option \\
\hline $\begin{array}{l}\text { Building } \\
\text { function }\end{array}$ & 1 & 2 & 3 & 4 & 5 & 6 & 7 & 8 & 9 & $\begin{array}{l}\text { Improveme } \\
\text { nt value }\end{array}$ \\
\hline $\begin{array}{l}\text { Tourist } \\
\text { accommodatio } \\
\text { n }\end{array}$ & 1 & 2 & 3 & 4 & 5 & 6 & 7 & 8 & 9 & $\begin{array}{l}\text { Commercial } \\
\text { building }\end{array}$ \\
\hline $\begin{array}{l}\text { Tourist } \\
\text { accommodatio } \\
\text { n }\end{array}$ & 1 & 2 & 3 & 4 & 5 & 6 & 7 & 8 & 9 & $\begin{array}{l}\text { Residential } \\
\text { building }\end{array}$ \\
\hline $\begin{array}{l}\text { Commercial } \\
\text { building }\end{array}$ & 1 & 2 & 3 & 4 & 5 & 6 & 7 & 8 & 9 & $\begin{array}{l}\text { Residential } \\
\text { building }\end{array}$ \\
\hline
\end{tabular}




\section{Appendix 2.4. Three-dimensional GIS (geographic information system) map of 384 buildings ranked by TOPSIS and VIKOR}

Figures 2.A1 and 2.A2 show the distribution of the 384 prioritised buildings in Wellington's $\mathrm{CBD}$. The heights represent their relative closeness values (close to the ideal point). In these figures, the higher a building, the greater the prioritisation should be for retrofitting.

Figure 2.A1. Three-dimensional GIS map of 384 buildings ranked by TOPSIS

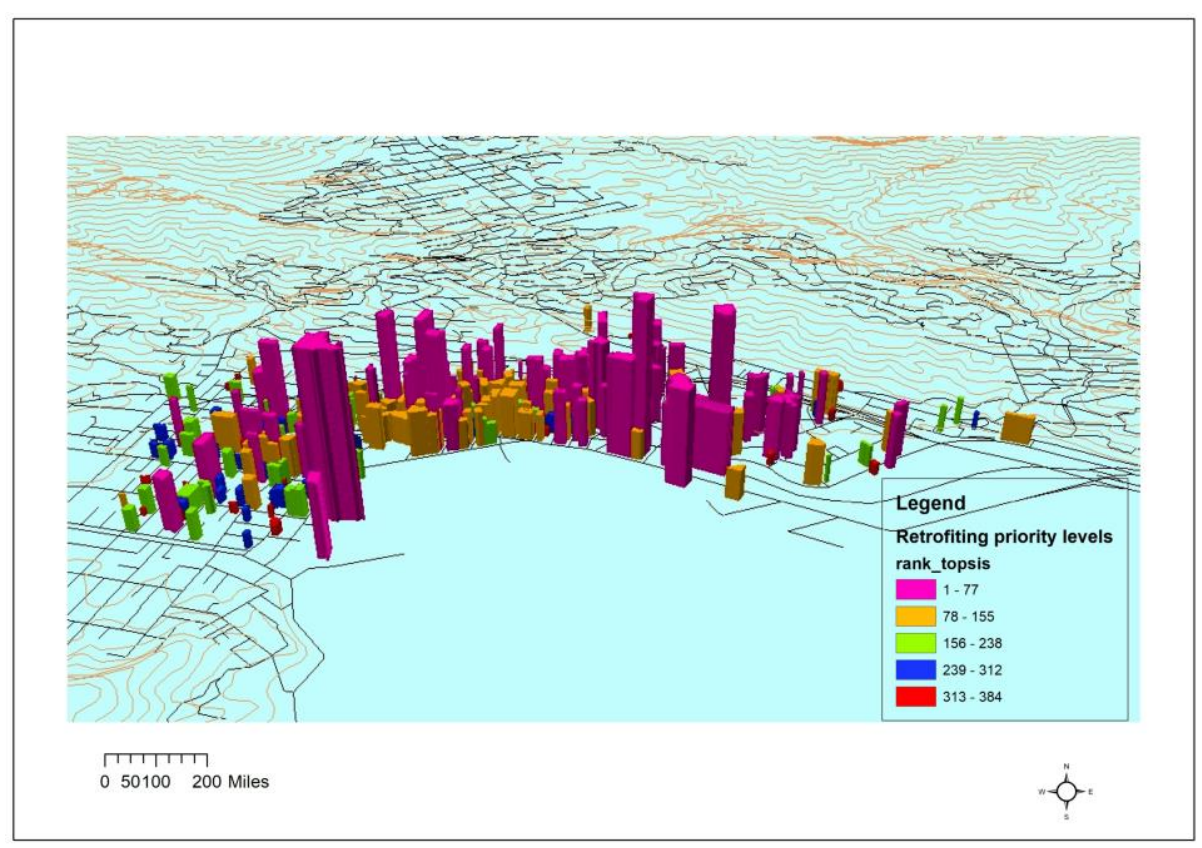

Figure 2.A2. Three-dimensional GIS map of 384 buildings ranked by VIKOR

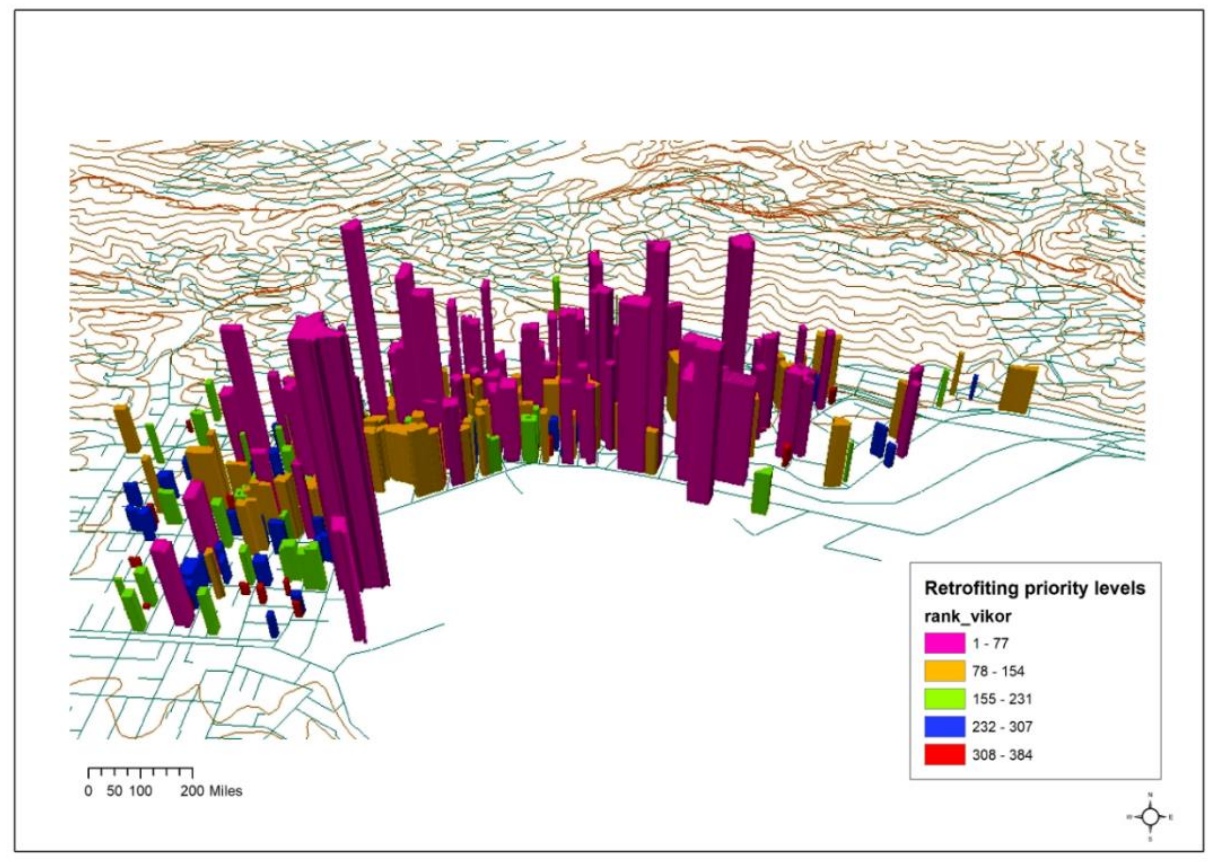


Figure 2.A3. Comparison of the prioritisation of all buildings ranked by TOPSIS and VIKOR

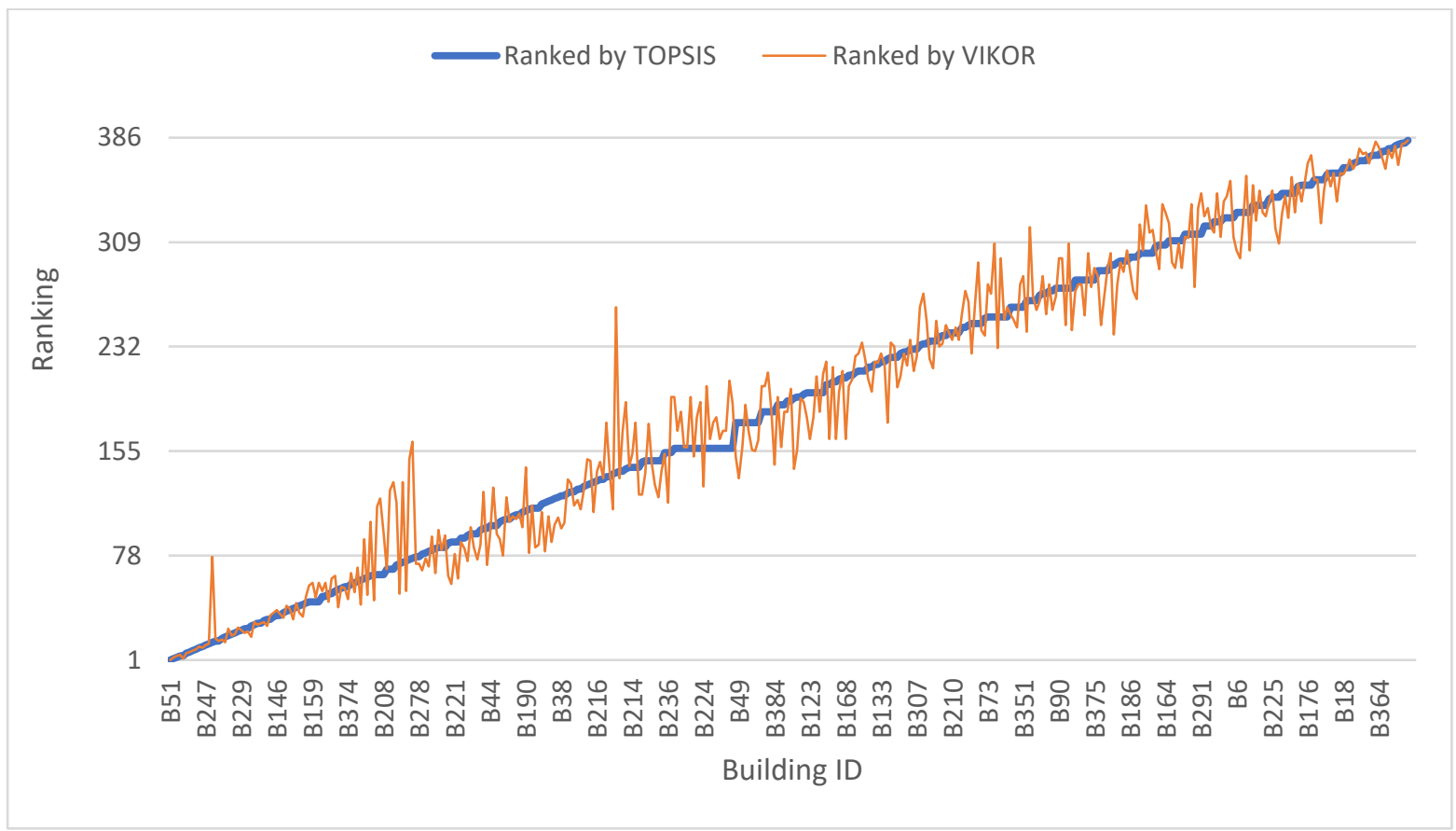

Notes: this figure shows the exact ranking, from 1-384, of the buildings according to the two methods. The horizontal axis shows the building identification (ID) and the vertical axis displays the rank, divided into five equal-size priority groups $(1-78 ; 79-154 ; 155-231 ; 232-$ 308; and 309-384) — the first one is the top priority group. 


\section{References}

Ali, Y., M. Sanusi, S. Ahamad, and T.A. Majid (2014) 'Application of TOPSIS method in prioritization of highway bridges for seismic retrofitting'. Engineering Structures and Technologies. 6(3). pp. 114-123.

Bana e Costa, C.A., C.S. Oliveira, and V. Vieira (2008) 'Prioritization of bridges and tunnels in earthquake risk mitigation using multicriteria decision analysis: application to Lisbon'. OMEGA: The International Journal of Management Science. 36(3). pp. 442-450.

Comerio, M.C. (1992) 'Impacts of the Los Angeles retrofit ordinance on residential buildings'. Earthquake Spectra. 8(1). pp. 79-94.

Dong, Y., G. Zhang, W.-C. Hong, and Y. Xu (2010) 'Consensus models for AHP group decision making under row geometric mean prioritization method'. Decision Support Systems. 49(3). pp. 281-289.

Elwood, K., O. Filippova, I. Noy, and J. Pastor Paz (2020) 'Seismic policy, operations, and research uses for a building inventory in an earthquake-prone city'. International Journal of Disaster Risk Science. 11. pp. 709-718. https://doi.org/10.1007/s13753-020-00313-7 (last accessed on 18 March 2021).

Flynn, J., P. Slovic, C.K. Mertz, and C. Carlisle (1999) 'Public support for earthquake risk mitigation in Portland, Oregon'. Risk Analysis. 19(2). pp. 205-216.

Greco, S., M. Ehrgott, and J. Rui Figueira (eds.) (2016) Multiple Criteria Decision Analysis: State of the Art Surveys. Springer Publishing, New York, NY.

Henry, R.S., D. Dizhur, K.J. Elwood, J. Hare, and D. Brunsdon (2017) 'Damage to concrete buildings with precast floors during the 2016 Kaikoura earthquake'. Bulletin of the New Zealand Society for Earthquake Engineering. 50(2). pp. 174-186.

Hwang, C.L. and K. Yoon (1981) Multiple Attribute Decision Making. Lecture Notes in Economics and Mathematical Systems. No. 186. Springer-Verlag, Berlin.

Joerin, F., G. Cool, M.J. Rodriguez, M. Gignac, and C. Bouchard (2010) 'Using multi-criteria decision analysis to assess the vulnerability of drinking water utilities'. Environmental Monitoring and Assessment. 166(1). pp. 313-330. 
Morton, A., J. Keisler, and A. Salo (2016) 'Multicriteria portfolio decision analysis for project selection'. In S. Greco, M. Ehrgott, and J. Rui Figueira (eds.) Multiple Criteria Decision Analysis: State of the Art Surveys. Springer Publishing, New York, NY. pp. 1269-1300.

National Institute of Science and Technology (2013) Cost Analyses and Benefit Studies for Earthquake-resistant Construction in Memphis, Tennessee. NIST GCR 14-917-26. 17 December. $\quad$ https://www.nist.gov/publications/cost-analyses-and-benefit-studiesearthquake-resistant-construction-memphis-tennessee (last accessed on 18 March 2021).

Opricovic, S. and G-H. Tzeng (2004) 'Compromise solution by MCDM methods: a comparative analysis of VIKOR and TOPSIS'. European Journal of Operational Research. 156(2).pp. 445-455.

Puranam, A. et al. (2019) 'A detailed inventory of medium- to high-rise buildings in Wellington's central business district'. Bulletin of the New Zealand Society for Earthquake Engineering. 52(4). pp. 172-192.

Reed, P., K. Schoonees, and J. Salmond (2008) Historic Concrete Structures in New Zealand: Overview, Maintenance and Management. Department of Conservation, Wellington.

Saaty, T. (1977) 'A scaling method for priorities in hierarchical structures'. Journal of Mathematical Psychology. 15(3). pp. 234-281.

Saaty, T. (1980) The Analytical Hierarchy Process. McGraw Hill, New York, NY.

Santa-Cruz, S. et al. (2016) 'Social sustainability dimensions in the seismic risk reduction of public schools: a case study of Lima, Peru'. Sustainability: Science, Practice and Policy. 12(1). pp. 34-46.

Schulze, W.D., D.S. Brookshire, R.K. Hageman, and J. Tschirhart (1987) 'Benefits and costs of earthquake resistant buildings'. Southern Economic Journal. 53(4). pp. 934-951.

Segal, E., M. Negev, E. Feitelson, and D. Zaychik (2017) 'Devising "policy packages" for seismic retrofitting of residences'. Natural Hazards. 89(1). pp. 497-519.

Shrestha, S.R., C. Orchiston, K. Elwood, D. Johnston, and J. Becker (2019) 'To Cordon or Not to Cordon': The Inherent Complexities of Post-earthquake Cordons Learned from Experiences in Christchurch and Wellington, New Zealand. Conference poster. https://ir.canterbury.ac.nz/handle/10092/17211 (last accessed on 18 March 2021). 
Valcárcel, J. et al. (2013) 'Methodology and applications for the benefit cost analysis of the seismic risk reduction in building portfolios at broad scale'. Natural Hazards. 69(1). pp. 845-868.

Vona, M., A. Anelli, M. Mastroberti, B. Murgante, and S. Santa-Cruz (2017) 'Prioritization strategies to reduce the seismic risk of the public and strategic buildings'. Disaster Advances. 10(4). pp. 1-15.

Wang, J-W., C-H. Cheng, and K-C. Huang (2009) 'Fuzzy hierarchical TOPSIS for supplier selection'. Applied Soft Computing. 9(1). pp. 377-386.

Wood, A., I. Noy, and M. Parker (2016) 'The Canterbury rebuild five years on from the Christchurch earthquake'. Reserve Bank of New Zealand Bulletin. 79(3). pp. 1-16. 


\title{
CHAPTER 3
}

\section{Wellbeing After a Managed Retreat:}

\section{Observations from a Large New}

\section{Zealand Program}

\begin{abstract}
:
Managed retreat programs aim to relocate households out of harm's way. In New Zealand, as elsewhere, managed retreat initiatives generate a highly polemical and emotional debate within affected communities, and between them and the government. Given the fraught implementation of managed retreats, understanding what happens to residents who are displaced by these programs is of immense importance. This chapter examines the wellbeing of the people who were forced to move as part of a large managed-retreat program that was implemented in Christchurch, New Zealand, after the 2011 earthquake the city experienced. Three indicators of subjective wellbeing are considered: quality of life, stress, and emotional wellbeing. Our aims are: (1) to describe the wellbeing of the relocated residents after they were forced to move, and identify which factors are correlated with their well-being; (2) to describe the subjective experience of the residents in their communication with the government and in their relation with the community; (3) to identify the effect of economic factors (household annual income, homeownership, and financial impacts) on their wellbeing; and (4) to relate these findings to possible policy lessons when designing managed retreat programs. We found that demographic factors, health conditions, and the type of government compensation the residents accepted, were all significant determinants of the wellbeing of the Red Zone residents. More social relations, better financial circumstances, and the perception of better government communication were also all associated positively with a higher quality of life, less stress, and higher emotional wellbeing.
\end{abstract}




\subsection{Introduction}

Managed retreat programs aim to relocate households or remove homes and other infrastructure out of the reach of hazards. They are most typically considered for coastal areas when coastal erosion is made worse by sea level rise, and where the future feasibility of continuing habitation looks bleak (Alexander et al, 2012). It is sometimes also considered because of other known coastal hazards such as tsunamis or hurricane storm surges (e.g., Ingram et al., 2006). In New Zealand, as elsewhere, managed retreat initiatives generate highly polemical and emotional discussions, as these programs affect people and their communities dramatically (Hanna et al., 2017; Hino et al., 2017).

Given the controversial and difficult implementation of managed retreat programs, it is clear that understanding what happens to residents who get displaced is of immense importance. An improved understanding of the factors that characterise how the retreat process is related to residents' wellbeing in its aftermath can have a significant impact on the design of managed retreat policies. This knowledge can help planners design programs more effectively and avoid some of the well-intentioned failures that often beset such efforts.

This chapter examines the large managed-retreat program that was implemented in Christchurch, New Zealand, after the 2011 earthquake the city experienced. In this program, the government re-zoned several areas of the city, and moved about 16,000 people (around 8000 households) by buying their homes at their pre-earthquake assessed values. This is an unusually large program. Admittedly, most managed retreat programs are associated with coastal and flooding hazards, but the motivation for the Christchurch Residential Red Zone (RRZ) program was not very different. Ultimately, the motivation was to reduce future riskboth mortality and morbidity risks and risk to assets.

Many studies investigated the impact of disasters of various kinds, including those associated with natural hazards, on individuals' wellbeing (Adams et al. 2002; Norris et al. 2002; Salcioglu et al. 2007). These generally found that disasters with significant loss of life, widespread damage to property, and serious and ongoing economic difficulties for the community, tend to trigger severe, lasting, and pervasive psychological problems such as anxiety and depression. Almond et al. (2009) pointed out the impacts of the Chernobyl disaster on health and schooling outcomes, but not its effect on subjective wellbeing. In contrast, we examine here the wellbeing of the people who were forced to move by the RRZ program - a program of post-disaster managed retreat - using a comprehensive survey. 
Although the term wellbeing is frequently used, there is no widespread agreed definition, and it is often used as an all-encompassing concept to describe the quality of people's lives (Dodge et al. 2012). Terms such as happiness, quality of life, and life satisfaction have all been used interchangeably to mean wellbeing (Allin, 2007; Robine and Jagger, 2003).

Generally, two ways to measure wellbeing have been used in previous research: objective and subjective. The objective measures identify an individual's requirements and examines whether these requirements are satisfied (for example, in terms of caloric intake), while subjective measures are based on surveys which ask individuals directly about their wellbeing (e.g., Veenhoven 2000; Diener and Lucas, 2002). Here, we use a subjective measurement approach, based on survey questionnaires, to evaluate the well-being of re-located people after the implementation of a managed retreat program.

Early in the $20^{\text {th }}$ century, subjective wellbeing studies began to take shape; these were characterized by very short scales. Bradburn (1969) showed that pleasant and unpleasant affect are independent and have different correlates. The conclusion from this work was that these two aspects must be investigated separately to obtain a comprehensive picture of individuals' wellbeing. This work demonstrated that the elimination of stress or sadness may not necessarily result in a corresponding increase in happiness or a good mood.

Since the review of the larger literature on subjective wellbeing provided by Diener (1984), the field has grown rapidly. One of the reasons lies in its democratic ethos - it fundamentally respects to what people think and feel about their lives rather than be based on experts' evaluation. Similarly, Diener et.al (2002) argue that the research on subjective wellbeing flourished because of the growing global trend toward individualism.

Subjective wellbeing is defined as the person's perception of her life as a whole (Soukiazis and Ramos, 2015). A number of researchers have identified three components of subjective wellbeing: life satisfaction or quality of life, positive moods and emotions, and negative moods and emotions (Diener et al. 1995; Lucas et al. 1996; Myers and Diener 1995; Diener et. al 2002). They also identified subjective wellbeing with a cognitive dimension and an affective dimension.

In this chapter, we considered three indicators for the measurement of subjective wellbeing: (1) subjective quality of life; (2) stress level; and (3) emotional wellbeing (as measured with the WHO-5 indicator). These factors fit the three dimensions theory of subjective wellbeing 
including: The cognitive dimension (quality of life); the affective dimension including an unpleasant affect (stress); and a pleasant affect (positive emotional wellbeing).

The relationship between wellbeing and disasters is, intuitively, persuasive. Many studies examined the factors associated with disaster survivors' psychological status. Lewin et al. (1998), Brewin et al. (2000), Norris et al. (2002), and Norris (2005) showed that demographic factors ( age, gender, ethnicity), socioeconomic status, severity of exposure to the shock, family characteristics, stressors, available social support, and resource loss, all significantly affected survivors' psychological state.

Evidence from previous studies demonstrates that subjective well-being is related to multiple factors (Pinquart and Sörensen, 2000; Peterson et al.,2014). It is now recognized, for example, that social relations (the bonding, linking and bridging connections within and between communities) affect well-being in several ways. As such, the personal impact of the breakup of communities that is associated with managed retreats needs to be evaluated (e.g., Prezza and Costantini, 1998; Pretty et al., 2006).

Some researchers also emphasize the importance of social capital in enhancing resilience and reducing the potential impacts of disasters (Aldrich, 2012a, 2012b; Aldrich and Sawada, 2015). Thus, unintentionally, the drive to reduce risk by instituting managed retreat programs might also be increasing risk as a community's collective ties are severed. Moriyama et al. (2019), in a paper possibly most similar to our own research, compare the well-being of the 2011 East Japan tsunami survivors who are placed in 'restoration public housing' using a similar subjective measure to the one we use (the WHO-5 indicator); though their comparison yields no statistically significant differences between that population and others who were affected by the tsunami.

The aims of this chapter were: (1) to describe the (subjective) wellbeing of the RRZ residents after they were forced to move, and identify which factors affect their well-being having already moved to new places. (2) to describe the subjective experience of the residents in their communication with the government and in their relationship with the community, (3) to identify the effect of economic factors (household annual income, home ownership, and financial impacts) on wellbeing; and (4) to relate these findings to possible lessons for policy makers when designing managed retreat programs.

To address these aims, we used a survey that specifically targeted the RRZ residents in their new homes, and whose direct aim was to gauge what happened to them (CERA, 2016). The 
rest of the chapter is organized as follows: Section 3.2 gives an overview of the study area and the financial offers that RRZ residents were given for their re-settlement. Section 3.3 describes how the data was collected, and what they include. Section 3.4 details the empirical models used to evaluate the determinants of wellbeing. The results of the statistical analysis are described in section 3.5, and section 3.6 concludes with some further observations.

\subsection{The RRZ area and the Crown offers}

Figure 3.1 shows the map of Christchurch. Greater Christchurch includes Christchurch City, and the Waimakariri and Selwyn districts to the north of the city. The population of Christchurch City pre-earthquake was approximately 348,000 people, while that of Waimakariri and Selwyn districts together was about 77,000 residents. The Christchurch earthquake on 22nd February 2011 was the worst natural disaster in New Zealand history; it caused the death of 185 people, and a reconstruction cost estimated at around 30 Billion US\$ (Wood et al., 2016).

East of the city centre, in the flat area between the centre and the coast along the Avon River, the earthquake caused severe damage, and significant liquefaction. In the hillside suburbs south-east of the centre, the earthquake destabilised cliffs, and many houses remained at risk from landslides and rock falls. The damage in both these areas was the most severe in the city. In June 2011, the government announced an emergency policy which aimed to designate some of the worst affected areas as "red zones". Red zones were eventually declared in parts of Waimakariri District around the Waimakariri River, parts of the flat land in Christchurch City along the Avon River, and parts of the Port Hills.

The residents in this Residential Red Zone (RRZ) were told that these areas were no longer zoned for residential use, and the Crown offered to purchase their homes and land. The government offered homeowners two options: (1) The Crown Option: the government buys both the building and land at their 2007 assessed values, and in return it owns any outstanding insurance claim for damage from the earthquakes. (2) The Insurance Option: the Crown will only purchase the land at its 2007 assessed value, and the homeowner will retain the remaining claim against their insurer for any damage. The final date for accepting these offers was 10th December 2015. By that deadline, 7,724 of 8,060 property owners in the residential red zone had accepted one of the government offers; 1,695 homeowners had accepted the Crown option and 6,029 properties had chosen the insurance option (Nguyen, 2019). 
Figure 3.1. Residential Red Zone Properties

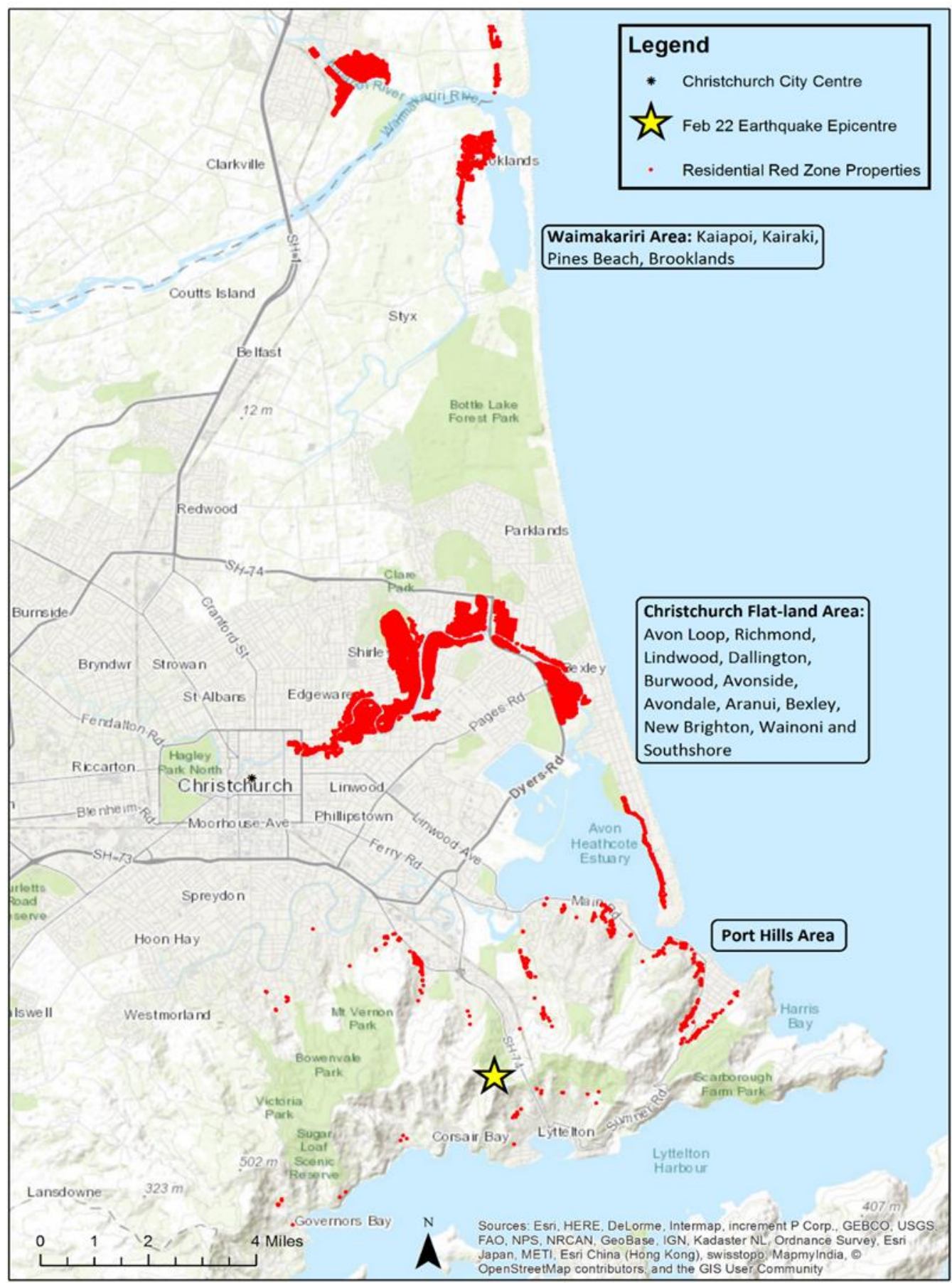




\subsection{Data and variables selection}

\subsubsection{The survey}

The Canterbury Earthquake Recovery Authority (CERA) RRZ Survey was conducted by the independent polling company Nielsen under contract from the New Zealand Government. The survey was conducted in Christchurch, during October and November 2015, almost five years after the earthquake. At that time, the vast majority of the RRZ households had already moved to new locations. Respondents, a sample of the RRZ population, were contacted using the contact information held by CERA - the ministerial-level authority which was implementing the RRZ program.

The survey, and consequently our analysis, was restricted to the former residential red zone property owners who accepted one of the government's offers for their properties. The sample size is 1890 homeowners, out of 7,724 (25\%); it was designed to represent the population of the RRZ households. A total of 136 questions included both categorical and ordinal questions. Most questions were based on a five-points Likert scale, with 1 classified as 'strongly disagree' and 5 as 'strongly agree'. We re-code all variables so that a higher score represents a higher level of wellbeing.

Table 3.1 provides a snapshot of the respondents to the survey. Among them, $41 \%$ were males and $59 \%$ were female. About $4 \%$ of the respondents were between the ages of 18 and $34,62 \%$ were between 35 and 64; and 34\% were older than $64.80 \%$ answered that they do not have any health problem at the time they were interviewed.

Table 3.1. Characteristics of the sample $(\mathrm{N}=1890)$

\begin{tabular}{lll}
\hline Variables & Level & Rate $(\%)$ \\
\hline Gender & Male & 41 \\
\cline { 2 - 3 } & Female & 59 \\
\hline Age & $18-34$ & 4 \\
\hline & $35-64$ & 62 \\
\hline Household annual income & +65 & 34 \\
& $<\$ 30000$ & 11 \\
& $\$ 30001-\$ 60000$ & 27 \\
\cline { 2 - 3 } & $\$ 60001-\$ 100000$ & 38 \\
\cline { 2 - 3 } & $\$ 100001-\$ 200000$ & 21 \\
\hline
\end{tabular}




\begin{tabular}{lll}
\hline & $>\$ 200001$ & 3 \\
\hline The Crown offers & The crown option & 30 \\
\hline Having health condition & The insurance option & 70 \\
\hline Overall quality of life & Yes & 18 \\
\hline & Extremely poor & 1 \\
\hline & Poor & 6 \\
\hline Neither poor nor good & 19 \\
\hline The stress level & Good & 56 \\
\hline & Extremely good & 18 \\
\hline Always & 3 \\
\hline Most of the time & 19 \\
\hline Sometimes & 55 \\
\hline & Rarely & 20 \\
\hline Never & 3 \\
\hline
\end{tabular}

Regarding their quality of life, $75 \%$ participants rated their overall quality of life as good or extremely good. Only $7 \%$ reported that their quality of life is extremely poor or poor. About their stress level, 22\% answered they were stressed 'always' or 'most of the time,' and $23 \%$ replied they 'rarely' or 'never' experienced adverse emotional wellbeing, while many respondents answered they experienced "most of the time" five positive emotional aspects during the two weeks before they were surveyed (table 3.2).

Table 3.2. WHO-5 emotional well-being index

\begin{tabular}{lllllll}
\hline & 0 & I & II & III & IV & V \\
\hline I have cheerful and in good spirits & 1 & 12 & 11 & 25 & 44 & 6 \\
\hline I woke up feeling fresh and rested & 3 & 15 & 15 & 25 & 36 & 5 \\
\hline $\begin{array}{l}\text { My daily life has been filed with } \\
\text { things that interest me }\end{array}$ & & 17 & 21 & 24 & 27 & 3 \\
\hline I have felt calm and relaxed & 12 & 19 & 22 & 23 & 22 & 3 \\
\hline I have felt active and vigorous & 2 & 18 & 12 & 26 & 34 & 8
\end{tabular}

Experience during the last two weeks: $0=$ At no time; $\mathrm{I}=$ Some of the time, $\mathrm{II}=$ Less than half of the time; III= More than half of the time; IV= Most of the time; V= All of the time. Rate (\%) 


\subsubsection{Dependent variables}

We examined three dependent variables. Quality of life is a categorical variable where respondents were asked to report their overall quality of life ranging from 1 (extremely poor) to 5 (extremely good). The stress level was assessed with the following question "In the past 12 months, how often have you experienced stress that has had a negative effect on you." Answers were: 1 (always), 2 (most of the time), 3 (sometimes), 4 (rarely), and 5 (never). We estimated the determinants of both of these dependent variables with ordered-logit regression models.

Finally, emotional wellbeing was evaluated by the WHO-5 wellbeing index (the World Health Organisation 5 items index). Respondents were asked to rate their experience over the last two weeks, ranging from 0 (at no time), 1 (some of the time), 2 (less than half of the time), 3 (more than half of the time), 4 (most of the time), and 5 (all of the time), in terms of five aspects "I am cheerful and in good spirits", "I woke up feeling fresh and rested", "My daily life has been filled with things that interest me", "I have felt calm and relaxed", and "I have felt active and vigorous". The raw scores were summed up to a score from 0 to 25 , with 0 being the lowest level of emotional wellbeing. The mean score of the WHO-5 index as a representative variable of the emotional wellbeing in this study was 13.7 while the standard deviation was 5.7. Table 3.3 shows the detail information of the total score of the WHO-5 index and its frequency, percentage and cumulative percentage. We use factor analysis to measure emotional wellbeing and estimate it as a continuous variable.

Table 3.3. The total score and frequency of the WHO-5 index

\begin{tabular}{cccc}
\hline Total score & Frequency & Percent & Cumulative percentage \\
\hline 0 & 35 & 1.57 & 1.57 \\
1 & 9 & 0.40 & 1.97 \\
2 & 28 & 1.26 & 3.23 \\
3 & 44 & 1.97 & 5.20 \\
4 & 56 & 2.51 & 7.71 \\
5 & 75 & 3.36 & 11.08 \\
6 & 64 & 2.87 & 13.95 \\
7 & 54 & 2.42 & 16.37 \\
8 & 82 & 3.68 & 20.04 \\
9 & 86 & 3.86 & 23.90 \\
10 & 104 & 4.66 & 28.57
\end{tabular}




\begin{tabular}{lccc}
11 & 125 & 5.61 & 34.17 \\
12 & 108 & 4.84 & 39.01 \\
13 & 135 & 6.05 & 45.07 \\
14 & 111 & 4.98 & 50.04 \\
15 & 142 & 6.37 & 56.41 \\
16 & 135 & 6.05 & 62.47 \\
17 & 148 & 6.64 & 69.10 \\
18 & 138 & 6.19 & 75.29 \\
19 & 141 & 6.32 & 81.61 \\
20 & 254 & 11.39 & 93.00 \\
21 & 49 & 2.20 & 95.20 \\
22 & 31 & 1.39 & 96.59 \\
23 & 25 & 1.12 & 97.71 \\
24 & 16 & 0.72 & 98.43 \\
25 & 35 & 1.57 & 100.00 \\
\hline
\end{tabular}

\subsubsection{Independent variables}

In this study, we examined several demographic factors including age (grouped into 18-34, 35-64, 65 and older with the second group as the reference category), ethnicity, gender, having children and having a partner (as a binary variable). Regarding the health factor, respondents were asked to report whether they have health condition or disability that has lasted six months or more and that restricts their everyday activities (as a binary variable).

In terms of economic factors, we included the household annual income (in NZ\$ - less than 30,$001 ; 30,001-60,000 ; 60,001-100,000 ; 100,001-200,000$; and 200,001 and up; with the first group as the reference category), home ownership (as a binary variable), and financial impact due to being in the Red Zone. The financial impact was measured through four questions. Respondents were asked to describe their financial position - specifically, in negative, no impact, or positive way, in terms of : (1) Their mortgage size, (2) The amount of equity they have in their property, (3) the amount of their available savings, and (4) the size/quality/value of their property.

In terms of social relations, participants were asked to rate the extent to which they feel a sense of community with others in the neighbourhood they live in now, and whether they feel that the neighbourhood their house/apartment is in now suits the needs of their household. 
Our study is focused on the wellbeing of residents after they were forced to move by the government's policy. Hence, we included in our model the quality of the government's interactions, the government offers (with the Crown option as the reference category), and the time when a property was confirmed as being red zoned. The government's interactions with the homeowners were measured based on five questions. Participants were asked to rate whether: (1) they were given sufficient time to make decisions about the offers, (2) they were provided with the best possible information to help them to make a decision about the offers, (3) they were treated respectfully and fairly, and (4) the red zoning and offer processes were clear, and (5) they have confidence in the government agencies involved.

\section{4. Empirical model}

\section{4.1. Factor analysis}

As we have a large set of observed variables, we used factor analysis to obtain a more limited set of predictors that can be conceptualized as: government communication, the financial impacts, and emotional wellbeing (Table 3.4). Factor analysis is a statistical technique for reducing the dimensionality of the data by describing linear combinations of the variables that contain most of the information and that permit meaningful interpretation of these groups.

An advantage of a factor score over a mean or total score is that the factor scores weights each of the items differently, based on how central it is to the true value. By contrast, when we generate a mean score for the set of items, each item counts as if it were equally central to the concept.

Table 3.4. Indicators for factor analysis

\begin{tabular}{lc}
\hline Effective government communication \\
\hline Item 1 & I was given sufficient time to make decisions about the Crown offer \\
\hline Item 2 & $\begin{array}{l}\text { I was provided with the best possible information help me to make decisions } \\
\text { about the Crown offer }\end{array}$ \\
\hline Item 3 & I was treated respectfully and fairly in my dealings with the Crown \\
\hline Item 4 & The red zoning and Crown offer process was clear \\
\hline Item 5 & Did you have confidence in the Government agencies involved \\
\hline Financial impacts: financial position in terms of a negative/no/positive impact, on \\
\hline Item 6 & Mortgage size
\end{tabular}




\begin{tabular}{ll}
\hline Item 7 & The amount of equity they have in their property \\
\hline Item 8 & The amount of their available savings. \\
\hline Item 9 & The size/quality/value of their property \\
\hline Item 10 & Overall financial position \\
\hline Emotional & wellbeing \\
\hline Item 11 & I have cheerful and in good spirits \\
\hline Item 12 & I have felt calm and relaxed \\
\hline Item 13 & I have felt active and vigorous \\
\hline Item 14 & I woke up feeling fresh and rested \\
\hline Item 15 & My daily life has been filled with things that interest me \\
\hline
\end{tabular}

\subsubsection{Wellbeing model}

The model of subjective wellbeing follows that of Brown et al. (2012). Given that the first two dependent variables (quality of life and the stress level) are ordinal, the empirical analysis is based on ordered logistic regressions. We can use ordered logit regression if the proportional odds (PO) assumption is satisfied. To test whether the PO assumption is met, we use the Brant test (Brant, 1990). The test result for the quality of life variable revealed that $\chi^{2}(42)=49.22$ and $\mathrm{p}=.21$, indicating that the proportional odds assumption cannot be rejected. However, for the stress level, the Brant test is $\chi^{2}(42)=60.5$; and $p=.03$, indicating that the PO assumption is rejected. Therefore, fitting a partial PO model rather than a PO model is a better option in this case. We estimate the following model:

$$
\log \left(\frac{P\left(W B_{i} \leq j\right)}{P\left(W B_{i}>j\right.}\right)=\log \left(\frac{\gamma_{i}^{j}}{1-\gamma_{i}^{j}}\right)=\beta_{1} D+\beta_{2} X+\beta_{3} E+\xi
$$

The ordered logit model can be expressed in terms of an underlying latent variable $y^{*}$. Here this could be interpreted as the individual's "true well-being". The higher the value of $y^{*}$, the more likely they are to report a higher category of self-assessed well-being. In our case, there are five categories, so the range of values $\mathrm{y}^{*}$ should be divided into five intervals, each one corresponding to a different category of self-assessed well-being. To make interpretation of the results easier, we report the odd ratio (OR), which is a ratio of two odds. In logistic regression, the odd ratio is also known as the exponentiated logit coefficient. When OR is greater than 1, the odds of success or of having an event for one group are larger than the odds for the other group. When OR is less than 1, the odds of success or of having an event decrease for one 
group are smaller than the odds for the other group. Finally, the OR equals to 1 indicates that there is no relationship between the predictor and the odds.

We treat the emotional wellbeing measure as a continuous variable. To evaluate the emotional wellbeing, we estimate the following linear model:

$$
W B=\beta_{1} D+\beta_{2} X+\beta_{3} E+\xi
$$

In equation (1) and (2) WB is individual wellbeing; $D$ is a vector containing the individual's demographics; $X$ is a vector of observed or reported values of the social variables (the economic factors, the health factors, social relations, and the government policy) that affect individual wellbeing; $E$ is a vector containing unobserved individually specific factors; $\xi$ is an error term

We have cross-sectional data that do not allow us to estimate $E$. However, many researchers accept the assumption of no correlation between $E$ and $X, E$ and $D$. We attempted to only use objective variables as predictor variables in this model to avoid shared-method variance. However, this was not always possible, so coefficients for the social relations and the government communication should be interpreted with additional caution. For details about the statistical properties of these models, please see Wooldridge (2019).

\subsection{Results}

\section{5.1. Factors extracted from the factor analysis}

Reliability for the factor analysis was measured by calculating the Cronbach's alpha. It is the proportion of the observed variance that represents true variance. If alpha equals to $80 \%$, it means that $80 \%$ of the variance in the scale represents the true score on the variable. The minimum proposed Cronbach's alpha is typically required to be above 0.6 and similarly the item-total correlation is required to be greater than 0.3 . In our study we obtained three latent variables: effective government communication, financial impacts, and emotional wellbeing. The Cronbach's alpha coefficients of these latent variables are $0.89,0.71$, and 0.91 , respectively.

The Bartlett's test results for the three groups of items are all statistically significant, indicating there is sufficient intercorrelation to conduct the factor analysis. For each group, all the factor loadings are greater than 0.6 , and there is only one factor having an eigenvalue greater than 1. Therefore, we scored and obtained one factor for each group to represent effective government communication, the financial impact, and emotional wellbeing variable. 


\subsubsection{Estimation results: Quality of life}

Table 3.5 shows the result of the ordinal logistic regression for quality of life. A positive coefficient corresponds to an odds ratio (OR) greater than 1, and a negative logit regression coefficient corresponds to an OR between 0 and 1. First, we estimated the model with objective measure variables only (column 1). Then, we ran regressions with subjective measure variables included (column 2). The inclusion of the subjective variables does not significantly alter the coefficients of the objective variables. Therefore, we conclude that including subjective variables does not lead to a substantial measurement error.

In terms of demographics, for the age predictor, the reference category is age ranging from 35 to 64. We expected to observe a u-shaped relationship for age (Brown et al, 2012), meaning the elderly and the youth have a higher average (subjective) quality of life compared to those who are middle-aged. We observe that older respondents $(>65)$ indeed reported higher quality of life than their younger middle-aged counterparts. However, the younger age group (18 to 34 ) has no statistically significant difference, indicating no difference in the quality of life level between the two age groups (18-34 and 35-64).

The coefficient on quality of life for Māori is not statistically different from that of European respondents (the default category) once holding all other variables constant. However, people identifying as others (in New Zealand, that category mostly includes Asians and Pacific Islanders) had lower subjective quality of life compared to those identifying as European. Females reported a higher average level of quality of life compared to males $(\mathrm{OR}=1.21, \mathrm{p}=.06)$. Having children and having a partner also contributed positively to quality of life. Maybe not surprisingly, reporting a health condition is associated with a significantly negative impact on reported quality of life.

In terms of the economic factors, the expected relationships also hold. For the annual household income predictor, the reference category is households having an annual income less than $\$ 30,000$. For the higher income groups $(\$ 30,001-\$ 60,000, \$ 60,001-\$ 100,000$, and $100,001-\$ 200,000)$ the odds ratio of three categories are 1.5; 2.1; and 3.0. For the last group, income which is greater than $\$ 200,001$, the estimated OR is not statistically significant. ${ }^{2}$

\footnotetext{
${ }^{2}$ This finding might provide a modest support for the well-documented Easterlin paradox (Easterlin, 1974).
} 
Furthermore, households that reported less adverse financial impacts from being red zoned and who own their home also reported higher quality of life.

The analysis confirms the importance of factors associated with social relations and government policy. It is noteworthy that feeling a sense of community with others in the neighbourhood and having a strong satisfaction with the neighbourhood are both statistically significant and positively associated with quality of life. The OR of the government communication is greater than 1 and statistically significant $(\mathrm{OR}=1.57)$, indicating that when the government communication is perceived as better, residents tend to report their quality of life as better as well. Furthermore, choosing the Insurance Option has a negative association with the reported quality of life $(\mathrm{p}=.003, \mathrm{OR}=0.74)$.

Table 3.5. Model estimation results (LHS: quality of life)

\begin{tabular}{|c|c|c|c|}
\hline VARIABLES & (1) & (2) & $95 \% \mathrm{CI}$ \\
\hline \multicolumn{4}{|c|}{ Age (base:35-64 years old) } \\
\hline \multirow[t]{2}{*}{24 to 35} & 1.153 & 1.196 & $(0.9,1.7)$ \\
\hline & $(0.199)$ & $(0.210)$ & \\
\hline \multirow[t]{2}{*}{$>=65$} & $1.537 * * *$ & $1.324 * *$ & $(1.03,1.67)$ \\
\hline & $(0.188)$ & $(0.166)$ & \\
\hline \multicolumn{4}{|l|}{ Ethnicity (base: European) } \\
\hline \multirow[t]{2}{*}{ Maori } & 1.128 & 1.284 & $(0.9,2.1)$ \\
\hline & $(0.265)$ & $(0.308)$ & \\
\hline \multirow[t]{2}{*}{ Others } & $0.763 *$ & $0.760 *$ & $(0.6,1.12)$ \\
\hline & $(0.124)$ & $(0.126)$ & \\
\hline \multirow[t]{2}{*}{ Female } & $1.191 *$ & $1.211 * *$ & $(1.03,1.5)$ \\
\hline & $(0.111)$ & $(0.115)$ & \\
\hline \multirow[t]{2}{*}{ Having children } & $1.376^{* * *}$ & $1.424 * * *$ & $(1.07,1.7)$ \\
\hline & $(0.158)$ & $(0.167)$ & \\
\hline \multirow[t]{2}{*}{ Have a partner } & $1.467 * * *$ & $1.344 * *$ & $(1,1.6)$ \\
\hline & $(0.167)$ & $(0.155)$ & \\
\hline \multirow[t]{2}{*}{ Having health condition } & $0.495 * * *$ & $0.541 * * *$ & $(0.4,0.7)$ \\
\hline & $(0.0599)$ & $(0.0670)$ & \\
\hline \multicolumn{4}{|l|}{ Economic factors } \\
\hline \multicolumn{4}{|c|}{ Household annual income $(\$ 1000)$} \\
\hline \multirow[t]{2}{*}{$\$ 30.1-60$} & $1.401 * *$ & $1.497 * *$ & $(1.03,2)$ \\
\hline & $(0.232)$ & $(0.252)$ & \\
\hline$\$ 60.1-\$ 100$ & $2.105 * * *$ & $2.113 * * *$ & $(1.4,2.7)$ \\
\hline
\end{tabular}




\begin{tabular}{lccc}
\hline & $(0.348)$ & $(0.354)$ & \\
& $3.450 * * *$ & $3.070 * * *$ & $(1.9,4)$ \\
& $(0.644)$ & $(0.582)$ & \\
Home ownership & $2.176^{* *}$ & 1.658 & $(0.9,3.3)$ \\
& $(0.731)$ & $(0.567)$ & \\
Financial impact & $2.139 * * *$ & $1.615 * *$ & $(0.9,2.1)$ \\
& $(0.422)$ & $(0.321)$ & \\
& $2.210 * * *$ & $1.687 * * *$ & $(0.7,0.9)$
\end{tabular}

\section{Social relations}

Felling a sense of community

$1.287 * * *$

(0.0676)

Neighbourhood suitability

The government offers

Time being Red zone

1.064

Insurance option

$0.661 * * *$

$0.740 * * *$

$(0.7,1.04)$

(0.0675)

(0.0771)

Government communication

$1.576 * * *$

(0.0826)

Observations $\quad 1,890 \quad 1,890$

***/**/* Indicating the significance levels of respectively 1\%, 5\% and 10\%. Robust standard errors are shown in parentheses

\subsubsection{Estimation results: Stress levels}

Regarding the stress level, a partial proportional odds model was fitted to estimate the ordinal outcome variable with the set of predictor variables. This model was used since it allows the effects of some predictor variables to vary when the proportional odds assumption (PO) does not hold $(\chi 2(42)=60.5 ; p=.03)$.

With the question "In the past 12 months, how often have you experienced stress that has had a negative effect on you", 3\% of respondents answered "always", $19 \%$ reported " most of the time", 55\% answered "sometimes", 20\% responded "rarely", and 3\% answered "never". Because only a small proportion of respondents have always or never experienced stress, we combine "always" and "most of the time" into a single category; and combine "rarely" and 
"never" into a single category. We also estimated regression with the original categories; these results are included in the appendix (table 3.2)

Examining each predictor variable, we found that having a health condition violated the PO assumption, while it was tenable for the other predictor variables. Therefore, we fit a partial PO model rather than a PO model. Table 3.6 reports the correlates of the stress level variable. Older respondents ( $>=65$ ) have less perceived stress than their younger counterparts (34 to 64). Ethnicity does not show any significant effect on the stress level of residents. This finding suggests that the observed bivariate relationship between ethnicity and stress is due to inequalities in the distribution of other variables (e.g. wealth or home ownership), rather than there being a direct effect of ethnicity on the stress level. Females experienced more stress than males $(\mathrm{OR}=0.7)$. Having kids also increases stress while having a partner does not appear to have a significant impact on the reported stress level.

In term of the economic factors, the regression analyses revealed that while the financial impact of the red zoning appeared to have a negative and statistically significant impact, income and home ownership were not associated significantly with reported stress.

In both model A comparing "most of the time" vs. "sometimes" and model B comparing "sometimes" vs. "rarely", having health condition has a statistically significantly impact on the stress level. The ORs of having health condition variable in these models are 0.35 and 0.57 , indicating that those having a health condition have experienced stress more frequently compared to those without.

Strongly feeling a sense of community with others in the neighbourhood and having a high satisfaction in the neighbourhood are highly significant and positively related to lower frequency of stress. Choosing the Insurance Option leads to more stress compared to the Crown Option, but this effect is not significant when controlling for the social relations and the government communication variables.

Taken together, being female and having children are significantly associated with higher stress. However, being older, having positive financial impact, feeling a sense of community and experiencing effective government communication are associated with less stress.

Table 3.6. Model estimation results (LHS: the stress level) 


\begin{tabular}{|c|c|c|c|}
\hline \multirow{2}{*}{\multicolumn{4}{|c|}{ Age (base:35-64 years old) }} \\
\hline & & & \\
\hline \multirow[t]{2}{*}{24 to 35} & 0.906 & 0.896 & $(0.5,1.19)$ \\
\hline & $(0.160)$ & $(0.160)$ & \\
\hline \multirow[t]{2}{*}{$>=65$} & $1.956 * * *$ & $1.742^{* * *}$ & $(1.4,2.8)$ \\
\hline & $(0.241)$ & $(0.218)$ & \\
\hline \multicolumn{4}{|l|}{ Ethnicity (base: European) } \\
\hline \multirow[t]{2}{*}{ Maori } & 0.967 & 1.033 & $(0.5,1.7)$ \\
\hline & $(0.224)$ & $(0.247)$ & \\
\hline \multirow[t]{2}{*}{ Others } & 0.870 & 0.894 & $(0.6,1.3)$ \\
\hline & $(0.142)$ & $(0.147)$ & \\
\hline \multirow[t]{2}{*}{ Female } & $0.725 * * *$ & $0.704 * * *$ & $(0.6,1)$ \\
\hline & $(0.0681)$ & $(0.0672)$ & \\
\hline \multirow[t]{2}{*}{ Having kids } & $0.800^{*}$ & $0.794 * *$ & $(0.5,0.9)$ \\
\hline & $(0.0923)$ & $(0.0931)$ & \\
\hline \multirow[t]{2}{*}{ Have partner } & 1.200 & 1.102 & $(0.7,1.5)$ \\
\hline & $(0.136)$ & $(0.127)$ & \\
\hline \multicolumn{4}{|l|}{ Economic factors } \\
\hline \multicolumn{4}{|c|}{ Household annual income $(\$ 1000)$} \\
\hline \multirow[t]{2}{*}{$\$ 30.1-60$} & 1.187 & 1.219 & $(0.9,2.1)$ \\
\hline & $(0.199)$ & $(0.207)$ & \\
\hline \multirow[t]{2}{*}{$\$ 60.1-\$ 100$} & 1.260 & 1.194 & $(0.8,2.01)$ \\
\hline & $(0.209)$ & $(0.201)$ & \\
\hline \multirow[t]{2}{*}{$\$ 100.1-\$ 200$} & 1.301 & 1.118 & $(0.7,1.9)$ \\
\hline & $(0.242)$ & $(0.211)$ & \\
\hline \multirow[t]{2}{*}{$>\$ 200.1$} & 1.252 & 1.040 & $(0.4,2.1)$ \\
\hline & $(0.426)$ & $(0.363)$ & \\
\hline \multirow[t]{2}{*}{ Home ownership } & $1.391 *$ & 1.064 & $(0.6,1.6)$ \\
\hline & $(0.275)$ & $(0.214)$ & \\
\hline \multirow[t]{2}{*}{ Financial impact } & $1.612 * * *$ & $1.281 * * *$ & $(0.7,0.9)$ \\
\hline & $(0.0774)$ & $(0.0673)$ & \\
\hline \multicolumn{4}{|l|}{ Social relations } \\
\hline \multirow[t]{2}{*}{ Felling a sense of community } & & $1.265^{* * *}$ & $(1.1,1.5)$ \\
\hline & & $(0.0657)$ & \\
\hline \multirow[t]{2}{*}{ Neighbourhood suitability } & & $1.370 * * *$ & $(1.1,1.6)$ \\
\hline & & $(0.0913)$ & \\
\hline \multicolumn{4}{|l|}{ The government offers } \\
\hline \multirow[t]{2}{*}{ Time being Red Zone } & 0.880 & 0.966 & $(0.6,1.1)$ \\
\hline & $(0.106)$ & $(0.119)$ & \\
\hline
\end{tabular}




\begin{tabular}{lccc}
\hline Insurance option & $0.802 * *$ & 0.893 & $(0.7,1.1)$ \\
& $(0.0814)$ & $(0.0923)$ & \\
Government communication & & $1.463 * * *$ & $(1.3,1.7)$ \\
& & $(0.0757)$ & \\
\hline
\end{tabular}

\begin{tabular}{|c|c|c|c|}
\hline $\begin{array}{l}\text { Model A- most of the time vs. } \\
\text { sometimes }\end{array}$ & & & \\
\hline Health condition & $\begin{array}{l}0.323 * * * \\
(0.0446)\end{array}$ & $\begin{array}{l}0.345 * * * \\
(0.0496)\end{array}$ & $(0.24,0.44)$ \\
\hline
\end{tabular}

\begin{tabular}{lccc}
\hline Model B- sometimes vs. rarely & & & \\
\hline Health condition & $0.536 * * *$ & $0.565^{* * *}$ & $(0.4,0.8)$ \\
& $(0.0882)$ & $(0.0953)$ &
\end{tabular}

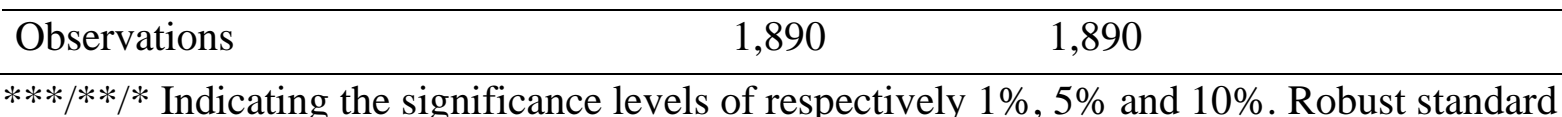
errors are shown in parentheses.

\subsubsection{Estimation results: Emotional wellbeing}

Table 3.7 shows the result of regression for emotional wellbeing obtained from factor analysis. We observe a Cohen's $\mathrm{f} 2=0.25$, which suggests an effect of moderate size, confirming the moderate-to-strong relationship between the dependent variable and the independent variables We also ran regression with the dependent variable - emotional wellbeing calculated by simply adding the five scores as suggested by the WHO (table 3.8). The results reveal that the correlations between predictor variables and emotional wellbeing are similar, with some differences in the coefficient values.

Table 3.7. Model estimation results (LHS: emotional wellbeing)- OLS

\begin{tabular}{lccccc}
\hline VARIABLES & $(1)$ & $(2)$ & $\begin{array}{c}(3) \\
95 \% \mathrm{CI}\end{array}$ & $(4)$ & $\begin{array}{c}\text { (5) } \\
\text { Effect size }\end{array}$ \\
\hline Age (base:35-64 years old) & & & & & \\
24 to 35 & 0.0728 & 0.0573 & $(-0.1,0.2)$ & & \\
& $(0.0833)$ & $(0.0790)$ & & & \\
& $0.270^{* * *}$ & $0.181^{* * *}$ & $(0.07,0.3)$ & $0.197 * * *$ & 0.09 \\
& $(0.0594)$ & $(0.0568)$ & & $(0.0519)$ & \\
Ethnicity (base: European) & & & & & \\
Maori & 0.0591 & 0.0504 & $(-0.16,0.3)$ & & \\
& $(0.112)$ & $(0.107)$ & & & \\
Others & -0.0281 & -0.0322 & $(-$ & & \\
\hline
\end{tabular}




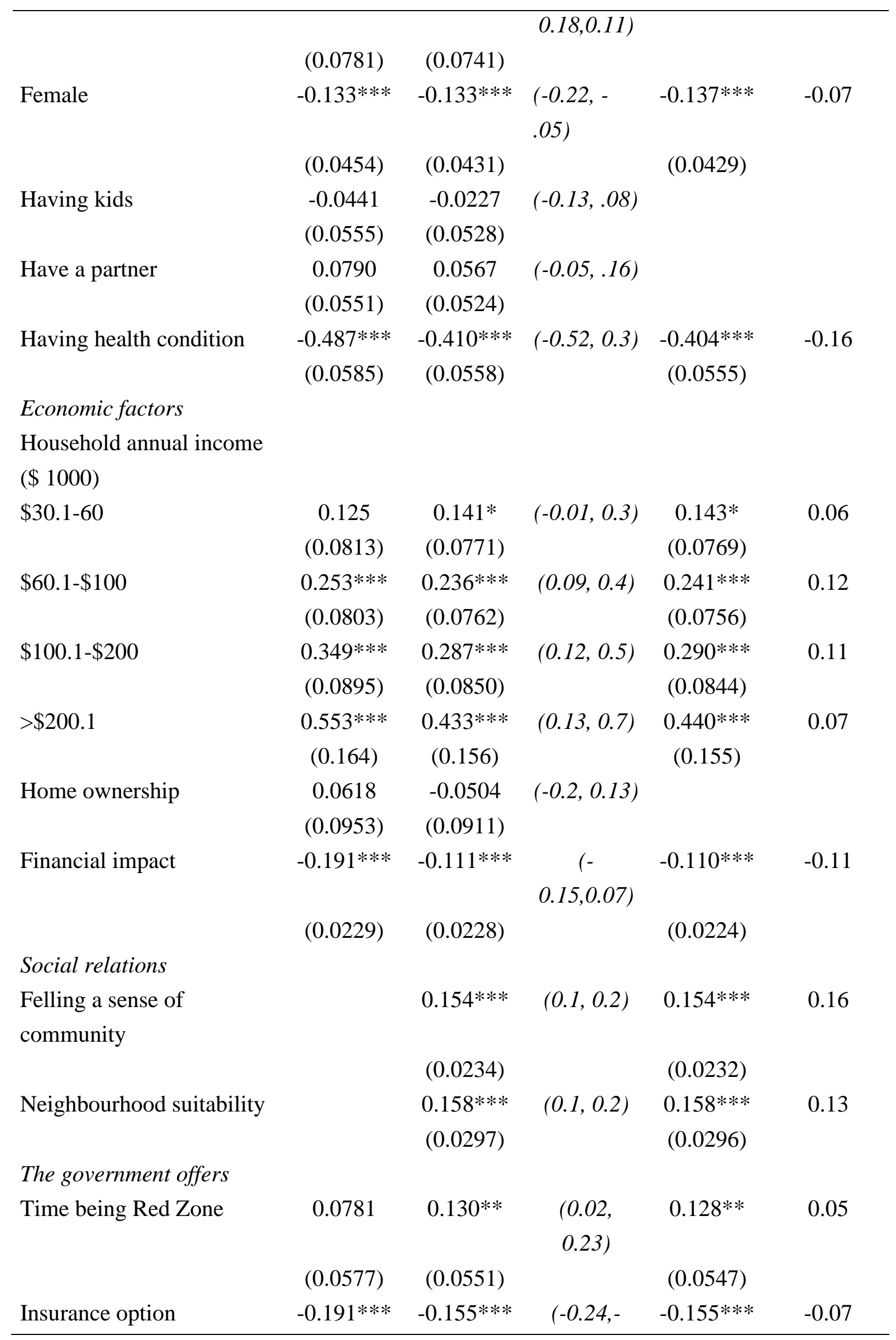


Government

communication

$0.151 * * *$

$(0.1,0.2)$

$0.153^{* * *}$

0.15
(0.0220)

1,890

0.201

$\begin{array}{lccc}\text { Observations } & 1,890 & 1,890 & 1,890 \\ \text { R-squared } & 0.11 & 0.203 & 0.201\end{array}$

***/**/* Indicating the significance levels of respectively $1 \%, 5 \%$ and $10 \%$. Robust standard errors are shown in parentheses

First, we estimated the model with the objective variables only (column 1). The model was then augmented with the subjective variables (column 2). - the $95 \%$ confidence intervals are reported in column 3. Then, we estimated a specification including only statistically significant variables (column 4) and calculated the effect size of those variables in column 5.

Older respondents $(>=65)$ have higher levels of emotional wellbeing than their younger counterparts (34 to 64) ( $\beta=0.18,95 \%$ CI 0.07,0.3). Females reported having lower levels of emotional wellbeing ( $\beta=-0.13,95 \% \mathrm{CI}-0.22$, -.05). Having children does not seem to have any significant effect on the reported levels of emotional wellbeing. Having a partner leads to a higher emotional wellbeing, but this effect is not statistically significant when controlling for social relations and the government communication variable. Ethnicity does not show any significant effect on the wellbeing of residents. This finding again suggests that the bivariate relationship between ethnicity and emotional wellbeing is due to inequalities in the distribution of other variables, such as social relations or income, rather than there being a direct effect of ethnicity on emotional wellbeing. Not surprisingly, having a health condition is significantly associated with lower levels of emotional wellbeing.

For the income measure, the reference category is households having an annual income less than $\$ 30,000$. Generally, when the annual household income increases, residents tend to report their emotional wellbeing as better. Similarly, financial impact correlated significantly and positively with emotional wellbeing. As expected, the coefficient for variables measuring social relations - feeling a sense of community with others in the neighbourhood $(\beta=0.154$, $95 \% \mathrm{CI} 0.1,0.2)$ and having a strong satisfaction with the neighbourhood $(\beta=0.158,95 \% \mathrm{CI}$ $0.1,0.2)$ - are both positive and statistically significant.

The variable measuring government communication $(\beta=0.15,95 \% \mathrm{CI} 0.1,0.2)$ is also statistically different from zero, and positive. In terms of the government offers, those who 
chose the Insurance Option reported lower emotional wellbeing than those who chose the Crown Option $(\beta=-0.155,95 \%$ CI $-0.24,-0.06)$. Moreover, those whose property was confirmed as being in the red zone areas later (in 2012) reported better emotional wellbeing than those having their property red-zoned earlier (in 2011).

Among the statistically significant variables, the magnitude of the effect of having a health condition, social relations, and government communication variable are highest, followed by the middle-income groups. We also observed an inverted u-shaped effect for income: having a higher income increases emotional wellbeing, but this effect decreases when income is very high (in as much as high income is precisely measured).

Table 3.8. Model estimation results (LHS: the WHO-5 wellbeing)- OLS

\begin{tabular}{|c|c|c|c|c|c|}
\hline VARIABLES & (1) & (2) & $\begin{array}{c}(3) \\
95 \% \mathrm{CI}\end{array}$ & (4) & $\begin{array}{c}\text { (5) } \\
\text { Effect size }\end{array}$ \\
\hline \multicolumn{6}{|l|}{ Age (base:35-64 years old) } \\
\hline 24 to 35 & $\begin{array}{c}0.400 \\
(0.467)\end{array}$ & $\begin{array}{c}0.313 \\
(0.443)\end{array}$ & $(-0.5,1.2)$ & & \\
\hline$>=65$ & $\begin{array}{l}1.519 * * * \\
(0.333)\end{array}$ & $\begin{array}{c}1.019 * * * \\
(0.318)\end{array}$ & $(0.4,1.6)$ & $\begin{array}{l}0.197 * * * \\
(0.0519)\end{array}$ & 0.09 \\
\hline \multicolumn{6}{|l|}{ Ethnicity (base: European) } \\
\hline Māori & $\begin{array}{c}0.342 \\
(0.627)\end{array}$ & $\begin{array}{l}0.292 \\
(0.597)\end{array}$ & $(-0.9,1.5)$ & & \\
\hline Others & $\begin{array}{l}-0.141 \\
(0.437)\end{array}$ & $\begin{array}{l}-0.164 \\
(0.415)\end{array}$ & $(-0.9,0.6)$ & & \\
\hline Female & $-0.745^{* * *}$ & $-0.746^{* * *}$ & $\begin{array}{l}(-1.22,- \\
0.3)\end{array}$ & $-0.137 * * *$ & -0.07 \\
\hline Having kids & $\begin{array}{c}(0.254) \\
-0.258 \\
(0.311)\end{array}$ & $\begin{array}{l}(0.242) \\
-0.138 \\
(0.296)\end{array}$ & $(-0.7,0.4)$ & $(0.0429)$ & \\
\hline Have a partner & $\begin{array}{c}0.436 \\
(0.309)\end{array}$ & $\begin{array}{c}0.312 \\
(0.294)\end{array}$ & $(-0.3,0.9)$ & & \\
\hline Having health condition & $\begin{array}{c}-2.730 * * * \\
(0.327)\end{array}$ & $\begin{array}{c}-2.300 * * * \\
(0.312)\end{array}$ & $(-2.9,-1.7)$ & $\begin{array}{c}-0.404 * * * \\
(0.0555)\end{array}$ & -0.16 \\
\hline Economic factors & & & & & \\
\hline $\begin{array}{l}\text { Household annual incom } \\
(\$ 1000)\end{array}$ & & & & & \\
\hline$\$ 30.1-60$ & 0.709 & $0.798 *$ & $(-0.5,1.6)$ & $0.143^{*}$ & 0.06 \\
\hline
\end{tabular}




\begin{tabular}{|c|c|c|c|c|c|}
\hline & $(0.456)$ & $(0.432)$ & & $(0.0769)$ & \\
\hline$\$ 60.1-\$ 100$ & $\begin{array}{c}1.420 * * * \\
(0.450)\end{array}$ & $\begin{array}{c}1.324 * * * \\
(0.427)\end{array}$ & $(0.5,2.1)$ & $\begin{array}{l}0.241 * * * \\
(0.0756)\end{array}$ & 0.12 \\
\hline$\$ 100.1-\$ 200$ & $\begin{array}{c}1.973 * * * \\
(0.501)\end{array}$ & $\begin{array}{c}1.623 * * * \\
(0.476)\end{array}$ & $(0.7,2.5)$ & $\begin{array}{l}0.290 * * * \\
(0.0844)\end{array}$ & 0.11 \\
\hline$>\$ 200.1$ & $\begin{array}{c}3.132 * * * \\
(0.918)\end{array}$ & $\begin{array}{c}2.460 * * * \\
(0.872)\end{array}$ & $(0.8,4.1)$ & $\begin{array}{c}0.440 * * * \\
(0.155)\end{array}$ & 0.07 \\
\hline Home ownership & $\begin{array}{c}0.351 \\
(0.534)\end{array}$ & $\begin{array}{l}-0.278 \\
(0.511)\end{array}$ & $(-1.3,0.7)$ & & \\
\hline Financial impact & $\begin{array}{c}-1.067 * * * \\
(0.128)\end{array}$ & $\begin{array}{c}-0.617 * * * \\
(0.128)\end{array}$ & $(-0.9,-0.4)$ & $\begin{array}{c}-0.110 * * * \\
(0.0224)\end{array}$ & -0.11 \\
\hline \multicolumn{6}{|l|}{ Social relations } \\
\hline $\begin{array}{l}\text { Felling a sense of } \\
\text { community }\end{array}$ & & $\begin{array}{c}0.867 * * * \\
(0.131)\end{array}$ & $(0.6,1.12)$ & $(0.0232)$ & 0.16 \\
\hline Neighbourhood suitability & & $\begin{array}{c}0.886 * * * \\
(0.166)\end{array}$ & $(0.6,1.2)$ & $\begin{array}{l}0.158 * * * \\
(0.0296)\end{array}$ & 0.13 \\
\hline \multicolumn{6}{|l|}{ The government offers } \\
\hline \multirow[t]{2}{*}{ Time being Red Zone } & 0.458 & $0.745^{* *}$ & $\begin{array}{l}(0.13 \\
1.35)\end{array}$ & $0.128 * *$ & 0.05 \\
\hline & $(0.323)$ & $(0.309)$ & & $(0.0547)$ & \\
\hline Insurance option & $\begin{array}{c}-1.080 * * * \\
(0.275)\end{array}$ & $\begin{array}{c}-0.875^{* * *} \\
(0.261)\end{array}$ & $(-1.4,-0.4)$ & $\begin{array}{c}-0.155^{* * *} \\
(0.0463)\end{array}$ & -0.07 \\
\hline $\begin{array}{l}\text { Government } \\
\text { communication }\end{array}$ & & $0.843 * * *$ & $(0.6,1.1)$ & $\begin{array}{l}0.153 * * * \\
(0.0220)\end{array}$ & 0.15 \\
\hline Observations & 1,890 & 1,890 & & 1,890 & \\
\hline R-squared & 0.11 & 0.203 & & 0.201 & \\
\hline
\end{tabular}

***/**/* Indicating the significance levels of respectively $1 \%, 5 \%$ and $10 \%$. Robust standard errors are shown in parentheses

\subsection{Discussion and conclusions}

The aim of this chapter was to analyse, quantitatively, the determinants of wellbeing for a population that was affected by a de facto involuntary relocation in a large managed retreat program. The Residential Red Zone program was implemented in New Zealand after the Christchurch 2010-2011 earthquake sequence and affected about 8,000 households (about 20,000 people). As far as we are aware, there has been little long-term follow-up research on 
populations that have been forced to relocate in managed retreat programs, globally, in spite of the obvious and increasing importance of these programs as an adaptation tool for climatic change.

Specifically, we focused on the relationship between three measures of wellbeing quality of life, stress, and emotional wellbeing, and the relocation. We investigated the determinants of these measures, using econometric tools, by focusing on the demographic characteristics, the economic circumstances, social relations, and the ways in which government policy was perceived by the affected households.

Generally, having to relocate did not mean residents reported low wellbeing measures. Demographic factors, health condition and the type of government compensation offer the residents accepted were all important to their levels of reported wellbeing. Social relations, the financial circumstances, and the government communication were all associated significantly and positively with a higher quality of life, less stress, and higher emotional wellbeing. Although the results presented here cannot imply causation, because of the limitation of the cross-sectional nature of the survey and the subjective nature of the wellbeing measurement, they do give some indications of those areas where improvements could potentially contribute to greater wellbeing of relocated households.

For example, previous research has frequently found that social capital contributes to psychological wellbeing. In this case, it is noteworthy that when this data was collected in 2015, the respondents had recently moved to new communities. Therefore, in other circumstances it is plausible that social relations can show more powerful impacts on wellbeing once the relocated have established themselves in their new communities. From a policy perspective, that suggests that the designers of managed retreat policies should design their programs in ways that encourage the establishment and strengthening of social capital (broadly defined). Surprisingly, this is often not the case.

Three further findings stand out as important in the managed retreat policy context. The significance of effective government communication is of obvious interest to the central and local governments who usually design either involuntary or voluntary managed retreat programs. It lends support to the inclusion of closer consultation between the government and residents as a necessary characteristic of the design of these programs. Some insights about what constitutes effective government communication - for example with regards to the timing 
of re-zoning announcements - can also be arrived at by examining the experience of the Christchurch RRZ.

The finding for the Insurance Option is also noteworthy from a practical implementation perspective. Choosing the Insurance Option, rather than the Crown Option, had an adverse impact on the residents' quality of life and emotional wellbeing. In practice, and maybe surprisingly, the majority of Red Zone residents chose the Insurance Option (about $70 \%$ ). Retroactively, this was a puzzling choice, as the insurance claim resolution process in Christchurch faced some significant hurdles and delays - hurdles and delays that could have been expected (Nguyen and Noy, 2019). Our work here confirms that choosing the Crown Option could have been a 'better' choice, as it allowed residents to settle their claims quickly and at pre-determined prices.

Why so many homeowners chose the Insurance Option remains, in our view, a mystery, and suggests a room for a more active policy by the regulatory and planning bodies. Nguyen (2019) found that opting for the Insurance Option was to some extent a result of peer pressure (or herd behaviour). It is important to observe that, after the fact, these households also reported lower quality of life. This specific finding suggests room for a more proactive management of household choice, by governments, in a post disaster managed retreat circumstance, especially if insurance is paying for some of the costs of these programs (Noy, 2020).

It is noteworthy that this Red Zone program was unique in that it was de jure voluntary, but was widely perceived to be, de facto, mandatory. This may explain why take up rate was so high, much higher than programs elsewhere (Hino et al., 2017). These details may suggest that other components of that program, such as the option choice, could have been better designed to lead to better outcomes for affected households.

It seems undeniable that these managed retreats programs will become an increasingly common policy tool in years to come, because of sea-level rise, and because the frequency and intensity patterns of extreme weather events is changing, globally. The places where communities have chosen to locate will become increasingly less appropriate as the climate continues to change, so that our need to move will only increase. We should therefore design managed retreats programs in ways that increase wellbeing, rather than detract from it. 


\section{Appendices}

Appendix 3.1: Testing normality of residuals, heteroskedasticity, and multicollinearity for the emotional wellbeing model.

We checked for the normality of residuals (graph 1 and graph 2 below). In the first graph, we produce a kernel density plot with the normal option requesting that a normal density be overlaid on the plot. The second graph shows a standardized normal probability (P-P) plot. There are no indications of non-normality, and we can accept that the residuals are close to a normal distribution.

We used Breusch-Pagan test with Ho: Constant variance and White's test with Ho: homoskedasticity to test the heteroskedasticity problem. The results for both Breusch-Pagan test and White's test with $\mathrm{p}=0.19$ and $\mathrm{p}=0.36$, respectively, indicate that we cannot reject Ho (there is no evidence of an heteroskedasticity problem). Furthermore, we computed Variance Inflation Factor (VIF) which is the degree that the variances in the regression estimates are increased due to multicollinearity. The largest VIF was 3.6 which is lower than the threshold of 10 and the mean of VIF was 1.84 , indicating that there is no sign of serious multicollinearity.

\begin{tabular}{|c|c|c|c|}
\hline Graph 1. Kernel density estimate & $\begin{array}{l}\text { Graph 2. Standardized normal } \\
\text { probability plot }\end{array}$ \\
\hline & & & \\
\hline
\end{tabular}




\section{Appendix 3.2. Oster (2019) sensitivity analyses for selection effects for Table 3.7}

Because of the cross-sectional nature of the survey, we cannot observe individually specific factors such as genetic characteristics. When we add subjective variables in the model (e.g., "Felling a sense of community", "Neighbourhood suitability", and "Government communication"), the shared method variance may occur. In order to explicitly model selection effects, some studies use treatment or Heckman models, which require the inclusion of at least one instrumental variable, or a variable that is truly endogenous. However, finding a strong instrumental variable is not always possible.

Oster (2019) developed a post-estimation test to evaluate the degree to which model coefficients are potentially affected by omitted variable bias. Oster's approach is based on the idea that if all variables affecting the outcome of interest were included in the regression, any possible selection effects would be controlled for and the remaining effect of the variable of interest would be the true effect. Oster assumes that such a model would explain $100 \%$ of the variation in the outcome variable and hence have an $\mathrm{R}^{2}=1$.

If the known variables are at least as important for explaining the outcome as the omitted variables, Oster suggests a procedure for calculating the expected change in the coefficient size of the variable of interest that would occur if $R^{2}=1$. If the coefficients change very little, this is an indication that selection bias is not significantly affecting the results.

We examine if the findings presented in Table 3.7 are robust to correcting for omitted variable bias using Oster's (2019) method and found that the coefficients for "Felling a sense of community", "Neighbourhood suitability", and "Government communication" are indeed robust. 
Appendix table 3.1. Treatment effect estimates of subjective variables

\begin{tabular}{|l|c|c|}
\hline & $\begin{array}{l}\text { Coefficient original } \\
\text { table 7 }\end{array}$ & $\begin{array}{l}\text { Treatment effect estimate } \\
\text { after Oster sensitivity } \\
\text { analyses }\end{array}$ \\
\hline Felling a sense of community & 0.154 & 0.153 \\
\hline Neighbourhood suitability & 0.158 & 0.12 \\
\hline Government communication & 0.151 & 0.156 \\
\hline
\end{tabular}

Appendix table 3.2: Model estimation results (LHS: the stress level) with five categories 1 (always), 2 (most of the time), 3 (sometimes), 4 (rarely), and 5 (never)

\begin{tabular}{|c|c|c|}
\hline VARIABLES & (1) & (2) \\
\hline \multicolumn{3}{|c|}{ Age (base:35-64 years old) } \\
\hline \multirow[t]{2}{*}{24 to 35} & 0.893 & 0.886 \\
\hline & $(0.157)$ & $(0.156)$ \\
\hline \multirow[t]{2}{*}{$>=65$} & $2.019 * * *$ & $1.793 * * *$ \\
\hline & $(0.245)$ & $(0.220)$ \\
\hline \multicolumn{3}{|c|}{ Ethnicity (base: European) } \\
\hline \multirow[t]{2}{*}{ Maori } & 0.975 & 1.045 \\
\hline & $(0.223)$ & $(0.245)$ \\
\hline \multirow[t]{2}{*}{ Female } & $0.726 * * *$ & $0.702 * * *$ \\
\hline & $(0.0674)$ & $(0.0660)$ \\
\hline \multirow[t]{2}{*}{ Having kids } & $0.775^{* *}$ & $0.766 * *$ \\
\hline & $(0.0886)$ & $(0.0886)$ \\
\hline \multirow[t]{2}{*}{ Have partner } & $1.209^{*}$ & 1.103 \\
\hline & $(0.136)$ & $(0.125)$ \\
\hline \multicolumn{3}{|c|}{ Economic factors } \\
\hline \multicolumn{3}{|c|}{ Household annual income $(\$ 1000)$} \\
\hline \multirow[t]{2}{*}{$\$ 30.1-60$} & 1.144 & 1.167 \\
\hline & $(0.190)$ & $(0.196)$ \\
\hline \multirow[t]{2}{*}{$\$ 60.1-\$ 100$} & 1.228 & 1.147 \\
\hline & $(0.202)$ & $(0.190)$ \\
\hline \multirow[t]{2}{*}{$\$ 100.1-\$ 200$} & 1.262 & 1.072 \\
\hline & $(0.232)$ & $(0.200)$ \\
\hline
\end{tabular}


Home ownership

Financial impact

Social relations

Felling a sense of community

Neighbourhood suitability

(0.0910)

The government offers

Time being Red zone

Government communication

\begin{tabular}{|c|c|c|}
\hline \multicolumn{3}{|l|}{ Model $1(Y>1$ vs. $Y \leq 1)$} \\
\hline \multirow[t]{2}{*}{ Ethnic (Others) } & $0.366 * * *$ & $0.344 * * *$ \\
\hline & $(0.136)$ & $(0.131)$ \\
\hline \multirow[t]{2}{*}{ Having health condition } & $0.221 * * *$ & $0.244 * * *$ \\
\hline & $(0.0630)$ & $(0.0717)$ \\
\hline \multirow[t]{2}{*}{ Insurance option } & $0.282 * * *$ & $0.322 * * *$ \\
\hline & $(0.116)$ & $(0.133)$ \\
\hline \multirow[t]{2}{*}{ Income $>\$ 200.1$} & 1.187 & $0.270^{*}$ \\
\hline & $(0.410)$ & $(0.184)$ \\
\hline \multicolumn{3}{|l|}{ Model $2(Y>2$ vs. $Y \leq 2)$} \\
\hline \multirow[t]{2}{*}{ Ethnic (Others) } & 0.828 & 0.828 \\
\hline & $(0.167)$ & $(0.171)$ \\
\hline \multirow[t]{2}{*}{ Having health condition } & $0.312 * * *$ & $0.336 * * *$ \\
\hline & $(0.0432)$ & $(0.0483)$ \\
\hline \multirow[t]{2}{*}{ Insurance option } & $0.731 * *$ & 0.839 \\
\hline & $(0.0967)$ & $(0.115)$ \\
\hline \multirow[t]{2}{*}{ Income $>\$ 200.1$} & 1.187 & 0.665 \\
\hline & $(0.410)$ & $(0.279)$ \\
\hline \multicolumn{3}{|l|}{ Model 3 (Y>3 vs. $Y \leq 3)$} \\
\hline \multirow[t]{2}{*}{ Ethnic (Others) } & 0.921 & 0.944 \\
\hline & $(0.188)$ & $(0.196)$ \\
\hline \multirow[t]{2}{*}{ Having health condition } & $0.521 * * *$ & $0.555 * * *$ \\
\hline & $(0.0858)$ & $(0.0936)$ \\
\hline Insurance option & 0.864 & 0.964 \\
\hline
\end{tabular}




\begin{tabular}{lcc} 
& $(0.109)$ & $(0.124)$ \\
Income $>\$ 200.1$ & 1.187 & 1.149 \\
& $(0.410)$ & $(0.448)$ \\
\hline Model 4 (Y>4 vs. Y $\leq 4)$ & & \\
\hline Ethnic (Others) & 1.709 & 1.776 \\
Having health condition & $(0.635)$ & $(0.668)$ \\
& 0.628 & 0.679 \\
Insurance option & $(0.229)$ & $(0.250)$ \\
& $0.555^{* *}$ & $0.585^{* *}$ \\
Income $>$ \$200.1 & $(0.144)$ & $(0.154)$ \\
& 1.187 & $2.967 *$ \\
\hline Observations & $(0.410)$ & $(1.750)$ \\
\hline$* * / * * / *$ Indicating the significance levels of respectively $1 \%, 5 \%$ and $10 \%$. Robust standard
\end{tabular}




\section{References}

Allin P. (2007) Measuring societal wellbeing. Economic \& Labour Market Review. Office for National Statistics. Vol 1(10), 46-52

Alexander, K. S., Measham, T. G. and Ryan. A. (2012) Managed retreat of coastal communities: understanding responses to projected sea level rise. Journal of Environmental Planning and Management, 55 (4), pg. 409-433.

Aldrich, D. P. (2012a). Building resilience: Social capital in post-disaster recovery. Chicago: University of Chicago Press.

Aldrich, D. P. (2012b). Social, not physical, infrastructure: The critical role of civil society after the 1923 Tokyo earthquake. Disasters, 36(3), 398-419.

Aldrich, D.P., Sawada, Y.,2015. The physical and social determinants of mortality in the 3.11 tsunami. Social Science and Medicine, 124, 66-75.

Almond, D., Edlund, L., Palme, M., 2009. Chernobyl's subclinical legacy: prenatal exposure to radioactive fallout and school outcomes in Sweden. Quarterly Journal of Economics, 1729-1772.

Adams, R. E., Bromet, E. J., Panina, N., Golovakha, E., Goldgaber, D., \& Gluzman, S. (2002). Stress and well-being after the Chernobyl nuclear power plant accident. Psychological Medicine, 32, 143-156.

Bradburn, N.M (1969). The structure of psychological wellbeing. Chicago:Aldine

Brewin, C. R., Andrews, B., \& Valentine, J. D. (2000). Meta-analysis of risk factors for posttraumatic stress disorder in trauma-exposed adults. Journal of Consulting and Clinical Psychology, 68, 748-766.

CERA, 2016. Residential Red Zone Survey (of Those Who Accepted the Crown Offer). Https://Dpmc.Govt.Nz/Sites/Default/Files/2017-03/Cera-Rrz-Surveyreport$\underline{\text { Feb2016.Pdf }}$ 
Chatters LM. 1998. Subjective well-being evaluations among older black Americans. Psychology and Aging, 3(2), 184-190.

Denise Brown, Julie Woolf \& Conal Smith (2012) An empirical investigation into the determinants of life satisfaction in New Zealand, New Zealand Economic Papers, 46:3, 239-251

Diener, E., Diener, M., \& Diener, C. (1995). Factors predicting the subjective well-being of nations. Journal of Personality and Social Psychology, 69, 851-864

Diener, E., Oishi, S., \& Lucas,R. E. (2002). Subjective well-being: The science of happiness and life satisfaction. In C.R. Snyder \& S.J. Lopez (Ed.), Handbook of Positive Psychology. Oxford and New York: Oxford University Press.

Dodge, Annette P. Daly, Jan Huyton, Lalage D. Sanders (2012) The challenge of defining wellbeing, International Journal of Wellbeing, 2(3), 222-235.

Easterlin (1974). Does Economic Growth Improve the Human Lot? Some Empirical Evidence. In Paul A. David; Melvin W. Reder (eds.). Nations and Households in Economic Growth: Essays in Honor of Moses Abramovitz. New York: Academic Press.

Hanna, C., White, I., Glavovic, B. (2017). Managed retreat in New Zealand: revealing the terminology, approaches and direction of local planning instruments. Report for the National Science Challenge: Resilience to Natures Challenges, University of Waikato, New Zealand.

Hino, M., Field, C. B., \& Mach, K. J. (2017). Managed retreat as a response to natural hazard risk. Nature Climate Change 7, 364-370.

Ingram, Jane C., Guillermo Franco, Cristina Rumbaitis-del Rio, Bjian Khazai, 2006. Postdisaster recovery dilemmas: challenges in balancing short-term and long-term needs for vulnerability reduction. Environmental Science \& Policy, 9(7-8), 607-613.

Lewin, T. J., Carr, V. J., \& Webster, R. A. (1998). Recovery from post-earthquake psychological morbidity:Who suffers and who recovers? Australian and New Zealand Journal of Psychiatry, 32, 15-20. 
Lucas, R.E., Diener, E., \&Suh,E. (1996). Discriminant validity of well-being measures. Journal of Personality and Social Psychology, 71, 616-628

Moriyama, N.; Iwasa, H.; Tsubokura, M.; Kuroda, Y.; Yasumura, S. Living in the Restoration Public Housing after the Great East Japan Earthquake Correlates with Lower Subjective Well-Being of Older Adults. Int. J. Environ. Res. Public Health 2019, 16, 2696.

Myers, D. (1995). Psychological recovery from disaster: Key concepts for delivery of mental health services. NCP Clinical Quarterly, 4(2). Retrieved on January 9, 2013 from http://xxx.icisf.org/newsa-announcements/31/35-psychological-recovery-from-disaster-keyconcepts-for-delivery-of-mentalhealth-services.

Nguyen, Cuong (2019). Homeowners' choice when the government proposes a managed retreat. International Journal of Disaster Risk Reduction.

Nguyen, Cuong and Ilan Noy (2019). Measuring the impact of insurance on urban earthquake recovery using nightlights. Journal of Economic Geography.

Norris, F. H., Friedman, M. J., \& Watson, P. J. (2002). 60,000 disaster victims speak: Part II. Summary and implications of the disaster mental health research. Psychiatry, 65, 240260.

Norris, F. H. (2005). Psychosocial consequences of natural disasters in developing countries: What does past research tell us about the potential effects of the 2004 tsunami? http://medipe2.psu.ac.th/ disaster/disasterlast/FranNorris_Tsunami.pdf

Noy, Ilan (2020). Paying a Price of Climate Change: Who Pays for Managed Retreats? Current Climate Change Reports, https://doi.org/10.1007/s40641-020-00155-x.

Oster, Emily (2019) Unobservable Selection and Coefficient Stability: Theory and Evidence. Journal of Business \& Economic Statistics, 37:2, 187-204.

Pinquart M, Sörensen S. (2001). Gender differences in self-concept and psychological wellbeing in old age: A meta-analysis. Journal of Gerontology: Series B. 56(4): P195-P213. 
Peterson, T. L., Chatters, L. M., Taylor, R. J., \& Nguyen, A. W. (2014). Subjective Well-being of Older African Americans with DSM IV Psychiatric Disorders. Journal of Happiness Studies, 15(5), 1179-1196.

Pretty, G., Bishop, B., Fisher, A., \& Sonn, C. (2006). Psychological sense of community and its relevance to well-being and everyday life in Australia. Melbourne, VIC: The Australian Psychological Society.

Prezza,, M., S. Costantini (1998). Sense of community and life satisfaction: Investigation in three different territorial contexts. Journal of Community and Applied Social Psychology 8: 181-194.

Robine, J. M., \& Jagger, C. (2003). Creating a coherent set of indicators to monitor health across Europe: The Euro-REVES 2 project. European Journal of Public Health, 13(3 Suppl), 6-14

Salcioglu, E., Basoglu, M., \& Livanou, M. (2007). Post-traumatic stress disorder and comorbid depression among survivors of the 1999 earthquake in Turkey. Disasters, 31(2), 115129.

Soukiazis, E., Ramos, S., 2015 The structure of subjective wellbeing and its determinants: A micro-data study for Portugal . Social Indicator Research (2016) 126:1375-1399

Veenhoven, R. (2000) The Four Qualities of Life: Ordering Concepts and Measures of the Good Life. Journal of Happiness Studies, vol.1, 1-39.

Wood Amy, Ilan Noy, and Miles Parker 2016. The Canterbury Rebuild Five Years on from the Christchurch Earthquake. Reserve Bank of NZ Bulletin 79(3), 1-16.

Wooldridge, Jeffrey, 2019. Introductory Econometrics: A Modern Approach. Cengage Learning, 7 th edition. 


\title{
CHAPTER 4
}

\section{The Income Consequences of Managed}

\section{Retreat}

\begin{abstract}
:
In New Zealand, after 2011 Canterbury earthquake, around 16000 people have been relocated from their communities through a managed retreat program (the Residential Red Zone), though little is known about the impact of this relocation on their income. We use individual-level comprehensive, administrative, panel data from Canterbury (2004-2018), and difference in difference evaluation method to explore the effects of displacement on the Red Zone residents. We find that compared to non-relocated neighbors, the displaced people experience a significant initial decrease in their wages and salaries, and in their total income. The impacts vary with time spent in the Red Zone and when they moved away. Wages and salaries of those who were red-zoned and moved in 2011 were reduced by $9 \%$, and $10.4 \%$ for those who were Red Zone residents and moved later (in 2012). Women faced greater decreases in wages and salaries, and total income, than males. There were no discernible impacts of the relocation on people's self-employment income. In sum, we find strong evidence that managed retreat policy has identifiable adverse real effects on personal income.
\end{abstract}




\subsection{Introduction}

Managed retreat - the relocation of households or infrastructures out of harm's way - is considered as one of the most appropriate responses for some locations to reduce exposure to future losses from disasters (Alexander et al., 2012, Thaler et al., 2016). Under the best of circumstances, relocation may bring many benefits to at-risk communities. Of the most common adaptation strategies, early managed retreat is usually the surest way to protect people and property from disaster risks (Bragg, 2021). It is likely to be less costly than protection strategies that involve maintenance of hard infrastructure or eventual dismantling of eroded property (Albel et al., 2011; Alexander et al., 2012; Koslov,2016). In many cases, it may be the most effective and sustainable strategy to reduce exposure to place-based harm, with added potential for long-term environmental and socio-economic co-benefits (Hanna et al.,2021).

While managed retreat has a compelling logic to it, it is typically heavily constrained by the strong emphasis in many legal systems on private property rights (Hartmann 2011). Therefore, in practice, managed retreat has many social, cultural, political, and economic challenges. It has the potential to disrupt communities, and cause health, sociocultural, and economic adverse impacts on those that relocate (Schwerdtle et al., 2018, Dannenberg et al.,2019). Thus, it may inadvertently and unintentionally increase, rather than decrease, vulnerability (Hanna et al., 2017). Managed retreat decisions mostly involve three groups: the affected community (both homeowners and renters), the local authorities, and the central government (Noy, 2020). As such, to implement an effective managed retreat program, policy makers need to understand these participants' concerns, incentives, and interests to address the how, where, and when of the planned retreat.

Historically, we can observe several successful managed retreat programs that we can learn from. One example where retreat was considered a success is the case of Valmeyer, Illinois (Koslov, 2016). Two-thirds of the town's nine hundred residents were relocated two miles to the east to higher ground, following the 1993 Great Midwest Flood. Residents chose to relocate but keep the town together and planned the move collectively. The town was rebuilt with financial support from the Federal Emergency Management Agency (FEMA). Only two years later the town was seen as progress after retreat and life return to normal.

In contrast, planned retreat from Byron Bay, Australia which was first announced in 1988 had a very different result. Planning controls were implemented by Byron Shire Council in New South Wales (NSW), requiring both existing and proposed development to be relocated 
when 20-50 meters from an erosion escarpment. However, this policy has since been abandoned due to immense political pressure and legal actions pursued by homeowners as a result of a perceived inconsistent application of the mandates, and their implications for property values (Harker, 2016). Affected residents have claimed that no social, economic, or environmental advantages from a retreat policy have been demonstrated, and therefore resisted the program (Buckley, 2008).

Given the challenges that at risk communities and their governing authorities face, lessons learned from what and how managed retreat program affected relocated residents are crucial. This knowledge can help planners design better relocation programs, and avoid some of the well-intentioned and unintended failures that often beset such efforts (Hoang and Noy, 2020).

In New Zealand, a large managed-retreat program was implemented in Christchurch, after the 2011 earthquake the city experienced. In June 2011, the government made a farreaching decision to red zone some of the worst affected areas. In those areas, most buildings were found to be uneconomic to repair or too risky to inhabit, and the success of engineering solutions was deemed to be uncertain and/or too costly. There was significant and extensive area-wide land damage, largely caused by liquefaction and slope instability, and a high risk of further damage to land and buildings from even low levels of shaking. Homeowners were told that these areas would no longer be zoned for residential use, and they were required to move away from those areas. The government compensated them for that by offering to purchase their house and land. This decision ultimately affected 8,060 properties and more than 16,000 people across Greater Christchurch (MacDonald et.al., (2016)

These red zones eventually encompassed land near the Waimakariri River, parts of the land in Christchurch City along the Avon River, and parts of the Port Hills. The areas near Waimakariri and the Avon were announced in 2011 while a small western part of the flat land and the Port Hills areas were red-zoned in 2012 and 2013 (Figure 1). In declaring these Red Zones, the government's purpose was to lead residents in these zones to relocate away from these risks and enable them to get on with their lives as quickly as possible by providing them full compensation for their homes and land. Some red zone property owners were not happy with these compensation offers and felt that they had no choice but to accept them (Mitchell, 2015). There were media reports that some residents were included "reluctantly and under duress", despite the official court proceedings showing the contrary (Smith, 2021). By April 
2015, approximately 7,800 property owners (over 95 percent of the eligible group) had accepted the government's offer to sell their properties to the Crown), most had already settled, and nearly all had already relocated.

The questions of what happened to Red Zone residents' wellbeing after retreat is less understood. Nguyen (2020) examined the factors that drove homeowners' choices between the two kinds of compensation offers they were given. Hoang and Noy (2020) analysed a survey that focused on subjective wellbeing (quality of life, stress level, and emotional wellbeing). However, these studies used data available only on the Red Zone residents, so they could not conclude anything about the impact of 'being Red Zoned' in shaping those residents' outcomes.

A mandated relocation may be associated with adverse economic outcomes for those who are forced to relocate. As can be expected, research that has looked at forced relocations because of the destruction wrought by disasters in low- and middle-income countries has found adverse impacts on income and employment, but these relocations are rarely managed well, nor are they adequately compensated, if at all (e.g., Godamunne, 2012; Badri et al., 2006). However, the connections between managed retreat programs, where people are given a long advance notice for the need to move, and economic outcomes have yet to be examined empirically (Noy,2020).

Here, we shed some light on the impacts of managed retreat programs on the affected population by examining the Red Zone residents' income before and after their relocations, and by comparing them to other Christchurch residents who have experienced similar levels of property damage and lived outside of the Red Zone. The study also exploits the variation in the timing of RRZ residents moving to evaluate how relocation following by a managed retreat changed individuals' income. We do this by using StatisticsNZ's Integrated Data Infrastructure (IDI), which includes administrative unit-record data on all people living in New Zealand. We use income data, decomposed by its sources (wages and salaries and self-employment income) that is available from the New Zealand tax authority (the Inland Revenue Department).

We apply a difference-in-difference (DID) technique that separates the 'treated' (those who moved because of their location within the RRZ) from the 'control' (those who never reside within the RRZ). Our methodology also allows us to analyze how the implementation of managed retreat program affected income over time - up to 7 years post- relocation. The objectives of this research are thus: (1) to estimate the impact of mandatory relocation (managed retreat) on the income of displaced individuals over time; (2) to evaluate whether the 
impact of relocation varies by the timing of the move and demographic factors (gender, age, and ethnicity); and (3) to relate these findings to possible policy lessons for the design of future managed retreat programs.

We find that relocated Red Zone residents experienced an income decline, both for their 'wages and salaries' component, and for total income from all sources. This adverse impact is more severe for women and for individuals who were red-zoned later. More specifically, wages and salaries of women who were red-zoned and moved in 2011 declined by $12 \%$, and by $19.6 \%$ if they were red-zoned and moved later (in 2012). Overall, income decreased right after they moved, and it took about 2 years to observe a nascent recovery signal (even though, on average, they did not get back to the pre-event level by 2018 - the last year we examined) (Figure 4.56). Furthermore, the effects on the youngest age group (20-29 years old in 2011) were largest, so that people at their early career stage faced greater decreases in wages and salaries, than older cohorts. We find no discernible effect of the relocation on people's self-employment income, for both men and women.

The next section provides an overview of the Residential Red Zone (RRZ) program; while section 4.3 describes the data we use here. Section 4.4 details the empirical specifications I estimate, and the results of this statistical analysis are described in section 4.5. Some robustness checks are provided in section 4.6, and section 4.7 concludes with some further observations.

\subsection{Residential Red Zone (RRZ) program}

After the devastating earthquake on the 22nd of February 2011, the government rezoned several areas in Christchurch. In the initial announcement about the re-zoning, on the 23rd of June 2011, the earthquake-affected areas were categorized into four zones: red zones which were mostly liquefaction-prone areas along the Avon river in Christchurch and the Waimakariri river north of the city; orange zones which were determined to require further investigation, green zones which were areas deemed viable for repair or reconstruction of damaged property, and white zones which still need to be mapped or were not residential land at all. Most of the white zone properties were in the Port Hills and the central business district areas. From that time to the end of 2011, several further adjustments were made, and these rezoned white and orange zone land to green (these included more than 20,000 properties). In February and March 2012, around 450 properties across Greater Christchurch were re-zoned from orange to red. From May till the end of 2012, properties in the Port Hills (around 650 
properties) and South Shore West (around 200 properties) were rezoned from white to red as well.

On the 24th of August 2012, the completion of the flat-land zoning review was released, followed by that of the land-zoning process for Greater Christchurch on the 31st of October 2012. The final review process was completed by the end of 2013. This brought the total number of the Red Zoned Port Hills properties to 714. The Port Hills red zones were identified later than the flat lands, largely because of the technical complexity in assessing risk (from rockfalls rather than liquefaction, respectively). As of March 2016, a total of 8060 properties across Greater Christchurch had been zoned red. Figure 1 maps the Red Zone area locations and the time they were categorized as RRZ (a timeline is provided in Appendix 4.2). 
Figure 4.1: Redzone areas and time of being RRZ residents.

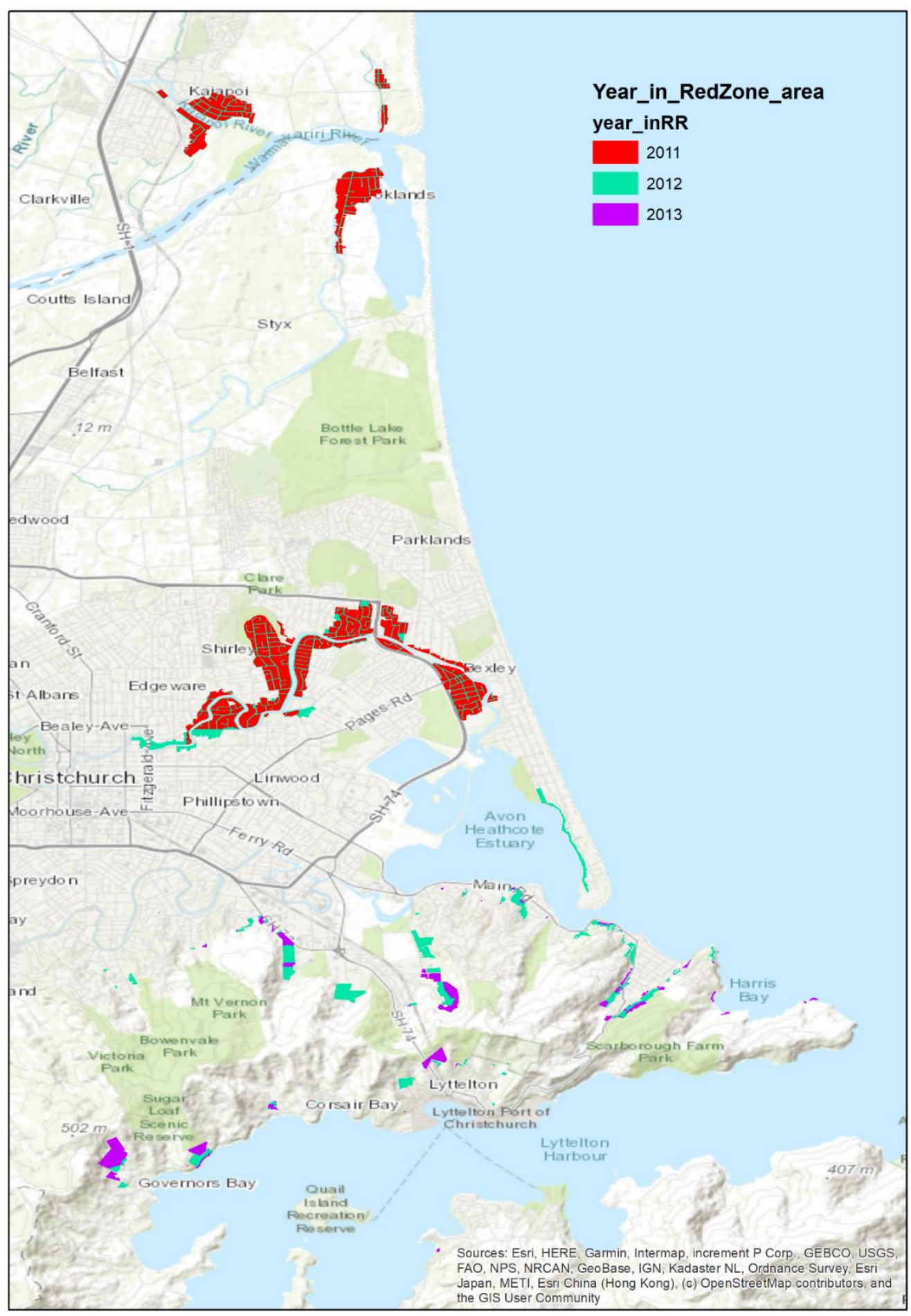




\subsection{Data}

\subsubsection{Data sources}

This study used linked data from Statistics New Zealand Integrated Data Infrastructure (IDI), which is a wide collection of government administrative and survey data that is linked together at the individual level and aims to include everyone living in the country.

The IDI contains information about the address updates that individuals have provided to various government agencies, and addresses recorded in surveys (such as the census). Exact addresses are not available for researchers, but the individuals are linked to a meshblock. A meshblock is a defined geographic area, varying in size from part of a city block to large areas of rural land. It is the smallest geographical area in NZ standard geographic classification, representing roughly 30 to 60 dwellings (about a hundred people). Meshblocks are combined to create larger aggregations - area units, territorial authorities, and regions. ${ }^{3}$

Our first task is to identify people who lived in the Residential Red Zone (RRZ) areas at the time the zoning announcements were released. To do this, we first defined the RRZ meshblocks and area units, and territorial authorities by overlapping the RR map and the geographical map (in 2018) provided by Stats NZ. In total, there are 348 distinct red zone meshblocks, in which 87 are boundary meshblocks which overlap both RRZ and non-RRZ areas. Most of the boundary meshblocks are in the Port Hill areas (16 in Sumner, 10 in Lyttelton, 7 in Moncks Bay). As a meshblock is the smallest geographic unit in the IDI data, we cannot identify the location of properties more precisely. We therefore removed the residents in the boundary meshblocks from our sample (as these meshblocks are partly in the RRZ, and partly outside it). Table 4.1 illustrates the number and percentages of RRZ meshblocks. Only 6 out of 261 (2\%) non-boundary meshblocks were red-zoned in 2013.

Table 4.1. Number and percentages of boundary and non-boundary redzone meshblocks

\begin{tabular}{cccc}
\hline \hline Year in RRZ areas & Boundary & Non-boundary & Total \\
\hline 2011 & 15 & 180 & 195 \\
2012 & 57 & 75 & 132 \\
2013 & 15 & 6 & 21
\end{tabular}

\footnotetext{
3 As areas grow and change, meshblocks get updated and can be compared overtime by the meshblock concordance table in the IDI. Territorial authorities are the second tier of local government in New Zealand, below regional councils and are defined are defined under the Local Government Act 2002 as city councils or district councils. In 2018, there were 67 territorial authorities: 12 cities, 53 district councils, Auckland Council, and Chatham Islands Council.
} 


\begin{tabular}{llll}
\hline Total & 87 & 261 & 348 \\
\hline \hline
\end{tabular}

After having the list of red zone meshblocks, we joined it to the full address dataset to have the record of red zone residents whose address notification date were from $1^{\text {st }}$ February 2010 to $23^{\text {rd }}$ June 2011; and their record of moving (the moved time and destination). We also compared the meshblock codes over the years through the meshblock concordance table to account for any administrative mapping changes.

This study cohort consists of RRZ residents and those who were living elsewhere in the same territorial authorities (Christchurch and Waimakariri districts) at the time that the managed retreat program was announced. We narrowed the group of 'control' people (against whom we compare the RRZ residents) to those who were living in the meshblocks that were affected by the same earthquake intensity shake levels in February 2011, ranging from 6.2 to 8.6 (these are identified through a shake map produced by the USGS). By doing this, we assumed that the properties belong to people in the treatment and control group were similarly affected by the 2011 earthquake.

We interpret the large managed retreat program as a quasi-random shock to mobility. We can estimate the causal effect of the forced move by comparing outcomes (total income, wages, and salaries - representing the employment effect, and self-employment income) for those whose houses were in the RRZ and had to move (our treatment group) versus those whose houses were out of red zone areas but were still in the same larger geographical area and experienced similar earthquake intensity (our control group).

We merged the list of people (treatment and control) with their tax records, their education, and personal demographic information (age, gender, ethnicity) available from the census. Therefore, we were able to study the economic consequences of the mobility shock over the next 7 years, for the individuals affected. We further restricted the sample to those aged 20-60 at the time of RRZ program announcement (in 2011), to capture only the working age population. We used data from 15 years (2004-2018). People without total income (income from all sources) in 2011 (equal to 0 or missing) were also removed from the sample.

\subsubsection{Context of the data}

$77.3 \%$ of the former RRZ residents were still in this area in 2011, 22.4\% were in the RRZ in 2012, and only $0.3 \%$ were still categorized in the RRZ in 2013. Among them, $82 \%$ 
relocated within the Canterbury region. Moreover, $66 \%$ relocated within the same territorial authority (Christchurch City or Waimakariri district). 16\% were still in Canterbury region but out of their original territorial authorities (Tables 4.2 and 4.3). For those people whose properties was red-zoned in 2011, the top three destination regions for those who moved away were Auckland, Otago, and Wellington (table 4.4)

Table 4.2. Number and percentages of people in RRZ areas

\begin{tabular}{ccc}
\hline \hline Year in RRZ areas & Number of people & Percentages (\%) \\
\hline 2011 & 4302 & 77.3 \\
2012 & 1245 & 22.4 \\
2013 & 18 & 0.3 \\
Total & 5565 & 100 \\
\hline \hline
\end{tabular}

Table 4.3. Destinations of relocated households

\begin{tabular}{lcc}
\hline \multicolumn{1}{c}{ Destinations } & Number of people & Percentages (\%) \\
\hline Regions & 4572 & 82.2 \\
In the Canterbury region & 993 & 17.8 \\
Out of the Canterbury region & & \\
Territorial authorities (TA) & 3684 & 66.2 \\
Same territorial authorities & 891 & 16.0 \\
Different TA, still in the Canterbury region & 993 & 17.8 \\
Different TA, outside the Canterbury region &
\end{tabular}

Table 4.4. Destination and time movement of people who were in RRZ areas in 2011

\begin{tabular}{llc}
\hline \hline Moved year & \multicolumn{1}{c}{ Destination (region) } & Percentages (\%) \\
\hline \multirow{2}{*}{2011} & Stayed in Canterbury & 82.16 \\
& Auckland & 4.4 \\
& Otago & 2.7 \\
& Wellington & 1.9 \\
& Marlborough & 1.5 \\
& Bay of plenty & 1.3
\end{tabular}


Tasman $\quad 1.1$

Westcoast 1

Others 4

Stayed in Canterbury $\quad 89.56$

Auckland 2.4

2012 Otago 1.7

Wellington 1

Others $\quad 5.3$

Stayed in Canterbury $\quad 89.36$

Auckland 2

After $2013 \quad$ Otago 3

Wellington 1

Others $\quad 4.6$

Table 4.5. Descriptive statistics

\begin{tabular}{|c|c|c|c|c|c|c|c|}
\hline \multirow[b]{2}{*}{ Variables } & \multicolumn{3}{|c|}{ Control group } & \multicolumn{3}{|c|}{ Redzone group } & \multirow[b]{2}{*}{$\begin{array}{c}\text { Balance } \\
\text { tests }\end{array}$} \\
\hline & $N$ & $\begin{array}{c}\text { Mean or } \\
\%\end{array}$ & $S D$ & $N$ & $\begin{array}{c}\text { Mean or } \\
\%\end{array}$ & SD & \\
\hline Gender & 157206 & & & 5565 & & & $\chi 2=1.884$ \\
\hline Male & 79389 & $50.5 \%$ & & 2755 & $49.5 \%$ & & \\
\hline Female & 77817 & $49.5 \%$ & & 2810 & $50.5 \%$ & & \\
\hline $\begin{array}{l}\text { Tertiary } \\
\text { education } \\
\text { enrolment }\end{array}$ & 157206 & & & 5565 & & & $\chi 2=1.321$ \\
\hline No & 40023 & $25.5 \%$ & & 1455 & $26 \%$ & & \\
\hline Yes & 117183 & $74.5 \%$ & & 4107 & $74 \%$ & & \\
\hline Qualification & & & & & & & v2-80 $01 * * *$ \\
\hline level & 157206 & & & 5565 & & & $x^{2-0} 9.011$ \\
\hline 01 & 4245 & $2.70 \%$ & & 162 & $2.90 \%$ & & \\
\hline 02 & 14307 & $9.10 \%$ & & 558 & $10 \%$ & & \\
\hline 03 & 21852 & $13.90 \%$ & & 852 & $15.30 \%$ & & \\
\hline 04 & 13362 & $8.50 \%$ & & 495 & $8.90 \%$ & & \\
\hline 05 & 8646 & $5.50 \%$ & & 351 & $6.30 \%$ & & \\
\hline 06 & 6444 & $4.10 \%$ & & 234 & $4.20 \%$ & & \\
\hline 07 & 25626 & $16.30 \%$ & & 729 & $13.10 \%$ & & \\
\hline 08 & 5187 & $3.30 \%$ & & 117 & $2.10 \%$ & & \\
\hline
\end{tabular}




\begin{tabular}{|c|c|c|c|c|c|c|c|}
\hline 09 & 2043 & $1.30 \%$ & & 45 & $0.80 \%$ & & \\
\hline 10 & 786 & $0.50 \%$ & & 12 & $0.20 \%$ & & \\
\hline Missing & 14307 & $9.10 \%$ & & 546 & $9.80 \%$ & & \\
\hline No qualification & 40023 & $25.50 \%$ & & 1455 & $26.00 \%$ & & \\
\hline Ethnicity & 157206 & & & 5565 & & & $\chi 2=15.958^{* * *}$ \\
\hline Non- Māori & 140247 & $89 \%$ & & 4869 & $87.5 \%$ & & \\
\hline Māori & 16959 & $11 \%$ & & 693 & $12.5 \%$ & & \\
\hline Age (in 2011) & 157206 & 37.3 & 11.82 & 5565 & 38.1 & 11.581 & $\mathrm{~F}=26.799^{* * *}$ \\
\hline $\begin{array}{l}\text { Total } \\
\text { income (\$NZD) }\end{array}$ & 157206 & 37781.3 & 33575.8 & 5565 & 36808.1 & 27406.9 & $\mathrm{~F}=4.567^{* *}$ \\
\hline $\begin{array}{l}\text { Wages \& salaries } \\
(\$ N Z D)\end{array}$ & 133353 & 37261.6 & 33081.4 & 4713 & 37041.7 & 27002.3 & $\mathrm{~F}=0.204$ \\
\hline
\end{tabular}

Statistical significance markers: $* \mathrm{p}<0.1 ; * * \mathrm{p}<0.05 ; * * * \mathrm{p}<0.01$. People aged 20-60 years in 2011. SD refers to the standard deviation; $\mathrm{N}$ refers to number of people.

Residents obviously did not self-select to be hit by the earthquake and/or be red-zoned. In New Zealand, the Ministry for Business, Innovation and Employment divides the country into three risk zones (high, medium, and low). ${ }^{4}$ Before the 2010-2012 sequence of earthquakes, Christchurch was classified as low-risk. The earthquake was thus not widely anticipated, and neither were the associated hazards (such as landslides and liquefaction). As a consequence of this seismic activity in 2010-2012, Canterbury (including Christchurch) was re-classified as high-risk. We used balance tests to test the similarity of observable pre-treatment features of the people in RRZ areas and their neighbours elsewhere in the city. Table 4.5 presents the summary statistics of control and treatment group in our analysis, and the balance tests (the last column) for various pre-relocation characteristics that are available in our data. For balance tests, the Fisher test (F test) was used for continuous variables (e.g., age, wages \& salaries, total income), and chi square tests were applied for categorical variables.

The average age of RRZ residents and control group are the similar - 38 years old. In the RRZ group, $49.5 \%$ were males, $12.5 \%$ were Māori, and 74\% enrolled in tertiary education. The control group, similarly, consists of 50.5\% males, 11\% Māori, and 75\% had tertiary education qualification. When we test for differences in these characteristics, we find that there are no systematic differences in gender, tertiary education enrolment, wages and salaries in

\footnotetext{
${ }^{4}$ These classifications are used in determining required building codes.
} 
2011. In terms of age, qualification level, and ethnicity, the differences are statistically significant but are small.

\subsection{Identification strategy}

\subsubsection{Empirical model and estimation}

We aim to estimate the causal effect of managed retreat program on economic outcomes. These are wages and salaries, total income, and self-employment income, by difference in difference method (DID).

The basic econometric model is:

$Y_{i t}^{*}=\alpha+$ Breat $_{i}+\gamma$ Post $_{t}+$ STreat $_{i} *$ Post $_{t}+\theta X_{i t}+\delta_{i}+\mu_{t}+\tau_{T A}+\varepsilon_{i t}(1)$

where $Y_{i t}^{*}$ is the disposable income (logarithm or sum of income) for person $i$ in period $t$; Treat $_{i}$ is a dichotomous indicator of treatment (in the RRZ before the managed retreat), Post $_{t}$ takes a value of 1 for all time periods $t$ after the treatment. $\delta_{i}, \mu_{t}, \tau_{T A}$ are individual, time, and location fixed effects. $X$ is a vector of control variables: Age, age square, gender, ethnicity, highest education level, tertiary education enrolment (binary), job sector. These exogenous control variables can impact income but are not influenced by the treatment. The error term is $\varepsilon_{\mathrm{it}}$. We include year fixed effect and Territorial Authorities fixed-effects in all regressions.

Residents were red zoned in different time, and also moved in different time from 2011 to 2016. We investigated the effect of being classified as RRZ residents, and the timing of the exit move on the three dependent income: wages \& salaries, self-employment income, and total income (income from all sources). We used tax records, which provide an objective measure of a person's income over time. Income come from several sources: Examples include wages and salaries, benefit payments from the Ministry of Social Development (MSD), Accident Compensation Corporation (ACC) disability insurance payments, and pension payments from MSD. The list of all income source categories and self-employment income source groups can be found in Appendix 4.2. We estimate specifications for both the absolute value of income and $\log$ of income.

The controls we include are age, age square, ethnicity, highest education level, gender, tertiary education entrance status, job sector, year fixed-effect and location fixed-effect. Ethnicity and gender were taken from the personal details table in the IDI. The table collates ethnicities that are reported in various datasets in IDI. The highest education level and tertiary 
education entrance data comes from the education quality dataset and tertiary education entrance dataset. The job sector was taken from the tax record table and is coded based on Australian and New Zealand Standard Industrial Classification 2006 (ANZSIC). By adding the vector of control variables, we increase the precision of the treatment estimates, and ideally eliminate any confounding variables to correctly specify the models. With these, we can also investigate possible heterogeneity of the treatment effects.

We estimate equation (1) for the whole cohort, then for men and women separately and by age category (20-29, 30-39, 40-49, 50-60). To capture the full dynamic changes in income, we evaluate the effect for each year following the implementation of the mandated relocation program.

\subsubsection{Parallel trends assumption}

The evidence from balance tests (table 4.5) states that Red Zone communities and their neighbours were relatively homogeneous. Furthermore, figure 2-3 illustrate the parallel trend in wages and salaries, total income of treatment and control group before the managed retreat program was applied in 2011.

Figure 4.2. Average wages and salaries from 2004 to 2018




Figure 4.3. Average total income from 2004 to 2018

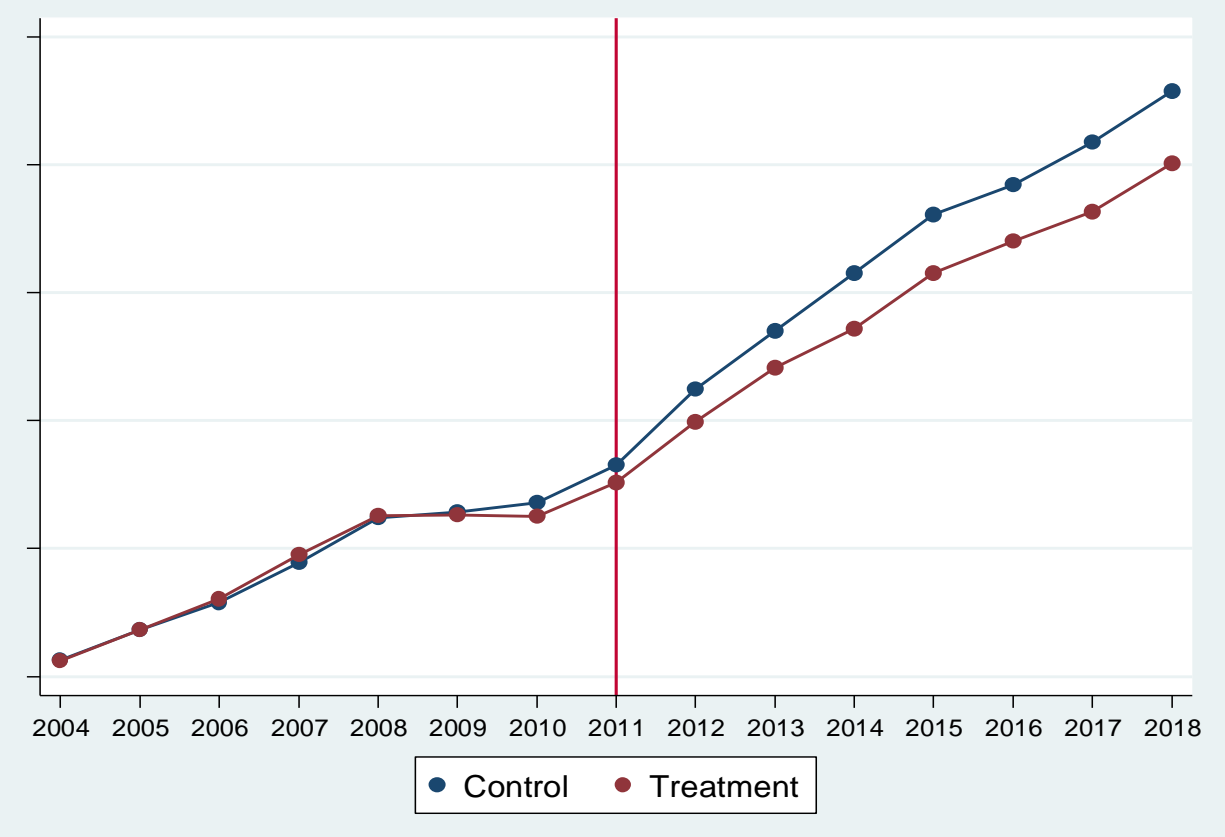

\subsection{Results}

Table 4.6-4.9 present the results for the regressions investigating the impact of relocation on income by source. To see how the assignment to be relocated affects income by gender, we estimate the effects separately for men and women. Each result is a separate regression which includes other control variables, including age, age square, job sector, year fixed effect, and territorial authority fixed-effects. Data shows that the variation in the job sector changing in the panel over 14 years is very small (this variable is dropped out from regressions). We run regressions (use panel robust SEs) for both sum of income and the natural logarithm of each income as the dependent variable. The reported coefficients are the impact of displacement. Although an increasing trend in income can be seen in both groups (figure 4.2-3), our comparisons of average changes show that relocation negatively affected RRZ residents' incomes.

\subsubsection{Wages and salaries}

Table 4.6 shows that there is a large and statistically significant reduction in wages and salaries caused by the relocation. Averaging the effects suggests an aggregate decline of $6.6 \%$ for people who were Red Zoned in 2011, and $10.4 \%$ for people who were in a year later in 2012. For women who were in the Red Zone earlier, their wages and salaries were reduced by 
$7 \%$ while this figure was $17.4 \%$ for people who were in Red Zone later. For men, table 4.6 reveals an aggregate decline of 5.5\% for those who were in Red Zone in 2011, but no statistically discernible effect for those there in 2012.

Table 4.6. Wages and salaries effects by timing of being RRZ residents (LHS: wages \&salaries)

\begin{tabular}{ccccccc}
\hline \hline \multirow{2}{*}{$\begin{array}{c}\text { Time of } \\
\text { being RRZ }\end{array}$} & \multicolumn{2}{c}{ All cohort } & \multicolumn{2}{c}{ Male } & \multicolumn{2}{c}{ Female } \\
\cline { 2 - 7 } residents & Sum & Log & Sum & Log & Sum & Log \\
\cline { 2 - 7 } & $(1)$ & $(2)$ & $(3)$ & $(4)$ & $(5)$ & $(6)$ \\
\hline 2011 & $-1829.5 * * * *$ & $-0.0658^{* * * * *}$ & $-1711.8^{* * *}$ & $-0.0545^{* * *}$ & $-1736.5 * * * *$ & $-0.0732^{* * * * *}$ \\
& $(-5.38)$ & $(-4.46)$ & $(-3.14)$ & $(-2.77)$ & $(-4.42)$ & $(-3.38)$ \\
2012 & $-2124.8^{* * *}$ & $-0.104 * * * *$ & -1536.3 & -0.0350 & $-2891.8 * * *$ & $-0.174 * * * *$ \\
& $(-3.04)$ & $(-3.54)$ & $(-1.52)$ & $(-0.94)$ & $(-3.20)$ & $(-3.87)$ \\
\hline \hline
\end{tabular}

$* \mathrm{p}<0.1, * * \mathrm{p}<0.05, * * * \mathrm{p}<0.01, * * * * \mathrm{p}<0.001$. Robust standard errors are shown in parentheses.

We further break the sample down into sub-groups based on the time they moved out (Table 4.7). The effect of displacement on wages and salaries for those who were red-zoned in 2011 and moved immediately was large and statistically significant. Compared to their neighbours, their wages and salaries decreased by around 2700 NZ\$ (per year) or $10 \%$ in a specification with controls (column (2)). The amount of mean lost income from wages and salaries for women were 2760 NZ\$ or $12 \%$ while these figures were $2140 \mathrm{NZ} \$$ or $7 \%$ for men. This difference is consistent with a labour force participation rate report that found a steeper decline in the labour participation rate among women in the aftermath of the earthquakes. For those who were red-zoned in the same year (in 2011) but moved one year later (in 2012), their wages and salaries also decreased (around 1890NZ\$ or 5.2\%). In this subgroup, as well, women were more negatively affected (2230NZ\$ or $6.2 \%)$.

For individuals who were red zoned later in 2012, and moved in the same year, their earnings loss was similar overall (10\%). The women in this sub-group faced even more negative effects from the RRZ relocation - their earning went down by nearly 2970 NZ\$ or $19.6 \% .5$

\footnotetext{
${ }^{5}$ There are no statistically observable impacts of the relocation for people who moved in 2013 or later, but this is a very small group, relative to those who moved in 2011 and 2012 (see tables 1-2).
} 
Table 4.7. Wages and salaries effects by timing of being RRZ residents and moving (LHS: wages \&salaries)

\begin{tabular}{|c|c|c|c|c|c|c|}
\hline & \multicolumn{2}{|c|}{ All cohort } & \multicolumn{2}{|c|}{ Male } & \multicolumn{2}{|c|}{ Female } \\
\hline & Sum & $\log$ & Sum & $\log$ & Sum & $\log$ \\
\hline & (1) & (2) & (3) & (4) & (5) & (6) \\
\hline \multicolumn{7}{|c|}{ Being $R R Z$ residents in $2011 \&$ moved in } \\
\hline 2011 & $\begin{array}{l}-2707.6^{* * * *} \\
(-5.46)\end{array}$ & $\begin{array}{l}-0.0990^{* * * * *} \\
(-4.35)\end{array}$ & $\begin{array}{l}-2142.5^{* * *} \\
(-2.66)\end{array}$ & $\begin{array}{l}-0.0696^{* *} \\
(-2.28)\end{array}$ & $\begin{array}{l}-2756.6^{* * * * *} \\
(-4.86)\end{array}$ & $\begin{array}{l}-0.121^{* * * * *} \\
(-3.67)\end{array}$ \\
\hline 2012 & $\begin{array}{l}-1893.3^{* * *} \\
(-3.18)\end{array}$ & $\begin{array}{l}-0.0515^{* *} \\
(-2.13)\end{array}$ & $\begin{array}{l}-1466.9 \\
(-1.53)\end{array}$ & $\begin{array}{l}-0.0386 \\
(-1.22)\end{array}$ & $\begin{array}{l}-2234.3^{* * * * *} \\
(-3.36)\end{array}$ & $\begin{array}{l}-0.0619^{*} \\
(-1.72)\end{array}$ \\
\hline \multicolumn{7}{|c|}{ Being RRZ residents in 2012 \& moved in } \\
\hline 2012 & $\begin{array}{l}-2218.0^{* *} \\
(-2.55)\end{array}$ & $\begin{array}{l}-0.104^{* * *} \\
(-2.83)\end{array}$ & $\begin{array}{l}-1410.2 \\
(-1.10)\end{array}$ & $\begin{array}{l}-0.00824 \\
(-0.17)\end{array}$ & $\begin{array}{l}-2968.6^{* * * *} \\
(-2.68)\end{array}$ & $\begin{array}{l}-0.196^{* * * * *} \\
(-3.53)\end{array}$ \\
\hline 2013 & $\begin{array}{l}-611.8 \\
(-0.29)\end{array}$ & $\begin{array}{l}-0.0517 \\
(-0.66)\end{array}$ & $\begin{array}{l}1641.3 \\
(0.59)\end{array}$ & $\begin{array}{l}-0.0427 \\
(-0.50)\end{array}$ & $\begin{array}{l}-4335.7 \\
(-1.64)\end{array}$ & $\begin{array}{l}-0.0777 \\
(-0.57)\end{array}$ \\
\hline
\end{tabular}

$* \mathrm{p}<0.1, * * \mathrm{p}<0.05, * * * \mathrm{p}<0.01, * * * * \mathrm{p}<0.001$. Robust standard errors are shown in parentheses.

We also disaggregate our main results by age (in 2011). Figure 4 reports these regressions for four age group (20-29, 30-39, 40-49, 50-60). The youngest group (20-29) experienced with relocation a decline in their wages and salaries. This effect is strong, statistically significant, and is persistent (7 years after their relocation). It took them 4 years (up to 2015) to start recovering their income. Although there may be some impact on relocated people aged groups from 30-60, it appears that relocation had much shorter effect on their wages and salaries than on the younger cohort. A full table of regression coefficients for each age group in each year following the relocation is provided in the appendix 4.3 (table A3.1) 
Figure 4.4. Effects of relocation on wages and salaries by age over time
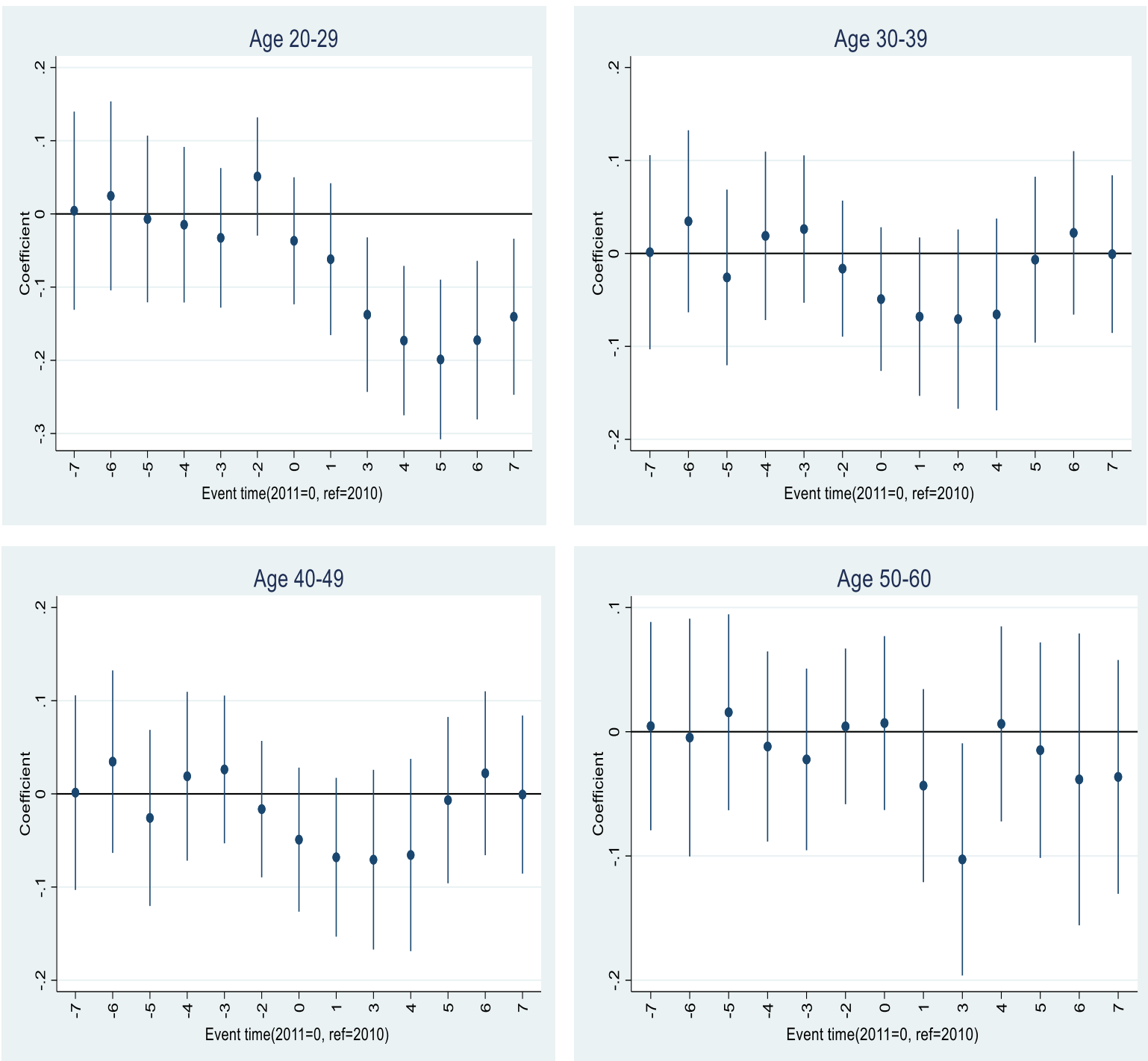

\subsubsection{Total income effects}

Total income is sum of income from 15 different sources listed in the Appendix 4.1. Table 4.8 suggests a large and significant decline in total income following the relocation for all cohort and for both men and women, regardless of the timing. Column (2) shows a decline by $5.6 \%$ for those who were in RedZone in 2011, and $8.8 \%$ for those who were in RedZone in 2012. The declines for men and women were similar for those who were in RedZone earlier, but for those in RedZone later, women experience a larger decrease in their total income (around NZ\$2690 or $11.3 \%$ compared to around NZD\$2000 or 6.2\%) (column 3-6) 
Table 4.8. Total income effects by timing of being RRZ residents (LHS: total income)

\begin{tabular}{ccccccc}
\hline \hline \multirow{2}{*}{$\begin{array}{c}\text { Time of } \\
\text { being RRZ }\end{array}$} & \multicolumn{2}{c}{ All cohort } & \multicolumn{2}{c}{ Male } & \multicolumn{2}{c}{ Female } \\
\cline { 2 - 7 } residents & Sum & Log & Sum & Log & Sum & Log \\
\cline { 2 - 7 } & $(1)$ & $(2)$ & $(3)$ & $(4)$ & $(5)$ & $(6)$ \\
\hline 2011 & $-1546.6^{* * * *}$ & $-0.0559^{* * * *}$ & $-1424.5^{* * *}$ & $-0.0539^{* * * *}$ & $-1403.7 * * * *$ & $-0.0532^{* * * *}$ \\
& $(-4.74)$ & $(-4.80)$ & $(-2.66)$ & $(-3.40)$ & $(-3.87)$ & $(-3.18)$ \\
2012 & $-2303.7 * * * *$ & $-0.0875^{* * * *}$ & $-1999.7^{* *}$ & $-0.0618^{* *}$ & $-2694.7 * * * *$ & $-0.113^{* * * *}$ \\
& $(-3.64)$ & $(-4.01)$ & $(-2.10)$ & $(-2.25)$ & $(-3.43)$ & $(-3.33)$ \\
\hline \hline
\end{tabular}

$* \mathrm{p}<0.1, * * \mathrm{p}<0.05, * * * \mathrm{p}<0.01, * * * * \mathrm{p}<0.001$. Robust standard errors are shown in

parentheses

Table 4.9 illustrates results when we divide our treatment group into sub-groups based on the timing of moving. The total income for those who were red-zoned and moved immediately in 2011, their income was reduced by 2546 NZ\$ or $8.7 \%$ (column 1-2). Interestingly, the amount of mean decline total income for men (2444 NZ\$ or $8.7 \%$ (column $5-6)$ ) is slightly larger than for women (2128 NZ\$ or 8.1\% (column 3-4)). For those who were red-zoned and moved in 2012, their income decreased by nearly 3000 NZ\$ or $11 \%$. In this subgroup, compared to the control group (that was not relocated), the income of relocated people was reduced by nearly 3330 NZ\$ or $15.8 \%$ for women, and 2484 NZ\$ or $5.6 \%$ for men.

Altogether, there is evidence of a decrease in both wages and salaries and total income for Red Zone residents after they were forced to move. The wages and salaries had a greater decrease than total income, indicating that residents may receive benefits or supports from government to compensate for their missing participant in the labour market, but overall, relocation has a negative impact on the total income of the displaced.

Table 4.9. Total income effects by timing of being RRZ residents and moving (LHS: total income)

\begin{tabular}{ccccccc}
\hline \hline & \multicolumn{2}{c}{ All cohort } & \multicolumn{2}{c}{ Male } & \multicolumn{2}{c}{ Female } \\
\cline { 2 - 7 } & Sum & Log & Sum & Log & Sum & Log \\
\cline { 2 - 7 } & $(1)$ & $(2)$ & $(3)$ & $(4)$ & $(5)$ & $(6)$ \\
\hline Being RRZ residents in 2011 \& moved & & & & & \\
In 2011 & $-2546.1 * * * *$ & $-0.0872^{* * * *}$ & $-2443.9^{* * * *}$ & $-0.0874^{* * * *}$ & $-2128.3^{* * * * *}$ & $-0.0810^{* * * *}$ \\
& $(-5.61)$ & $(-5.15)$ & $(-3.22)$ & $(-3.68)$ & $(-4.23)$ & $(-3.41)$
\end{tabular}




\begin{tabular}{ccccccc} 
In 2012 & $-1149.3^{* *}$ & -0.0261 & -659.3 & -0.0156 & $-1456.4^{* *}$ & -0.0330 \\
& $(-1.96)$ & $(-1.35)$ & $(-0.68)$ & $(-0.61)$ & $(-2.36)$ & $(-1.15)$ \\
\hline Being RRZ residents in 2012 \& moved & & & & \\
In 2012 & $-2955.7^{* * * *}$ & $-0.109^{* * * *}$ & $-2483.6^{* *}$ & $-0.0558^{*}$ & $-3326.6^{* * * *}$ & $-0.158^{* * * *}$ \\
& $(-3.82)$ & $(-4.11)$ & $(-2.12)$ & $(-1.65)$ & $(-3.47)$ & $(-3.89)$ \\
In 2013 & 708.0 & -0.0558 & 1721.5 & -0.117 & -1272.8 & -0.00377 \\
& $(0.37)$ & $(-0.83)$ & $(0.62)$ & $(-1.39)$ & $(-0.55)$ & $(-0.04)$ \\
\hline \hline
\end{tabular}

$* \mathrm{p}<0.1, * * \mathrm{p}<0.05, * * * \mathrm{p}<0.01, * * * * \mathrm{p}<0.001$. Robust standard errors are shown in parentheses

We also examined the relocation's impacts on self-employment income, but did not find much statistically significant impact. There is a statistically significant decrease in the sum of self-employment income (column 1), but it is only weakly significant (at 10\% level). See Table A7.1 in Appendix 4.7.

\subsubsection{Dynamics of impacts}

In our previous analyses (using equation (1)), we were constrained to a single average treatment effect for the entire span of the post treatment period. Yet, we can also analyse the dynamic effect of relocation on income. Suppose treatment occurs at time k, we estimate the linear panel model with dynamic policy effects:

$Y_{i t}^{*}=\alpha+\sum_{\boldsymbol{m}=-\boldsymbol{a}}^{\boldsymbol{p}} \beta_{\boldsymbol{m}}$ treat $_{i t}+\theta X_{i t}+\delta_{i}+\mu_{t}+\tau_{T A}+\varepsilon_{i t}(2)$

Where: $\mathrm{t}=\mathrm{k}+\mathrm{m}$

Most of the terms in the equation (2) are the same as in the equation (1): individual, time, and location fixed effects, control variables, and the error term. The key feature of this model is the summation term. It includes a leads and p lags of the treatment. The income at time $t$ can only be directly affected by the value of the policy at most $m \geq 0$ periods. Therefore, any estimates for $\beta$ for $m<0$ that are statistically different from zero would suggest the model is mis-specified (as the relocation already had an impact on the affected individuals before the earthquakes occurred).

Beyond a placebo-type test, this allows us to measure the relocation effects by year. In Figure 5, we provide graphs displaying the point estimate and $95 \%$ confidence interval for the treatment effect over time ( 7 years pre- and post- the managed retreat event). Full tables (Table 
A4.1) reporting coefficients for the whole sample, and for men and women separately, are provided in Appendix 4.4.

Figure 4.5: Event study estimates for effect of managed retreat on wages \& salaries for those who were in RRZ areas in 2011

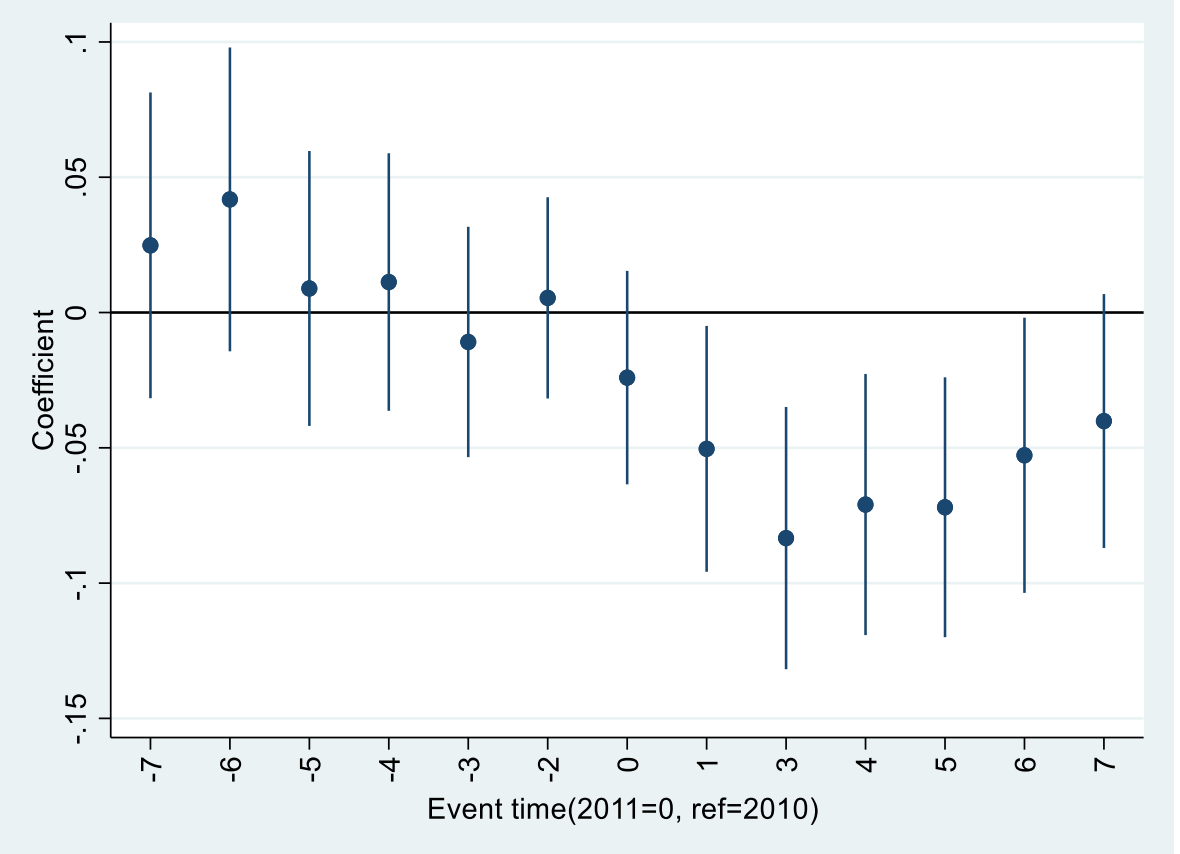

Figure 4.6: Event study estimates for effect of managed retreat on wages \& salaries for those who were in RRZ areas in 2012

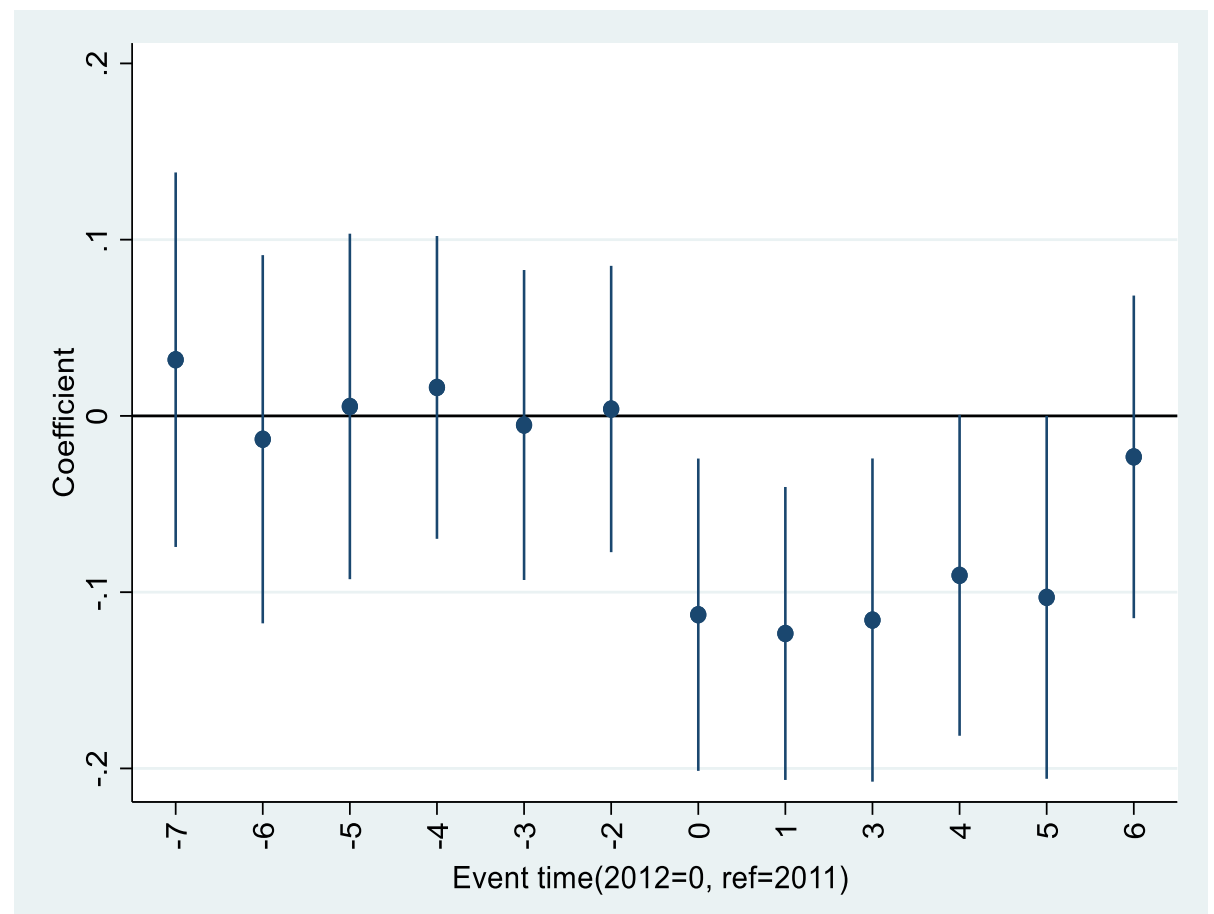


The DiD analysis presented earlier identifies a single, constant average treatment effect (ATE) for all post treatment periods (a wages and salaries reduction of $6.6 \%$ and $10.4 \%$ for those who were in RRZ in 2011 and 2012). Here in figures 5-6, we observe the negative effect of relocation right after the forced moved. For those who were in the RRZ in 2011, this effect gets larger for two years (until 2013), and then incomes starts to recover. The wages and salaries reduction of those who were placed in the RRZ later (in 2012) is somewhat bigger. This larger effect is fairly stable during 2012-2016 and recovers to just below the pre-event income level by 2017 . These patterns indicate that even 7 years after the managed retreat, wages and salaries still have not recovered to their pre-event level.

\subsubsection{Differences by gender}

Table 6-9 showed the regression coefficients for women are larger than men, suggesting that women were more adversely affected than men by the relocation. We can compare the regression coefficients of men with women by testing the null hypothesis $\mathrm{Ho}$ : $\mathrm{Bf}=\mathrm{Bm}$, where $\mathrm{Bf}$ is the regression coefficient for women, and $\mathrm{Bm}$ is the regression coefficient for men. We first make a dummy variable for woman, then a product of woman and post treatment. We rerun regressions with gender dummy for each dependent variable (wages\& salaries and total income).

The variable named "females" in table 4.10 test the null hypothesis of equal impacts. All of these coefficients, however, are significant, indicating that the women experienced statistically observable larger adverse effects on their incomes (though both men and women have experienced a decrease in their income). Tables with full regression coefficients for subgroups based on their timing of being RRZ residents and moving are provided in Appendix 4.5 .

Table 4.10. The regression coefficients differences by gender following the relocation (LHS: $\log$ income)

\begin{tabular}{lcccc}
\hline \hline & \multicolumn{2}{c}{ Being RRZ residents in 2011 } & \multicolumn{2}{c}{ Being RRZ residents in 2012 } \\
\cline { 2 - 5 } & Wages\& salaries & Total income & Wages\& salaries & Total income \\
\cline { 2 - 5 } & $(1)$ & $(2)$ & $(3)$ & $(4)$ \\
\hline \multirow{2}{*}{ Females } & $-0.0558^{*}$ & $-0.0699 * * *$ & $-0.208^{* * * * *}$ & $-0.133 * * *$ \\
& $(-1.93)$ & $(-3.07)$ & $(-3.57)$ & $(-3.07)$ \\
Age & $0.242 * * * *$ & $0.227 * * * *$ & $0.243 * * * *$ & $0.225 * * * *$ \\
& $(22.90)$ & $(32.75)$ & $(22.45)$ & $(31.92)$ \\
Age square & $-0.00237 * * * *$ & $-0.00205^{* * * *}$ & $-0.00238^{* * * *}$ & $-0.00206^{* * * *}$ \\
\hline \hline
\end{tabular}




\begin{tabular}{ccccc}
\hline \hline & $(-162.66)$ & $(-173.00)$ & $(-161.29)$ & $(-171.79)$ \\
Constant & $4.419 * * * *$ & $4.682 * * * *$ & $4.387 * * * *$ & $4.760 * * * *$ \\
& $(11.68)$ & $(18.55)$ & $(11.35)$ & $(18.60)$ \\
Observations & 1535739 & 1814952 & 1505262 & 1779594 \\
R square & 0.601 & 0.591 & 0.601 & 0.591 \\
\hline \hline $\mathrm{p}<0.1, * * \mathrm{p}<0.05, * * * \mathrm{p}<0.01, * * * * \mathrm{p}<0.001$. & Robust standard errors are shown in parentheses
\end{tabular}

\subsection{Caveats and Conclusions}

Our study analysed the impact of a policy intervention, a 'managed retreat' program that was implemented after the Christchurch earthquake of February 2011. Specifically, it focused on the impact of these relocations on the affected individuals' income (from various sources). This is the first study that is able to follow people after they have been relocated and identify what happened to them (in terms of their income). As managed retreat programs are increasingly being considered, in diverse locations and circumstances, as a potentially important tool for climate change adaptation, this identification is becoming more and more important for shaping policy, in New Zealand and elsewhere.

Our study shows that being red-zoned had a negative impact on wages \& salaries, and consequently also on the total income of the displaced individuals. Unsurprisingly, the longterm effect of relocation on income was smaller than the short-term impacts. The effect for early-career workers was bigger and lasted longer than for their counterparts. Beyond this, the observation that the adverse impact on wages \& salaries was bigger than on the total income, suggests that whatever assistance or benefits RRZ residents received from the government, these were not enough to fully compensate for what they lost in their short-term earning potential in the labour market.

We also find that the adverse relocation effect on women's income was stronger than on men's. Here we observe that top five job sectors (64\%) where women work in are public administration \& safety, health care \& social assistance, education and training, retail trade, and accommodation \& food services, whereas $57 \%$ men work in public administration \& safety, manufacturing, construction, retail trade, and professional, scientific, and technical services. Future research may determine to what extent relocation effects the income of displacement people, in terms of sectors they are employed in, and the distance they relocated to their new homes.

Some limitations are worth noting. Firstly, we had no access to the actual Red Zone contracts that people signed with the Canterbury Earthquake Recovery Authority (CERA) and 
the amount of compensation they received - this amount was mostly determined by the value of their house, as previously assessed for property taxes, if they owned their residence. Renters did not receive any assistance whatsoever. Our focus is on the impact of people when they are mandated to retreat/relocate, but it is conceivable that the impact may be different for renters and homeowners, and according to the amount of compensation received. Unfortunately, with our data, we cannot make those distinction.

Furthermore, there is a large literature that ties social capital (bonding, bridging, and linking social connections - see Aldrich, 2012) to economic outcomes, especially in postdisaster situations (though more generally, too). Presumably, this might be important for managed retreat schemes, since in this case whole neighbourhoods were scattered because of the RRZ policy. This was different for the Port Hills area, where the red-zoned properties were quasi-randomly located within neighbourhoods that were not red-zoned (since the red zoning in the Port Hills was associated with the increasing risk of rockfall and slope instability). Ideally, we should have compared the outcomes for Port Hills RRZ with the other groups of RRZ residents. However, the IDI contains only a very small number of people that can be confidently identified as living in the Port Hills RRZ.

Finally, it is important to note that the main conclusion from our findings is that people who are forced to endure a managed relocation suffer also because their income declines (beyond all the other psychological, social, environmental, and economic effects they may endure). As such, it is important to make sure managed retreat programs are designed with this potential loss in mind, and that if these losses do occur, there are mechanisms in place to help those adversely affected. 


\section{Appendices}

\section{Appendix 4.1: List of income source categories in the IDI data}

In the IDI data, income data are available for the following categories:

- 'W\&S' Wages and salaries

- 'BEN' Benefit payments from the Ministry of Social Development (MSD)

- 'CLM' Accident Compensation Corporation (ACC) payments

- 'PEN' Pension payments from MSD

- 'PPL' Paid parental leave payments from MSD.

- 'STU' Student allowance payments from MSD

- 'C00' Total shareholder Salary amount

- 'C01' Company director/shareholder receiving PAYE deducted income.

- 'C02' Company director/shareholder receiving WHT deducted income.

- 'P00' Sole trader income

- 'P01' Partner receiving PAYE deducted income.

- 'P02' Partner receiving withholding tax deducted income.

- 'S00' Sole trader income

- 'S01' Sole Trader receiving PAYE deducted income.

- 'S02' Sole Trader receiving withholding tax deducted income.

- 'S03' Net rent income

\section{Self-employed income source categories.}

The self-employment income includes income from one of the source categories below:

- 'C01' Company director/shareholder receiving PAYE deducted income

- 'P01' Partner receiving PAYE deducted income

- 'S01' Sole Trader receiving PAYE deducted income.

- 'C02' Company director/shareholder receiving WHT deducted income

- 'P02' Partner receiving withholding tax deducted income.

- 'S02' Sole Trader receiving withholding tax deducted income. 


\section{Appendix 4.2: Timeline of the managed retreat program}

29 March 2011 Establishment of the Canterbury Earthquake Recovery Authority (CERA)

18 April 2011 Passing of the Canterbury Earthquake Recovery Act 2011

23 June 2011 Announcement of the Government purchase offer to owners of insured red zoned residential properties in the Christchurch flat areas. Property owners could accept:

- 100 percent of the 2007 rateable value for land, buildings, and fixtures on the property (any residual insurance claim was then assigned to the Government), or

- 100 percent of the 2007 rateable land value only (and all insurance claims on buildings and fixtures on the property were retained by the owners)

18 August 2011 Announcement that this same offer would be extended to owners of the 940 insured red zoned residential properties in Waimakariri District and also in the Port Hills south-east of Christchurch.

19 August 2011 Mailout of purchase offers to the first 3,000 owners of eligible red zoned properties.

13 September 2012 Announcement of the Government purchase offers for owners of vacant land, and commercial and uninsured properties, in the flat-land residential red zone.

26 August 2013 Decision of the High Court that the government had no prerogative power to create the RRZ, and that the Canterbury Earthquake Recovery Minister had not followed correct statutory procedure.

3 December 2013 The Court of Appeal decided that the decision to red zone parts of Greater Christchurch was lawful, and that there was a rational basis for distinguishing between insured and uninsured properties, but that the 50 percent offer was not in line with the Recovery Act.

13 March 2015 Decision of the Supreme Court that the Government's September 2012 decisions relating to uninsured RRZ property owners and to vacant residential land owners were not lawfully made.

21 April 2015 Announcement of the decision to develop a Recovery Plan, allowing public commentary on the Government offers to owners of red zoned commercial, vacant and uninsured properties. Eventually, uninsured properties were offered the same as insured ones. 


\section{Appendix 4.3. Effects of relocation on wages \& salaries by age over year}

Table A3.1: Effects of relocation on wages and salaries by age (LHS: log wages \& salaries)

\begin{tabular}{|c|c|c|c|c|}
\hline \multirow[b]{2}{*}{ Year } & \multicolumn{4}{|c|}{ Age group } \\
\hline & $20-29$ & $30-39$ & $40-49$ & $50-60$ \\
\hline \multirow[t]{2}{*}{2004} & 0.00442 & 0.00132 & 0.00132 & 0.00451 \\
\hline & $(0.06)$ & $(0.02)$ & $(0.02)$ & $(0.11)$ \\
\hline \multirow[t]{2}{*}{2005} & 0.0246 & 0.0346 & 0.0346 & -0.00467 \\
\hline & $(0.37)$ & $(0.69)$ & $(0.69)$ & $(-0.10)$ \\
\hline \multirow[t]{2}{*}{2006} & -0.00690 & -0.0258 & -0.0258 & 0.0157 \\
\hline & $(-0.12)$ & $(-0.54)$ & $(-0.54)$ & $(0.39)$ \\
\hline \multirow[t]{2}{*}{2007} & -0.0148 & 0.0189 & 0.0189 & -0.0119 \\
\hline & $(-0.27)$ & $(0.41)$ & $(0.41)$ & $(-0.30)$ \\
\hline \multirow{2}{*}{2008} & -0.0327 & 0.0262 & 0.0262 & -0.0223 \\
\hline & $(-0.67)$ & $(0.65)$ & $(0.65)$ & $(-0.60)$ \\
\hline \multirow[t]{2}{*}{2009} & 0.0511 & -0.0164 & -0.0164 & 0.00433 \\
\hline & $(1.24)$ & $(-0.44)$ & $(-0.44)$ & $(0.14)$ \\
\hline \multirow[t]{2}{*}{ Reference: 2010} & - & - & - & - \\
\hline & - & - & - & - \\
\hline \multirow[t]{2}{*}{2011} & -0.0367 & -0.0491 & -0.0491 & 0.00696 \\
\hline & $(-0.83)$ & $(-1.25)$ & $(-1.25)$ & $(0.19)$ \\
\hline \multirow[t]{2}{*}{2012} & -0.0618 & -0.0681 & -0.0681 & -0.0434 \\
\hline & $(-1.17)$ & $(-1.57)$ & $(-1.57)$ & $(-1.09)$ \\
\hline \multirow[t]{2}{*}{2013} & -0.0804 & -0.0683 & -0.0683 & -0.0404 \\
\hline & $(-1.63)$ & $(-1.64)$ & $(-1.64)$ & $(-1.17)$ \\
\hline \multirow[t]{2}{*}{2014} & $-0.138 * *$ & -0.0707 & -0.0707 & $-0.103^{* *}$ \\
\hline & $(-2.55)$ & $(-1.44)$ & $(-1.44)$ & $(-2.16)$ \\
\hline \multirow[t]{2}{*}{2015} & $-0.173 * * * *$ & -0.0656 & -0.0656 & 0.00630 \\
\hline & $(-3.32)$ & $(-1.25)$ & $(-1.25)$ & $(0.16)$ \\
\hline \multirow[t]{2}{*}{2016} & $-0.199 * * * *$ & -0.00673 & -0.00673 & -0.0149 \\
\hline & $(-3.57)$ & $(-0.15)$ & $(-0.15)$ & $(-0.34)$ \\
\hline \multirow[t]{2}{*}{2017} & $-0.172 * * *$ & 0.0221 & 0.0221 & -0.0384 \\
\hline & $(-3.12)$ & $(0.49)$ & $(0.49)$ & $(-0.64)$ \\
\hline \multirow[t]{2}{*}{2018} & $-0.140 * * *$ & -0.000739 & -0.000739 & -0.0364 \\
\hline & $(-2.58)$ & $(-0.02)$ & $(-0.02)$ & $(-0.76)$ \\
\hline Observations & 526371 & 386844 & 386844 & 283386 \\
\hline $\mathrm{R}$ square & 0.566 & 0.553 & 0.553 & 0.663 \\
\hline
\end{tabular}




\section{Appendix 4.4. Event study estimates for effect of managed retreat}

Table A4.1. Event study estimates for effect of managed retreat on wages and salaries (LHS: $\log$ wages \& salaries)

\begin{tabular}{|c|c|c|}
\hline & $\begin{array}{c}\text { In RRZ areas in } 2011 \text { (Ref.2010) } \\
\text { Coefficient (SEs) }\end{array}$ & $\begin{array}{c}\text { In RRZ areas in } 2012 \text { (Ref.2011) } \\
\text { Coefficient (SEs) }\end{array}$ \\
\hline Year & (1) & (2) \\
\hline 2005 & $\begin{array}{l}0.0418 \\
(1.46)\end{array}$ & $\begin{array}{l}0.0319 \\
(0.59)\end{array}$ \\
\hline 2006 & $\begin{array}{c}0.00889 \\
(0.34)\end{array}$ & $\begin{array}{c}-0.0132 \\
(-0.25)\end{array}$ \\
\hline 2007 & $\begin{array}{c}0.0113 \\
(0.46)\end{array}$ & $\begin{array}{c}0.00537 \\
(0.11)\end{array}$ \\
\hline 2008 & $\begin{array}{c}-0.0109 \\
(-0.50)\end{array}$ & $\begin{array}{c}0.0162 \\
(0.37)\end{array}$ \\
\hline 2009 & $\begin{array}{c}0.00541 \\
(0.29)\end{array}$ & $\begin{array}{c}-0.00516 \\
(-0.12)\end{array}$ \\
\hline 2010 & - & $\begin{array}{c}0.00391 \\
(0.09)\end{array}$ \\
\hline 2011 & $\begin{array}{c}-0.0241 \\
(-1.20)\end{array}$ & $\begin{array}{l}- \\
-\end{array}$ \\
\hline 2012 & $\begin{array}{c}-0.0504 * * \\
(-2.17)\end{array}$ & $\begin{array}{c}-0.113 * * \\
(-2.50)\end{array}$ \\
\hline 2013 & $\begin{array}{c}-0.0662 * * * \\
(-3.11)\end{array}$ & $\begin{array}{c}-0.123 * * * \\
(-2.91)\end{array}$ \\
\hline 2014 & $\begin{array}{c}-0.0834 * * * * \\
(-3.37)\end{array}$ & $\begin{array}{c}-0.155^{* * *} \\
(-3.14)\end{array}$ \\
\hline 2015 & $\begin{array}{c}-0.0710 * * * \\
(-2.88)\end{array}$ & $\begin{array}{c}-0.116^{* *} \\
(-2.48)\end{array}$ \\
\hline 2016 & $\begin{array}{c}-0.0720 * * * \\
(-2.94)\end{array}$ & $\begin{array}{c}-0.0904^{*} \\
(-1.95)\end{array}$ \\
\hline 2017 & $\begin{array}{c}-0.0528 * * \\
(-2.03)\end{array}$ & $\begin{array}{c}-0.103^{*} \\
(-1.96)\end{array}$ \\
\hline 2018 & $\begin{array}{c}-0.0401 * \\
(-1.68)\end{array}$ & $\begin{array}{c}-0.0232 \\
(-0.50)\end{array}$ \\
\hline Observations & 1535739 & 1504560 \\
\hline R2 & 0.600 & 0.601 \\
\hline
\end{tabular}


Table A4.2: Event study estimates for effect of managed retreat on wages and salaries (LHS: $\log$ wages $\&$ salaries)

\begin{tabular}{|c|c|c|c|c|c|c|}
\hline \multirow[t]{2}{*}{ Year } & \multicolumn{3}{|c|}{$\begin{array}{c}\text { Being RRZ residents in } 2011 \\
\text { (Ref. 2010) }\end{array}$} & \multicolumn{3}{|c|}{$\begin{array}{c}\text { Being RRZ residents in } 2012 \\
\text { (Ref. 2011) }\end{array}$} \\
\hline & All cohort & Males & Females & All cohort & Males & Females \\
\hline 2005 & $\begin{array}{l}0.0418 \\
(1.46)\end{array}$ & $\begin{array}{c}0.0758^{*} \\
(1.88)\end{array}$ & $\begin{array}{c}0.00916 \\
(0.23)\end{array}$ & $\begin{array}{c}0.0319 \\
(0.59)\end{array}$ & $\begin{array}{c}0.0974 \\
(1.37)\end{array}$ & $\begin{array}{l}-0.0423 \\
(-0.52)\end{array}$ \\
\hline 2006 & $\begin{array}{c}0.00889 \\
(0.34)\end{array}$ & $\begin{array}{l}0.0221 \\
(0.62)\end{array}$ & $\begin{array}{c}-0.00647 \\
(-0.17)\end{array}$ & $\begin{array}{c}-0.0132 \\
(-0.25)\end{array}$ & $\begin{array}{r}-0.0223 \\
(-0.31)\end{array}$ & $\begin{array}{c}-0.00820 \\
(-0.10)\end{array}$ \\
\hline 2007 & $\begin{array}{c}0.0113 \\
(0.46)\end{array}$ & $\begin{array}{c}0.0313 \\
(0.93)\end{array}$ & $\begin{array}{c}-0.00946 \\
(-0.27)\end{array}$ & $\begin{array}{c}0.00537 \\
(0.11)\end{array}$ & $\begin{array}{c}0.00654 \\
(0.10)\end{array}$ & $\begin{array}{c}0.00114 \\
(0.01)\end{array}$ \\
\hline 2008 & $\begin{array}{l}-0.0109 \\
(-0.50)\end{array}$ & $\begin{array}{c}-0.00261 \\
(-0.09)\end{array}$ & $\begin{array}{l}-0.0174 \\
(-0.57)\end{array}$ & $\begin{array}{l}0.0162 \\
(0.37)\end{array}$ & $\begin{array}{l}0.0256 \\
(0.47)\end{array}$ & $\begin{array}{c}0.00441 \\
(0.06)\end{array}$ \\
\hline 2009 & $\begin{array}{c}0.00541 \\
(0.29)\end{array}$ & $\begin{array}{l}0.0317 \\
(1.18)\end{array}$ & $\begin{array}{c}-0.0190 \\
(-0.71)\end{array}$ & $\begin{array}{c}-0.00516 \\
(-0.12)\end{array}$ & $\begin{array}{l}-0.0455 \\
(-0.78)\end{array}$ & $\begin{array}{c}0.0372 \\
(0.54)\end{array}$ \\
\hline 2010 & - & - & $\begin{array}{l}- \\
-\end{array}$ & $\begin{array}{l}0.00391 \\
(0.09)\end{array}$ & $\begin{array}{l}-0.0176 \\
(-0.32)\end{array}$ & $\begin{array}{l}0.0224 \\
(0.37)\end{array}$ \\
\hline 2011 & $\begin{array}{l}-0.0241 \\
(-1.20)\end{array}$ & $\begin{array}{l}0.0166 \\
(0.60)\end{array}$ & $\begin{array}{l}-0.0633^{* *} \\
(-2.18)\end{array}$ & - & $\begin{array}{l}- \\
-\end{array}$ & - \\
\hline 2012 & $\begin{array}{l}-0.0504 * * \\
(-2.17)\end{array}$ & $\begin{array}{l}0.00260 \\
(0.08)\end{array}$ & $\begin{array}{l}-0.0992 * * * \\
(-2.93)\end{array}$ & $\begin{array}{l}-0.113 * * \\
(-2.50)\end{array}$ & $\begin{array}{l}0.00180 \\
(0.03)\end{array}$ & $\begin{array}{l}-0.232 * * * * \\
(-3.30)\end{array}$ \\
\hline 2013 & $\begin{array}{l}-0.0662 * * * \\
(-3.11) \\
-\end{array}$ & $\begin{array}{l}-0.0145 \\
(-0.51)\end{array}$ & $\begin{array}{l}-0.114 * * * * \\
(-3.65)\end{array}$ & $\begin{array}{l}-0.123 * * * \\
(-2.91)\end{array}$ & $\begin{array}{l}-0.0470 \\
(-0.87)\end{array}$ & $\begin{array}{l}-0.208 * * * \\
(-3.19)\end{array}$ \\
\hline 2014 & $\begin{array}{l}0.0834 * * * * \\
(-3.37)\end{array}$ & $\begin{array}{l}-0.0161 \\
(-0.49)\end{array}$ & $\begin{array}{l}-0.143 * * * * \\
(-3.94)\end{array}$ & $\begin{array}{l}-0.155^{* * *} \\
(-3.14)\end{array}$ & $\begin{array}{l}-0.0780 \\
(-1.18)\end{array}$ & $\begin{array}{l}-0.238 * * * \\
(-3.27)\end{array}$ \\
\hline 2015 & $\begin{array}{l}-0.0710^{* * *} \\
(-2.88)\end{array}$ & $\begin{array}{l}-0.0548 \\
(-1.56)\end{array}$ & $\begin{array}{l}-0.0819 * * \\
(-2.38)\end{array}$ & $\begin{array}{l}-0.116^{* *} \\
(-2.48)\end{array}$ & $\begin{array}{l}-0.0417 \\
(-0.69)\end{array}$ & $\begin{array}{l}-0.193 * * * \\
(-2.72)\end{array}$ \\
\hline 2016 & $\begin{array}{l}-0.0720 * * * \\
(-2.94)\end{array}$ & $\begin{array}{l}-0.0367 \\
(-1.10)\end{array}$ & $\begin{array}{l}-0.101 \text { *** } \\
(-2.81)\end{array}$ & $\begin{array}{l}-0.0904 * \\
(-1.95)\end{array}$ & $\begin{array}{l}-0.0685 \\
(-1.14)\end{array}$ & $\begin{array}{l}-0.109 \\
(-1.54)\end{array}$ \\
\hline 2017 & $\begin{array}{l}-0.0528 * * \\
(-2.03)\end{array}$ & $\begin{array}{l}-0.0403 \\
(-1.12)\end{array}$ & $\begin{array}{l}-0.0601 \\
(-1.61)\end{array}$ & $\begin{array}{l}-0.103^{*} \\
(-1.96)\end{array}$ & $\begin{array}{l}-0.0490 \\
(-0.78)\end{array}$ & $\begin{array}{l}-0.159^{*} \\
(-1.87)\end{array}$ \\
\hline 2018 & $\begin{array}{l}-0.0401^{*} \\
(-1.68)\end{array}$ & $\begin{array}{l}-0.0244 \\
(-0.74)\end{array}$ & $\begin{array}{l}-0.0523 \\
(-1.53)\end{array}$ & $\begin{array}{l}-0.0232 \\
(-0.50)\end{array}$ & $\begin{array}{l}0.0477 \\
(0.84)\end{array}$ & $\begin{array}{l}-0.0974 \\
(-1.31)\end{array}$ \\
\hline Observation & & & & 17 & & 755 \\
\hline $\mathrm{R}$ square & 0.600 & 0.630 & 0.556 & 0.601 & 0.631 & 0.557 \\
\hline
\end{tabular}


Appendix 4.5. Wages \& salaries, total income effects on females compared to males

Table A5.1. Wages and salaries effects by gender (Ref: males) (LHS: log wages \& salaries)

\begin{tabular}{lcccccc}
\hline & \multicolumn{2}{c}{ Being RRZ residents in 2011 } & \multicolumn{2}{c}{ Being RRZ residents in 2012 } \\
\cline { 2 - 7 } & All cohort & Moved in & Moved in & & Moved in & Moved in \\
& $-0.0558^{*}$ & $-0.0993 * *$ & -0.0750 & $-0.208^{* * * *}$ & $-0.269 * * * *$ & -0.0959 \\
Females & $(-1.93)$ & $(-2.22)$ & $(-1.57)$ & $(-3.57)$ & $(-3.68)$ & $(-0.60)$ \\
& $0.242 * * * *$ & $0.242 * * * *$ & $0.244 * * * *$ & $0.243 * * * *$ & $0.243 * * * *$ & $0.244 * * * *$ \\
Age & $(22.90)$ & $(22.59)$ & $(22.70)$ & $(22.45)$ & $(22.43)$ & $(22.42)$ \\
& - & - & - & - & - & - \\
Age & $0.00237 * * *$ & $0.00238^{* * *}$ & $0.00238^{* * *}$ & $0.00238^{* * *}$ & $0.00238^{* * *}$ & $0.00238^{* * *}$ \\
square & $*$ & $*$ & $*$ & $*$ & $*$ & $*$ \\
& $(-162.66)$ & $(-161.62)$ & $(-161.42)$ & $(-161.29)$ & $(-161.10)$ & $(-160.79)$ \\
Constant & $4.419 * * * *$ & $4.422^{* * * *}$ & $4.376^{* * * *}$ & $4.387 * * * *$ & $4.393 * * * *$ & $4.368 * * * *$ \\
& $(11.68)$ & $(11.55)$ & $(11.42)$ & $(11.35)$ & $(11.37)$ & $(11.25)$ \\
$\mathrm{N}$ & 1535739 & 1512594 & 1508058 & 1505262 & 1501524 & 1494606 \\
r2 & 0.601 & 0.601 & 0.601 & 0.601 & 0.601 & 0.601 \\
\hline \hline
\end{tabular}

$* \mathrm{p}<0.1, * * \mathrm{p}<0.05, * * * \mathrm{p}<0.01, * * * * \mathrm{p}<0.001$. Robust standard errors are shown in parentheses

Table A5.2. Total income effects by gender (Ref: males) (LHS: log wages \& salaries)

\begin{tabular}{lcccccc}
\hline \hline & \multicolumn{3}{c}{ Being RRZ residents in 2011 } & \multicolumn{3}{c}{ Being RRZ residents in 2012 } \\
\cline { 2 - 7 } & All cohort & Moved in & Moved in & & Moved in & Moved in \\
& 2011 & 2012 & All cohort & 2012 & 2013 \\
\hline Females & $-0.0699 * * *$ & $-0.0625^{*}$ & $-0.0884 * *$ & $-0.133 * * *$ & $-0.197 * * * *$ & 0.0315 \\
& $(-3.07)$ & $(-1.94)$ & $(-2.32)$ & $(-3.07)$ & $(-3.73)$ & $(0.23)$ \\
Age & $0.227 * * * *$ & $0.226 * * * *$ & $0.227 * * * *$ & $0.225 * * * *$ & $0.225 * * * *$ & $0.226 * * * *$ \\
& $(32.75)$ & $(32.41)$ & $(32.27)$ & $(31.92)$ & $(31.91)$ & $(31.96)$ \\
& - & - & - & - & - & - \\
Age & $0.00205^{* * *}$ & $0.00205^{* * *}$ & $0.00205^{* * *}$ & $0.00206 * * *$ & $0.00206 * * *$ & $0.00206 * * *$ \\
square & $*$ & $*$ & $*$ & $*$ & $*$ & $*$ \\
& $(-173.00)$ & $(-172.09)$ & $(-171.77)$ & $(-171.79)$ & $(-171.61)$ & $(-171.24)$ \\
Constant & $4.682^{*} * * *$ & $4.722^{*} * * *$ & $4.706 * * * *$ & $4.760 * * * *$ & $4.762 * * * *$ & $4.728 * * * *$ \\
& $(18.55)$ & $(18.62)$ & $(18.42)$ & $(18.60)$ & $(18.61)$ & $(18.40)$ \\
$\mathrm{N}$ & 1814952 & 1788312 & 1782186 & 1779594 & 1775229 & 1766778 \\
$\mathrm{r} 2$ & 0.591 & 0.591 & 0.592 & 0.591 & 0.591 & 0.592 \\
\hline$* \mathrm{p}<0.1, * * \mathrm{p}<0.05, * * * \mathrm{p}<0.01, * * * * \mathrm{p}<0.001$. Robust standard errors are shown in parentheses
\end{tabular}




\section{Appendix 4.6. Job sectors by gender}

The data shows that people may not decide to change the sector they are working in because of relocation. However, some high paying jobs may take longer time to find than others in the new community. On the other hand, low paying jobs could lead to a withdrawal from the labor market if people go for other options. Table A6.1 reports the industrial groups and their percentages for the whole cohort. The proportions are similar to both treatment and control group.

Table A6.1. Top 5 job sectors people working in by gender

\begin{tabular}{lclc}
\hline \hline \multicolumn{1}{c}{ Females } & \multicolumn{2}{c}{ Males } \\
\hline \multicolumn{1}{c}{ Job sectors } & Percentages (\%) & \multicolumn{1}{c}{ Job sectors } & Percentages (\%) \\
\hline $\begin{array}{l}\text { Public administration \& } \\
\text { safety }\end{array}$ & 17.6 & $\begin{array}{l}\text { Public administration } \\
\text { \& safety }\end{array}$ & 16.1 \\
Health care \& social & 16.3 & Manufacturing & 14.7 \\
assistance & 11.1 & Construction & 11 \\
Education and training & 11 & Retail trade & 8.2 \\
Retail trade & & Professional, scientific & \\
Accommodation \& food & 7.8 & \& technical services & 7 \\
services & 36.2 & Others & 43 \\
Others & &
\end{tabular}




\section{Appendix 4.7. Self-employment income effects}

Table A7.1. Self-employment income effects by timing of being RRZ residents and moving (LHS: self-employment income)

\begin{tabular}{|c|c|c|c|c|c|c|}
\hline & \multicolumn{2}{|c|}{ All cohort } & \multicolumn{2}{|c|}{ Male } & \multicolumn{2}{|c|}{ Female } \\
\hline & Sum & $\log$ & Sum & $\log$ & Sum & $\log$ \\
\hline & (1) & (2) & (3) & (4) & $(5)$ & (6) \\
\hline \multicolumn{7}{|c|}{ Being RRZ residents in 2011 \& moved } \\
\hline \multirow[t]{2}{*}{ In 2011} & -2782.9 & -0.0761 & -3419.9 & -0.0649 & -1333.4 & -0.114 \\
\hline & $(-1.14)$ & $(-0.58)$ & $(-0.96)$ & $(-0.38)$ & $(-0.42)$ & $(-0.57)$ \\
\hline \multirow[t]{2}{*}{ In 2012} & 496.1 & 0.0650 & -3674.0 & 0.130 & 6669.6 & -0.0456 \\
\hline & $(0.12)$ & $(0.35)$ & $(-0.70)$ & $(0.55)$ & $(1.10)$ & $(-0.15)$ \\
\hline \multicolumn{7}{|c|}{ Being RRZ residents in 2012 \& moved } \\
\hline \multirow[t]{2}{*}{ In 2012} & $-11072.9 *$ & -0.294 & $-13656.7 * *$ & -0.230 & -4967.6 & -0.392 \\
\hline & $(-1.93)$ & $(-1.24)$ & $(-2.10)$ & $(-0.79)$ & $(-0.49)$ & $(-0.96)$ \\
\hline \multirow[t]{2}{*}{ In 2013} & -7130.3 & -0.590 & -6249.6 & -0.00917 & -5664.8 & -1.186 \\
\hline & $(-0.98)$ & $(-1.13)$ & $(-0.93)$ & $(-0.02)$ & $(-0.47)$ & $(-1.61)$ \\
\hline
\end{tabular}




\section{References}

Ashenfelter, O. \& Rouse, C. (1998). Income, schooling, and ability: Evidence from a new sample of identical twins. The Quarterly Journal of Economics, 113(1): 253-284.

Abel, N.; Gorddard, R.; Harman, B.; Leitch, A.; Langridge, J.; Ryan, A.; Heyenga, S. (2011) Sea Level Rise, Coastal Development and Planned Retreat: Analytical Framework, governance Principles and an Australian Case Study. Environmental Science \& Policy 14(3) 279-288.

Alexander, K., Ryan, A. \& Measham, T. G. (2012). Managed retreat of coastal communities: understanding responses to projected sea level rise. Journal of Environmental Planning and Management, 55 (4), 409-433.

Badri, S., Asgary,A., Eftekhari, A.R. \& Levy, J. (2006). Post Disaster Resettlement, Development and Change: A Case Study of the 1990 Manjil Earthquake in Iran. Disasters 30(4): 451-468.

Bragg, W.K.; Gonzalez, S.T.; Rabearisoa, A.; Stoltz, A.D.(2021) Communicating Managed Retreat in California. Water 13, 781.

Buckley RC (2008) Misperceptions of climate change damage coastal tourism: case study of Byron Bay, Australia. Tour Rev Int 12:71-88

CERA. (2016): Residential redzone survey (of those who accepted the crown offer). Report prepared for the Canterbury earthquake recovery authority (Report Prepared by Neilsen for the Canterbury Earthquake Recovery Authority: Residential Red Zone Survey: (of those who accepted the Crown offer) - February 2016 (dpmc.govt.nz)

Clarke, A. (2014) Data dictionary for IR derived data in the IDI.

Dannenberg, A.L., Frumkin, H., Hess, J.J. et al. Managed retreat as a strategy for climate change adaptation in small communities: public health implications. Climatic Change 153, 114 (2019)

Furquim,F., Corral,D., Hillman,N. A Primer for Interpreting and Designing Difference-inDifferences Studies in Higher Education Research. Chapter 12 Springer Nature Switzerland 
AG2020- Higher Education: Handbook of Theory and Research, 2020, Volume 35 ISBN : $978-$ 3-030-31364-7

Godamunne, N. (2012). Development and displacement: the national involuntary resettlement policy (NIRP) in practice. Sri Lanka Journal of Social Sciences, 35/36(1/2), 37-50.

Hanna, C., White, I., Glavovic, B. (2017). Managed retreat in New Zealand: revealing the terminology, approaches and direction of local planning instruments. Report for the National Science Challenge: Resilience to Natures Challenges, University of Waikato, New Zealand.

Hanna, C., White, I., \& Glavovic, B. C. (2021). Managed retreats by whom and how? Identifying and delineating governance modalities. Climate Risk Management, 31, 100278.

Hartmann T (2011) Contesting land policies for space for rivers - rational, viable, and clumsy floodplain management. Journal Flood Risk Management 4(3):165-175

Harker, J. (2016). Housing built upon sand: Advancing managed retreat in New Zealand. Australian Journal of Environmental Law, 3(Jun 2016), 66-85.

Hino, M.; Field, C.B.; Mach, K.J (2017) Managed retreat as a response to natural hazard risk. Natural Climate Change 7, 364-370

Hoang T, Noy I. 2020. Wellbeing after a managed retreat: observations from a large New Zealand program. International Journal Disaster Risk Reduction 48:101589

Jörn-Stephen Pischke (2005) Empirical Methods in Applied Economics (Lecture Notes)

Kim S. Alexander, Anthony Ryan \& Thomas G. Measham (2012) Managed retreat of coastal communities: understanding responses to projected sea level rise, Journal of Environmental Planning and Management.

L. Koslov (2016) The case for retreat Public Culture , 28 (2) (2016), pp. 359-387

MacDonald M, Carlton S (2016) Staying in the red zones: monitoring human rights in the Canterbury earthquake recovery. New Zealand Human Rights Commission, Auckland Red_Zone_Report_FINAL_-_201016.pdf (hrc.co.nz) 
Mach, K.; Kraan, C.; Hino, M.; Siders, A.; Johnston, E.; Field, C. (2019) Managed retreat through voluntary buyouts of flood-prone properties. Science Advances, Vol 5, No. 10

Mitchell, Michelle (2015) Relocation after disaster: engaging with insured residential property owners in Greater Christchurch's land damaged. brookings-planned-relocations-study-newzealand-june-12-2015.pdf

Neal, W.J.; Bush, D.M.; Pilkey, O.H. Managed Retreat (2017) In Encyclopaedia of Engineering Geology; Finki, C., Makowski, C., Eds.; Encyclopaedia of Earth Sciences Series; Springer International Publishing: Cham, Switzerland; pp. 1-7. ISBN 978-3-319- 12127-7

Noy, I (2020). Paying a Price of Climate Change: Who Pays for Managed Retreats?. Current Climate Change Report 6, 17-23

Nguyen, C (2020) Homeowners' choice when the government proposes a managed retreat, International Journal of Disaster Risk Reduction, 47.

Schwerdtle P, Bowen K, McMichael C (2018) The health impacts of climate-related migration. BMC Medicine 16(1):1

Smith, G., Saunders, W., Vila, O. et al. A comparative analysis of hazard-prone housing acquisition programs in US and New Zealand communities. J Environ Stud Sci 11, 392-403 (2021).

Statistics New Zealand (2015). IDI Data Dictionary: IR tax data (September 2015 edition). Available from http://www.stats.govt.nz/browse_for_stats/snapshots-of-nz/integrated-datainfrastructure/idi-data/irtax-data.aspx

Thaler, T. Just retreat—how different countries deal with it: examples from Austria and England. Journal of Environmental Studies and Science 11, 412-419 (2021) 


\section{Chapter5}

\section{Conclusion}

New Zealand is one of the most vulnerable countries in the world to the impact of disasters because of its location and small size. The Christchurch earthquake on 22nd February 2011 was the worst natural disaster in New Zealand history; it caused the death of 185 people, and a reconstruction cost estimated at around 30 billion US\$. We remain at risk from future disasters including earthquakes, volcanoes, tsunami, and floods. Therefore, we need to prepare and plan for them. An effective way to design a future policy is to learn from previous policies that the government made. My dissertation research examines various aspects of disaster risk management policy in Aotearoa New Zealand.

The second chapter develops a method to rank and prioritise buildings for seismic retrofit in Wellington. This algorithm is based on four general criteria-life safety, and geospatial, economic, and socio-cultural roles. The two MCDA algorithms examined in this chapter, TOPSIS and VIKOR, yielded broadly similar results of the rank of buildings to prioritise for retrofits. The authorities can use this type of list principally to start evaluations of buildings, from the top, and work down at a speed determined by other considerations. An example of a factor that might accelerate a retrofit is the availability of public funding. This is a new approach to a critical problem that not only confronts New Zealand, but also many other cities around the world, including Los Angeles, Portland, and Vancouver in the East Pacific, and Indonesia, Japan, and Taiwan, on the Western side of the Pacific Ocean.

This need for retrofitting is increasing globally, owing to dramatic improvements in knowledge of seismic risk (from its geology to its engineering) over the past few decades. Since the building stock in many earthquake-prone cities was largely constructed before such information was widely available or utilised, the existing buildings pose a significant risk even if they were built according to the code available at the time. A prioritisation algorithm like the one developed here could also be used, for instance, when deciding on investment priorities in lower income countries in earthquake-prone cities such as Kathmandu, Nepal, and Lima, Peru. 
The third chapter uses a survey of Residential Red Zone homeowners to gauge their satisfaction with the various characteristics of the program, so that future programs can be better designed. We found that demographic factors, health conditions, and the type of government compensation the residents accepted, were all significant determinants of the wellbeing of the Red Zone residents. More social relations, better financial circumstances, and the perception of better government communication were also all associated positively with a higher quality of life, less stress, and higher emotional wellbeing.

The fourth chapter investigates the impact of the Residential Red Zone program on the income of those affected by it, using Statistics New Zealand IDI data. We find that relocation has a negative impact on the income of the displaced household group. The impacts vary with time spent in the Red Zone and when they moved away. Wages and salaries of those who were red-zoned and moved in 2011 were reduced by $9 \%$, and 10.4\% for those who were Red Zone residents and moved later (in 2012). Women faced greater decreases in wages and salaries, and total income, than men. There were no discernible impacts of the relocation on people's selfemployment income.

These three chapters provide valuable evidence-based policy implications that can improve risk management in New Zealand. It is my hope that chapter two may assist Wellington City Council, and other local councils in New Zealand, in choosing where to start in their program of seismic strengthening. I also hope that chapters 3-4 will assist policymakers in designing much needed managed retreat programs - a specific need that was recently highlighted in the first Climate Change Risk Assessment that was conducted by the New Zealand Climate Change Commission.

Some limitations in this thesis are worth noting. In chapter 2, I recognize that the structural evaluations of the buildings are important and should be included in the examination, this data was incomplete at the time this research was conducted and remain so now. Chapter 3 is based on a survey that does not allow investigating how a managed retreat program influences the relocated people's well-being. Therefore, the research question is restricted to the impact of the independent variables on shaping satisfaction with the program and cannot be extended to an overall assessment of the managed retreat policy. Chapter 4, I had no access to the actual Red Zone contracts that people signed with the Canterbury Earthquake Recovery Authority (CERA) and the amount of compensation they received both from the government 
and insurance organizations. Furthermore, there is no available data in terms of household composition, and property values in the IDI data for the whole analysed period (2004-2018).

\section{Future research}

Chapter 2 suggests a prioritization strategy for retrofitting or demolishing high-rise buildings in Wellington CBD. As more data become available over time, future research may combine TOPSIS and VIKOR with other techniques such as furzy numbers.

Chapter 3-4 in this thesis go some way in highlighting the impact of relocation on residents' wellbeing. In Chapter 3, I analysed an informative and lengthy survey and confirmed that social relations are associated positively with a higher quality of life, less stress, and higher emotional wellbeing. If the physical address information of respondents is made available, future research can be done to understand more about how social relations affect residents' wellbeing by applying spatial econometrics techniques. Chapter 4 found evidence that managed retreat policy has identifiably higher adverse effects on women's income than men. I described the top five job sectors that men and women are working for. Future research may identify to what extent relocation affects the income of displaced people, in terms of sectors they are employed in, and the distance they relocated to their new homes. 